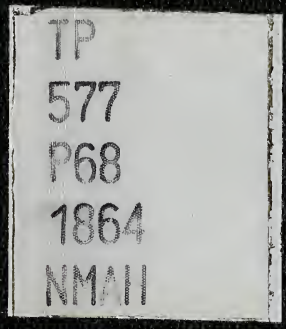

3 310

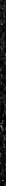




\title{
WARSHAW COLLECTION
}

$$
\text { OF }
$$

\author{
BUSINESS AMERICANA
}

ALBANY, N. Y. 









\section{OPINIONS OF THE PRESS.}

- This is a treatise on the whole art of brewing. At first we thought the processes described by Mr. PITT were rather too extensive for small familiez, but upon turning over his pages we find that he descends as low as eight or even two-and-a-half bushels of malt. The little book is so clearly written that anybody may understand it.' Gardeners' CHRONICLe.

'THIS work will prove of the very greatest benefit to the community at large. Among the books of ntility that have been published for the million, none will rank higher than "How to Brew good Beer." In its peculiar department it will take its stand with the best scientific works of this most scientific day.'

REVIEW.

'THIs is the best treatise we ever read on an art about which, after all the books that have been written, there yet seems some natural knack which no study can impart. Mr. PITT's book will correct errors, and prevent bad beer from being brewed. For practical hints it is indisputably a great acquisition; it is well written, and reflects credit on its Author.' JoHN BULI.

'Mr. Prtre's "Guide to the Art of Brewing" appears to be based upon careful observation and a lengthened experience. We have no hesitation in recommending its use in all quarters, since we are confident that even experienced hands may learn something from its pages. Those who are beginning to brew will here find much assistance in acquiring a practical knowledge of the art.'

Bell's Weekly Messenger.

' THIs little book not only pretends to be, but is, a complete guide to the art of brewing all kinds of beer, and a practical induction to all the mysteries of malt. Thanks to Mr. PrTT we now perceive a way of supplying ourselves with good sound beer of any degree of strength or quality of flavour. People who have serious ideas on the subject of home-brewed malt liquor cannot do better than buy this compact little volume. Its practical information is conveyed in a good, though unpretending style; and when a plan, diagram, or illustrative design of any kind is necessary, it is certain to be found.'

DaILY News. 
'JUDGING from the minuteness of the instructions given, based upon a long and well-applied experience, we believe this little manual to be what its Author professes, "a complete guide to the art of brewing ale, bitter ale, table ale, brown stout, porter, and table beer." Directions for making malt are likewise added. It appears that the work is the result of twenty years' experience in brewing, and that during that lengthened period the Author has not only persevered in watching the results of experiments of all kinds occurring to his own mind, but he has availed himself of every opportunity of profiting by the experience of others. The Author likewise expresses himself so clearly and plainly that the most inexperienced in the art of brewing can find no difficulty in following out his directions.'

WINDSOR AND ETON EXPRESS.

'To enable heads of families to brew beer for themselves, by guarding them against disappointment and pecuniary loss in making the attempt, is the object of the present publication. In all matters treated of by him, Mr. PITT appears likely to prove a competent and trustworthy guide.'

\section{The Miduand Counties Herald.}

"THE "October" brewings have just terminated, but if any of our readers should find the product not to his taste, we recommend him to buy this little book and brew for himself. Mr. PITT tells us how to brew ale, bitter ale, table ale, brown stout, porter, and table beer; more than all this, if the malt should fail this manual will give directions how to make it afresh. The wood engravings which accompany the text will be found very useful to those who intend in future to brew their own ale.'

Morning Heratd.

'THE fullest practical details of the whole process connected with brewing are lucidly given, together with valuable information respecting brewhouses, cellars, and apparatus, with various diasrams and measure tables, constituting a perfect "handbook" in this popular department, and affording valuable assistance in preventing our favourite beverage becoming " hard, cloudy, or sour." "

The Sun. 


\section{THE ART}

OF

\section{B R E W IN G.}


LONDON

PRIXTED BY SPOTTISWOODE AXD CO.

NEW-STREET SQUARE 


\section{HOW TO BREW G00D BEER.}

A COMPLETE GUIDE TO

THE ART OF BREWING AIE, BITTER ALE, TABLE-ALR, BROWN STOUT, PORTER, AND TABLE-BWER.

TO WHICH ARE ADDED

PRACTICAL INSTRUCTIONS FOR MAKING MALT.

BY

\section{JOHN PITT}

SATE BUTLER TO SIR WILIIAM R. P. GEARY, BART.

SECOND EDITION.

LONDON :

LONGMAN, GREEN, LONGMAN, ROBERTS, \& GREEN.

1864.

\section{LBRARIES}





\section{PREFACE.}

THe OBJECT of this book is to enable any one who may read it, to brew good beer. It is well known that there are comparatively few families in the habit of brewing their own beer, who have not often experienced (and especially in summer) the disappointment and pecuniary loss consequent on their beer becoming cloudy, hard, or sour.

The author has had upwards of twenty years' experience in brewing, and he has made and preserved an accurate statement of the particulars of each brewing, during the whole of that period. For the last thirteen years he has had the entire management of a two-quarter brewing plant, and cellars, such as he has fully described in this work. During the first four years (as well as in his previous practice) he was unable to prevent frequent failures, but by perseverance in varying his 
method of brewing, and carefully examining the particulars of the processes in which the successful brewings differed from the unsuccessful, he was at length enabled, about nine years ago, to fix upon a method of brewing which has never failed during that period (though tested in about ninety brewings) to produce a pure, excellent, and sound-keeping beverage. That method is described in this work with such minuteness and accuracy, that all who exactly follow it must meet with the same successful result, however inexperienced they may be in the art of brewing.

The author has carefully read almost every work which has been written on the subject of brewing during the present century. $\mathrm{He}$ is therefore well aware of the great contrariety of opinion among the various authors, and has detected many of their practical errors.

The leading features of the method of brewing recommended in this work are-care in the selection of the malt and yeast used, the purity of the wort drawn from the malt, and the energetic method of the fermenting and cleansing processes, - all of which tend to prevent the evil which the eminent German chemist, Professor Liebig, has pointed out; namely, that 'the ex- 
cess of gluten left in beer is one great cause of its decay.'

The work is classified under forty-three heads. The brewhouse, cellars, and brewing apparatus are described with a fullness of detail never before attempted. They are illustrated by four diagrams carefully drawn to a scale of $\frac{1}{10}$ th of an inch to a foot.

Full instructions for selecting malt, hops, water, and yeast are given.

The thermometer is alluded to, and a description and diagram of the saccharometer is introduced. The use of the saccharometer is fully explained. This instrument has been justly termed 'The brewer's compass.'

The quantity of malt and hops required, and the cost of brewing, are stated.

Next follow minute practical instructions for conducting the six processes of which brewing consists ; namely, mashing, boiling, cooling, fermenting, cleansing, and cellaring. The quantity of water used is accounted for, and the method of ascertaining the produce per quarter of the malt is given.

How to make and use finings is next explained. The author's opinion concerning what is called 
'the boiling fermentation' is recorded, and also his reasons for concluding that it does not proceed from electricity.

Besides ale, table-ale, and table-beer, the author's experience has enabled him to explain how to brew superior bitter ale, and brown stout, and porter. Practical information respecting brewing from sugar with malt, and also about the bottling of malt liquors, is given. Allusion is likewise made to the undesirableness of using unmalted barley with malt, and to the pernicious practice of putting poisonous drugs in beer.

The method of brewing from 8 bushels of malt, and also from $2 \frac{1}{2}$ bushels of malt, is described.

The work concludes with extracts from a very elaborate article in the supplement to the ' Encyclopædia Britannica,' on the art of making malt, written by Dr. Thomson, F.R.S., in 1817 ; together with a few extracts (marked in parentheses) from a report on malting \&c. drawn up by Dr. Thomson, in conjunction with Drs. Hope and Coventry, ordered by the House of Commons to be printed. These combined extracts contain a very practical, clear, and complete description of the four processes of which malting consists; namely, steeping, couching, flooring, and kilndrying. 


\section{CONTENTS.}

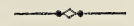

Description of the Brewhouse . . . . . . 1

Explanation of the Ground Plan on Diagram 1 . . . 3

The Brewing Plant-Size of the Utensils . . . . 4

Elevations on Diagram 2 . $\quad$. . . . 5

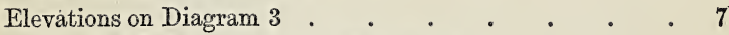

Ground Plan of the Cellars on Diagram 4 . . . . 8

The Adaptation of the Brewhouse and Cellars, not only for Private Families, but for the Requirements of the Public Brewer on a minor scale, or for the Licensed

Victualler who desires to brew his own Beer . 10

Full details respecting the Materials, the Construction, and

the Fixing of the various Utensils . . . . 11

Sundry Requisites for the Brewhouse . • • . 28

Description of the Casks . . . . . . . 31

Sundry Requisites for use in the Cellars . . . . 33

Malt . . . . . . . . . 35

Hops . . . . . . . . . 38

Water . . . . . . . . . 39

Yeast . . . . . . . . . 40

The Thermometer . . . . . . . . 41

The Saccharometer ..$\quad$. . . . 41

Quantity of Malt and Hops required . . . . 47 
Remarks . . . . . . . . . . . 49

Cost of Brewing . . . . . . . . 51

Mashing . . . . . . . . . . 53

Boiling . • . . . . . . . . 63

Cooling . $\quad . \quad$. $\quad . \quad$. $\quad . \quad . \quad . \quad 68$

Fermentation . . . . . . . . 73

Fermentation of the Ale while in the Tun . . . 76

Cleansing of the Ale . . . . . . . . 81

Cellaring . . . . . . . . . . 91

Fermentation of the Table-Beer $\quad . \quad . \quad .{ }^{*} 103$

Quantity of Water used and accounted for . $\quad$. 109

Method of ascertaining the Produce of the Malt $\quad .110$

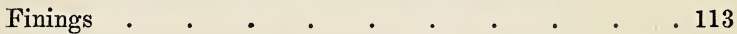

Table-Ale. . . . . . . . . . . 116

The Boiling Fermentation . • . . . . 119

Superior Bitter Ale • . . . . . . . 121

Brown Stout . . . . . . . . . 123

Porter . • . . . . . . . . 125

Brewing from Malt and Sugar . . . . . . 126

Bottling . . . . . . . . . 127

Unmalted Barley with Malt $\quad$. $\quad . \quad$. $\quad . \quad .129$

Drugs in Beer . . . . . . . . . . 130

Brewing from Eight Bushels of Malt . $\quad$. $\quad . \quad 130$

Brewing from Two and a Half Bushels of Malt . . 131

Making of Malt _ . . . . . . . . 135 


\section{HOW TO BREW GOOD BEER.}

\section{DESCRIPTION OF THE BREWHOUSE.}

The following wood-engravings represent a brewhouse, fitted up with a two-quarter brewing plant, with cellarage underneath, of the same dimensions on the ground-plan as the brewhouse.

Brewhouse. - Inside measurement: length, 26 feet; width, 22 feet: height of walls, 12 feet. In the centre there will be a rise to the single span roof of 7 feet. There should be no ceiling or inner roof: two openings are required in the roof, these apertures may be about 2 feet square in the clear, and their roofs raised 2 feet, with fixed open loufer boarding on all sides: they should be placed 6 feet from the end walls, and in the centre of the roof, that nearest the coppers will give light at the top of the large copper; 
they are intended to facilitate the escape of steam, and can be closed when requisite by a sliding horizontal door to each, with lines and pulleys. The three windows on the side where the coolers are fixed should be of loufer boarding, made to open and shut like venetian blinds. The two glazed windows on the other side of the brewhouse should open outwards; the floor must be well paved, with a good fall to the drain under the lower platform. See No. 7 on Diagram 1.

Diagram 1.

Ground-plan of the Brewhouse.

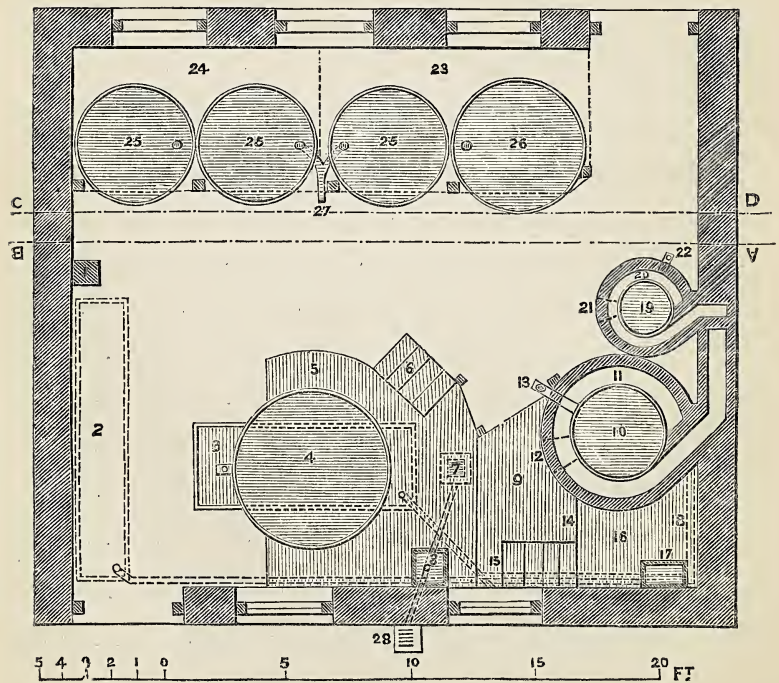


The brewhouse and plant (or utensils) are adapted for producing seven or eight barrels* of beer from any quantity of malt, varying from ten to twenty bushels.

\section{Explanation of the Ground-plan on Diagram 1.}

1, Liquor pump. 2, Liquorback, or cistern for water. 3, Underback. 4, Mash-tun. 5, Lower platform. 6, Steps to ascend ditto. 7, Mouth of drain under lower platform. 8, Raised sink and liquor tap on lower platform. 9, Raised parement level with lower platform. 10, Bottom of large copper. 11, Bottom of flue round ditto. 12, Furnace door of large copper. 13, Tap and tube of large copper. 14, Entrance to recess for coals. 15, Steps to upper platform. 16, Upper platform. 17, Wort pump on upper platform. 18, Pipes from liquorback and underback to copper. 19, Bottom of small copper. 20, Bottom of flue round small copper. 21, Furnace door of small copper. 22, Tap and tube of ditto. 23, Upper cooler. 24, Lower cooler. 25, Fermenting tuns. 26, Large fermenting tun. 27, A junction of branch pipes with main pipe (see page 26). 28, Grating of drain outside of brewhouse.

The walls of the brewhouse are given in the diagram as 18 inches thick; if 14 inches thick is thought sufficient it will of course cost less, and there will be a trifling increase of vacant space.

* A barrel is thirty-six gallons. A hogshead is one and a half barrel; and a butt is two hogsheads. 


\section{THE BREWING PLANT.}

\section{Size OF THE Utensils.}

(Inside Measurement.)

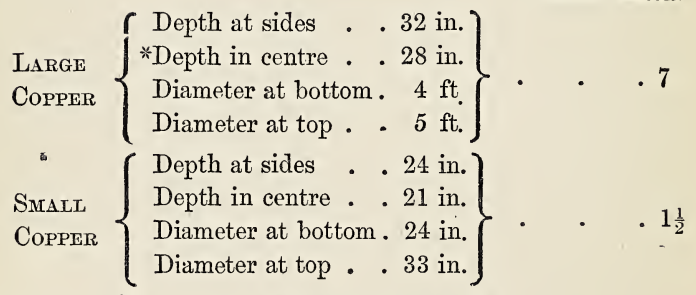

$\left.\left.\begin{array}{r}\text { Mash-TuN, } \\ \text { depth inside }\end{array}\right\} 2 \mathrm{ft.} 8 \mathrm{in} . \begin{array}{l}\text { Average diameter } \\ \text { inside, taken half- } \\ \text { way down }\end{array}\right\}+5 \mathrm{ft} .9 \frac{1}{2} \mathrm{in} .-12 \frac{1}{4}$

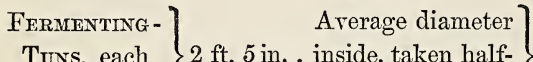
depth inside

way down . .

$\left.\begin{array}{c}\text { Large Fer- } \\ \text { menting-Tun } \\ \text { depth inside }\end{array}\right\} 2 \mathrm{ft.} 6$ in. $\left.\begin{array}{l}\text { Average diameter } \\ \text { way down taken half- }\end{array}\right\} 5 \mathrm{ft.} 0$ in. $-8 \frac{1}{2}$

* The bottom of the copper should be raised inside like the bottom of a wine bottle, and rounded at the edge of the bottom. This conical form of the bottom inereases its strength and durability, and allows the wort to drain more completely from the hops.

$\uparrow$ The inch fall towards the tap, in fixing the mash-tun and its false bottom and side shoot, will reduce its capacity to about $11 \frac{1}{4}$ barrels. 
Contain barrels.

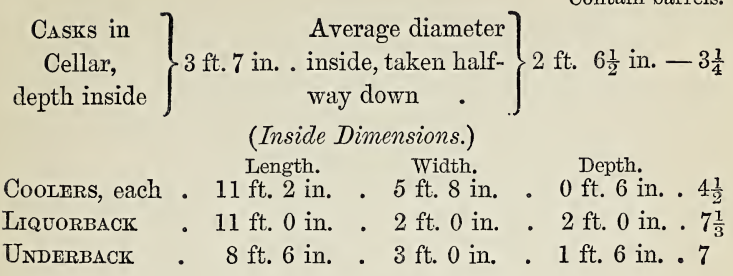

Diagram 2.

Section on the line A B.--See Diagram 1.

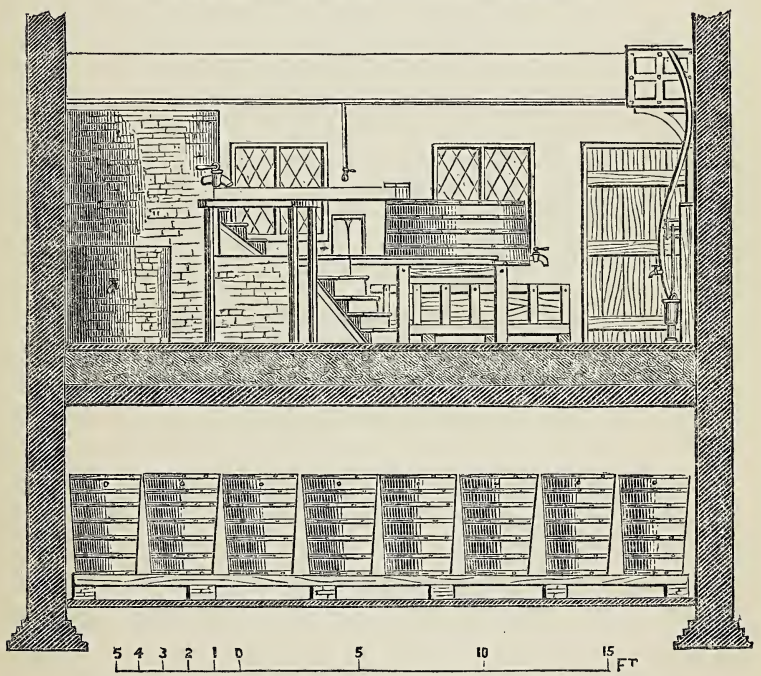

Eletations on Diagram 2.

Brick bearers on cellar floor

ft. in.

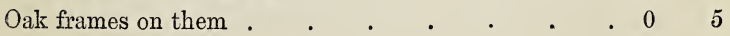


Outside depth of casks called Butts, but holding $3 \frac{1}{4}$

ft. in. barrels

Height of moveable yeast receiver on Diagram 3 . $\quad \begin{array}{lll}2 & 9\end{array}$

Distance from floor of tap in the pipe from the fer-

menting tuns, where the hose screws on . . 60

Spring of the arch commences distant from cellar floor $5 \quad 0$

Crown of arch from floor . . . . . . 80

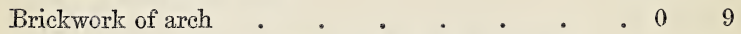

Earth above, including space for fall in the paving . 16

Pavement of brewhouse . . . . . . . . 03

Oak bearers on floor, supporting underback . . . 066

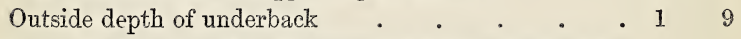

Space between mash-tun bearer and the underback for

its lid . . . . . . . . . 03

Thickness of oak frame for supporting mash-tun . . $0 \quad 6$

Outside depth of mash-tun . . . . . . . 30

Fall from copper tap to mash-tun . . . . 06

Lowest part of copper tap, from the floor . . . 66

Fall in tap tube. . . . . . . . . 03

Top of large copper from floor . . . . . . 96

Brickwork above copper (not shown on the Diagram) . 06

Bottom of liquorback, inside from floor . . . 100

Fall in pipe leading from liquorback to copper . $\quad \begin{array}{lll}0 & 0\end{array}$

Top of liquorback from floor . . . . . . 120

Lower platform from floor • • • . . . . 36

Sink above lower platform . . . . . . 16

Liquor tap above sink . . . . . . 16

Raised pavement from floor . . . . . . . 36

Upper platform, above raised pavement . . . 36

Top of small copper from floor . . . . . . 40

Tap of ditto from floor . . . . . . 20

Top of windows and doors from floor . . . . 80

Height of tap in pipe from pump . . . . 26

Height from floor of rail, on three posts, between copper tap and steps, to lower platform . . $6 \quad 0$ 
Diagram 3.

Section on the line C D.--See Diagram 1.

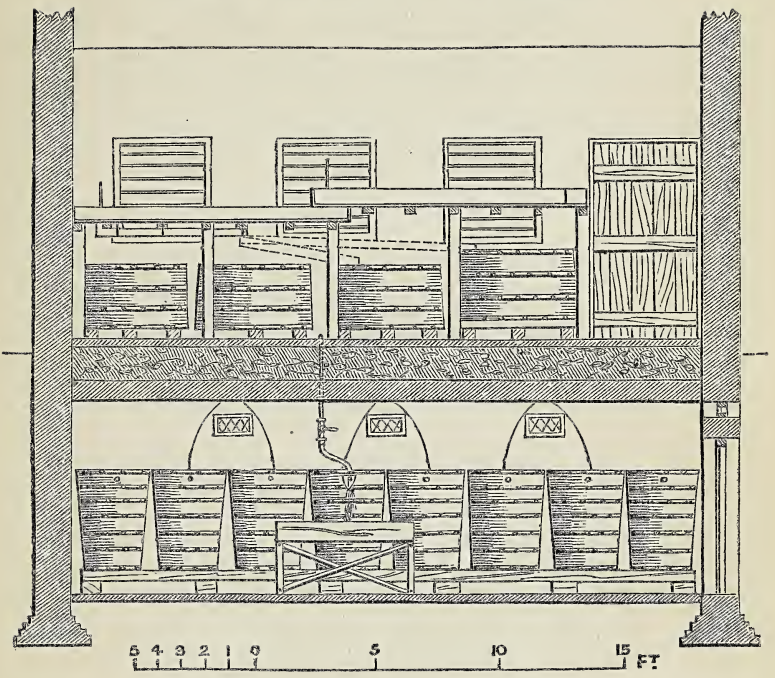

Exefations on Diagram 3.

Bottom of cellar windows from floor a d . . 64

Oak bearers of three fermenting tuns from brewhouse

floor . . . . . . . . . 04

Outside depth of three fermenting tuns . . . 28

Top of lower cooler from floor . . . . . . 54

Oak frame, supporting large fermenting tun . . 08

Outside depth of large fermenting tun . . . 29

Top of upper cooler from floor . . . . . . . 60

Top of cellar windows and doors from floor . . 80

Floor of brewhouse raised above the ground outside . 06 


\section{Diagram 4.}

Ground-plan of the Cellars.

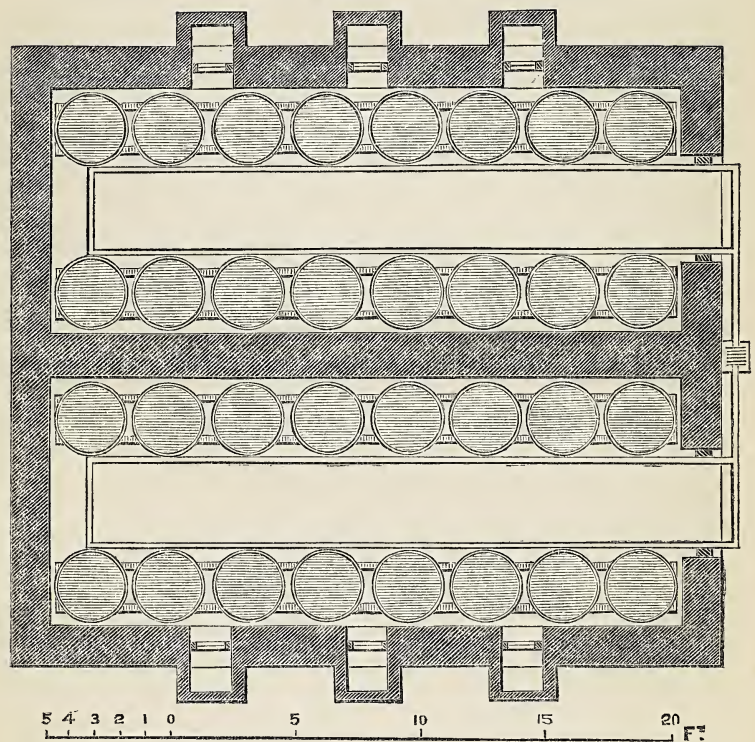

These are two separate vaults, occupying the same space of ground as the brewhouse. They will contain thirty-two butts, or about one hundred barrels of beer, which quantity of beer may, with the brewing plant already described, be conveniently brewed in four or five weeks. The windows of the cellars (9 inches high, and 18 
inches wide!, should be glazed, and open and shut on a swivel, by means of a double line. For security, an iron bar may be fixed horizontally in each window.

There will be 18 inches between the door frame and the top of the cellar, in which a window, similar to the others, may be placed over each door, to supply ventilation when desired. The walls of the cellars should be 18 inches thick, and the middle wall 2 feet thick.

The cellars must be well paved, and raised 4 inches in the centre, to give an incline to the gutters on each side. These gutters are open, and are $1 \frac{1}{2}$ inch deep and 3 inches wide. They should be 3 feet 6 inches from each other. They should have a good fall towards, and run under, the doorsill to a drain outside of the cellar. Water may be laid on to the cellars from the liquorback in the brewhouse. The tap should be at the end farthest from the doors. The paving under the casks should be laid with an incline to the gutters; but the fall should not exceed an inch (see page 32 ). The frames of 5 inch square oak, resting on the brick bearers, extend the whole length of the cellars. The lengths are placed 14 inches apart, and kept so by cross pieces between. The back 
length is 6 inches from the wall, and the front one 6 inches from the gutter; the cellars are each 10 feet wide, and 26 feet in length.

The casks must be taken up to the brewhouse to be cleaned. In cases where there is a difficulty of communication between the cellars and the brewhouse, the casks might be raised by a crane into the brewhouse, through a trap-door in the floor, under the liquorback, or at the upper end of the upper cooler. The cellars may be united by an inner door in that case, and one of the outer doors dispensed with. These alterations would remove three casks from the cellars.

The adaptation of the Brewhodse and Cellars not only for Private Families, but for the requirements of the Public Brewer on A Minor Scale; or, for the Licensed VicTUALLER, WHO DESIRES TO BreW hIS OWN BEER.

Although the brewhouse and cellars are more especially suited for the use of private families, yet the public brewer, on a minor scale, whose trade ranges between five hundred and a thousand barrels per annum, might brew that quantity of 
beer with the two-quarter brewing plant described in this work. The cellars and casks can be used for storage, prior to racking the beer from the butts, for the purpose of sending it to the publican or private consumer.

If the cellar floor was lowered, the butts could stand higher for the purpose of racking the beer more conveniently from them into smaller casks. If the brewhouse and cellars were attached to a public-house, the pipes from the engine at the bar might be fixed to any of the casks in the cellars, and the beer drank without any other racking, which would be a great advantage to the beer, with respect to briskness and flavour (see page 100 ), and also aid in keeping it perfectly mild and sound.

\section{DETAILS RESPECTING THE MATERIALS, THE CONSTRUCTION, AND THE FIXING OF THE VARIOUS UTENSILS.}

The details are given in the order in which they are numbered on Diagram 1.

1. Liquor-pump.-The pipe from the pump to the liquorback may be 2 inches diameter inside. If a well is sunk for the purpose of supplying the brewhouse with water, it should not be 
less than six feet from the wall of the brewhouse, and it should be sunk outside of that building.

2. Liquorback.-Made of well-seasoned deal $1 \frac{1}{2}$ inch thick, and strengthened by outside pieces of the same 3 or 4 inches wide, lined throughout with lead; a warning overflow pipe by the pump, and also a waste plug and pipe at the lowest end are requisite, the latter is for the purpose of cleaning out the cistern and draining it dry when out of use. The liquorback has a slight fall to the end nearest the wall, and is supported by iron brackets projecting from the end wall. It should have a lid, made of inch deal, and in two detached parts. A leaden pipe, $1 \frac{1}{2}$ inch diameter inside, runs from the liquorback to the large copper. A branch pipe, 3 feet 6 inches long, supplies water to the lower platform; and another branch pipe, of 1 inch diameter inside, passes from the liquor pipe by the wort pump, and above the large copper, to a tap, fixed 6 inches above the small copper, in order to supply the latter with water.

3. Undierback.-Made of well-seasoned deal, $1 \frac{1}{2}$ inch thick. The joints must be extremely well tongued, strengthened with outside pieces, 3 inches wide, and placed 1 foot apart. Six inches 
from the end, nearest the copper, and, close to the side next the wall, cut a hollow in the bottom, 6 inches in diameter, and $\frac{3}{4}$ inch deep, for the wortpipe to dip into. At the same end, on the other side, an inch diameter waste vent, with a plug cut an inch shorter than the depth of the ressel, is needed. A lid, made of inch deal, to slide on and off, in two parts, with handles on the top: one part 6 feet long, and the other 2 feet 9 inches long. This vessel must have a fall of 1 inch towards the end nearest the copper. It projects 18 inches in front of the mash-tun.

Frame for supporting Mash-tun.-This is made of oak, 6 inches square. It is 3 feet high. There are four legs, placed 3 feet 6 inches apart every way, and morticed into two pieces, each 9 feet long. Between these long pieces there are fixed two cross pieces, each 3 feet 6 inches long, placed 5 feet apart, or 18 inches from the ends of the long pieces; as the latter extend 18 inches or more on two sides of the mash-tun, they support part of the lower platform.

4. Mash-tun.-Made of the best well-seasoned English or Hamburgh oak, 2 inches thick, with 5 iron hoops, $2 \frac{1}{2}$ inches wide, and $\frac{1}{8}$ th of an inch thick. The bottom made of well-seasoned Chris- 
tiana or Dantzic deal, and in pieces not more than 7 inches wide, for fear of warping. The two narrow end pieces may be of oak, to sustain the pressure used in driving it together. The mashtun must be made 3 inches wider at bottom than at top, to prevent the hoops from dropping off when it is out of use in summer. The lid may be of well-seasoned inch deal, in pieces 7 inches wide, and strengthened with wide cross pieces, to prevent warping. It should be in two parts, with handles on the top.

The mash-tun is placed 18 inches from the side wall, and the taphole end projects about a foot, beyond one of the 9 feet long pieces, which support the mash-tun. The taphole is bored close to the bottom, in the middle of the end farthest from the copper. The mash-tun must have an inch fall towards that end. The mashtun tap may be 10 inches long, and should be $1 \frac{1}{4}$ inch diameter inside, without any strainer at its end; and the part which turns should lift out when required: it should not enter the inside of the mash-tun more than an inch.

False bottom to the Mash-tun.-Made of the best well-seasoned deal an inch thick and to fit neatly and tightly under a fixed lining carried 
round the mash-tun, 2 inches from the bottom. The fixed lining, which keeps down the false bottom, is a wooden hoop 3 inches wide, an inch thick at the bottom, and tapering to a $\frac{1}{4}$ inch at the upper part, which is rounded that the mashing rule may glide off it. The false bottom is supported by three cross pieces and one circular piece a few inches from its edge; these pieces may be 2 inches wide and must be precisely $I$ inch thick, they are nailed to the false bottom, and must be hollowed about 2 inches wide and $\frac{3}{4}$ inch deep twice in every foot, to allow the liquor and wort to run freely in every direction.

The false bottom must be perforated with holes an inch apart bored with a tapering bit, and afterwards burnt with a tapering iron to prevent the roughness, which would hinder the escape of the wort through them; the holes should be $\frac{3}{16}$ ths of an inch in diameter at the top, and $\frac{5}{16}$ ths of an inch underneath. The false bottom may be in five divisions, the middle one being $6 \frac{1}{2}$ inches wide, and the other four 16 inches wide each.

Upright shoot in Mash-tun.-This is a trough 5 inches square inside, with four sides made of 
$\frac{3}{4}$ inch deal; it stands inside of the mash-tun, at the point nearest the tap of the large copper, and is kept there by a band of iron $1 \frac{1}{2}$ inch wide, fixed on three sides of it and projecting 4 inches at each end, in order to fit on to staples driven into the mash-tun 4 inches from the top; pins being put into the staples to keep the shoot in its proper place. The piece next the side of the mash-tun rests upon the bottom of that vessel, but the other three sides are cut 1 inch shorter to prevent their being lower than the false bottom. The piece which fits close to the mash-tun is cut level with the top of that vessel, but the other three sides are 6 inches higher. Care must be taken that there is no aperture at the bottom that would permit the malt to get under the false bottom. The middle piece of the false bottom is the same width as the upright shoot, and it is $6 \frac{1}{2}$ inches shorter than the diameter of the mash-tun bottom, in order to admit that shoot. It cannot be removed until the shoot is taken out; the latter has a rim an inch thick fixed outside on three sides of it, placed an inch from its lower end ; this rim rests upon the false bottom.

5. Lower Platform.A flooring of $1 \frac{1}{2}$ inch 
deal covering all the space between the raised pavement and the mash-tun, and extending threefourths of the way along that vessel. This flooring is 4 inches above the bottom of the mashtun and fits neatly and closely up to it. It is clear underneath, being supported by cross pieces from the raised pavement to the bearer of the mash-tun.

6. Steps to ascend Lower Platform.-Made of $1 \frac{1}{2}$ inch deal, 2 feet wide, 9 inches tread, and 9 inches each step in height.

7. Mouth of Drain under Lower Platform.-This drain runs under the nearest side wall to the outside of the brewhouse. See No. 28 on Diagram 1. It should be sufficiently large to allow the ready escape of a considerable quantity of water, and it must be well trapped to prevent any stench arising.

8. Raised Sink and Liquor Tap or Lower Platform. - See Diagram 2, page 5, and elevations, page 6. Made 18 inches square, and 2 inches deep. Lined with lead and a waste pipe in it. A tap, $\frac{3}{4}$ inch bore, fixed above.

9. Raised Pavement level with Lower Platform. - In front of the furnace of the large copper, and level with the bottom of the front of the 
ash-pit, a brick pavement is laid, raised 3 feet 6 inches from the floor. This is carried out 3 feet in front of the copper, and 18 inches beyond the furnace, or 8 feet from the side wall; but only 6 feet at the end next the mash-tun. It extends to the end wall, covering all the space between the large copper and the side wall. An arch may be made to raise and support this pavement and the copper, but there should be no recess open underneath the pavement. The perpendicular brickwork on the floor of the brewhouse extends from the side wall, until it finds a junction with the brickwork of the large copper just beyond the tap of the latter.

10, 11, 12. Large Copper with its Furnace and Flue.-For the size and form of the copper, see page 4 . The ash-pit under the furnace should be 16 inches wide and 2 feet high in front; but the back part may be 2 feet 6 inches high, being sunk 6 inches lower than the raised pavement, No. 9. No door is required to the ash-pit. The bottom of the furnace consists of iron bars 3 feet long, 2 inches thick, and 1 or $1 \frac{1}{2}$ inch wide, fixed $\frac{1}{2}$ an inch apart, supported by and let into a stout iron bar across the centre and at each end. The furnace door with its 
frame may be about 18 inches square, and be let into the 9-inch front brickwork 4 inches. The centre of the furnace door should be 5 feet from the side wall.

There must be 3 feet clear between the widest part of the copper brickwork and the side wall of the brewhouse.

It is the bottom of the flue that is shown on Diagram 1, page 2. The copper rests upon two fire-brick side benches 9 inches wide (Diagram 1, page 2), built up even with the top of the furnace door, leaving 2 feet 6 inches of the width of the centre of the bottom of the copper exposed to the fire. One of these side benches extends to. the back of the copper, and the other two-thirds or three-fourths of that distance; the remaining one-third or one-fourth, together with the space at the back of the copper, forms the entrance of the flue; from thence the smoke, heat, and flame proceed completely round the copper from the bottom to near the top before it can reach the flue and chimney in the end wall of the brewhouse.

The heat and smoke are led round the copper in consequence of a perpendicular pillar of brickwork, 9 inches thick, being carried from the c 2 
bottom to the top of the copper. Its position at the back of the copper is seen on Diagram 1, page 2.

The brickwork from the furnace bars to the entrance of the flue should be laid sloping. The upright brickwork round the copper is $4 \frac{1}{2}$ inches thick, and strengthened by three iron hoops, placed 9 inches apart, laid flat, and built in the brickwork. From the shape of the copper the flue will be 6 inches wider at the bottom than at the top, about 5 inches wide at the latter, and 11 inches wide at the former. The top edge of the copper is $3 \frac{1}{2}$ inches wide, and it rests upon and is kept firm by a course of bricks forming the top of the flue. Two soot doors are required, one on the left hand side of the tap, and the other on the right hand side of the furnace door. A covering over the front part of the furnace, and over the tap tube, fills the space between the bottom of the copper and the brickwork forming the bottom of the flue at that part; a damper should be placed in the flue, 6 inches higher than the top of the copper brickwork.

The copper lid, made of inch deal, should be 6 feet in diameter, and in three parts, with handles to each part; when in use, it rests upon 
a course of bricks, 6 inches higher than the top of the copper, but sloped to 5 inches at the end next the copper. These bricks should be 7 inches long, and $1 \frac{1}{2}$ inch of one end of them should rest on the outer edge of the copper; they may be 3 inches wide at one end, and $2 \frac{1}{2}$ inches at the other, in order to fit into the circle; they must be set in cement, or else covered with lead: this additional depth of 6 inches will aid in preventing an overflow of the wort while boiling.

13. Tap of large Copper.-It must be $2 \frac{1}{4}$ inches diameter inside, at the mouth, and the tube connected with it 6 inches in diameter, at the end fixed to the copper; the total length of the tap and tube is about 26 inches: the mouth of the tap should partially curve downwards, project not less than 10 inches from the brickwork, and be fixed 8 feet distant from the side wall. The tap is turned by a rod 2 feet long.

14. Entrance to Recess for Coals.-This is an opening 2 feet wide, and about 3 feet high. The recess will hold a ton of coals, and part of the raised pavement forms its floor: it is underneath the upper platform.

15. Steps to Upper Platform.-These are similar to the steps of the lower platform, except 
that they should be made 3 inches narrower, to give more width to the coal entrance.

16. Upper Platform.-Made of $1 \frac{1}{2}$ inch deal; it is 3 feet lower than the brickwork at the top of the copper. It covers the whole space between the copper and the side wall to the length of 5 feet 6 inches from the end wall. This platform gives access to the wort pump, and to the large copper.

17. Wort Pump.-This is fixed on the upper platform, close to the side wall, and near the end wall, with its handle towards the mash-tun.

18. Pipes from Liquorback and Underback, to large Copper.-See Liquorback, p. 12.-From the upper platform, the water is turned on to the large copper by means of a stop-tap in the pipe, placed 2 feet from the copper. The pipe of the wort pump should be 2 inches in diameter inside; one end of it rests on the lower end of the underback, and passing down that vessel, dips into the hollow in the bottom already described, p. 13. The wort runs into this cavity, and is drawn from thence into the pipe. The other end of the wort pipe, and also the pipe from the liquorback, are let into the top of the copper brickwork. The ends of each pipe should project 3 inches over the side of the copper. 
19, 20, 21. Small Copper, with its Flue and Furnace.-For size and shape of copper, see page 4. Diameter of brickwork, 4 feet; the flue constructed on the same principle as that of the large copper, and about 6 inches wide at bottom, and 3 inches at top. The furnace door, with its frame, may be 14 inches square; the ash-pit, 10 inches high, and 1 foot wide; a lid to the copper made of inch deal. This copper is used chiefly to heat water for washing the casks.

22. Tap and Tube to small Copper.-The tap should project 6 inches from the brickwork. For its situation, see Diagrams 1 and 2, pages 2 and 5 .

23, 24. Coolers.-For their dimensions, see page 5 . They should not be more than 6 inches deep inside; the bottoms made of $1 \frac{1}{2}$ inch deal, well seasoned, and the joints well tongued; the sides of deal, 2 inches thick. When from long use they become very leaky, they may be lined throughout with lead, weighing 6 pounds per square foot. The lead should pass over the top of the sides, and be nailed on the outside. The leaden linings will always prevent foulness, leakage, and decay; they will last a very long time, and then be worth half the price of new linings. The upper cooler is fixed with its top edge 6 feet 
from the floor, or 6 inches lower than the tap of the large copper; and it must have a fall of 1 or 2 inches to the end next the other cooler.

The lower cooler is so fixed that one end of it passes 18 inches along under the upper one, and close up to it, and has a fall of 1 or 2 inches towards its other end. At the lowest end of each cooler a moveable plug, $1 \frac{1}{2}$ inch in diameter, should be fixed. They may be placed 2 feet from the front of the lowest ends, that in the upper cooler being 9 inches from the end; but in the lower cooler the socket should be 18 inches from the end. These wooden plugs (see Diagram 3, page 7) are 18 inches long, and when driven in by a mallet, fit neatly and close.

The coolers are supported by a framework made of deal 4 inches wide and 3 inches thick, carried along the side wall, and also at the lowest end of the lower cooler. Strong supports of 4-inch-square oak are placed under the coolers between each of the fermenting tuns, and at the upper end of the upper cooler, leaving room for access to the back of the fermenting tuns. The bottoms of the coolers are strengthened by pieces of 3-inch-square deal placed 18 inches apart, one end of each piece resting on the frame next the 
side wall; and the other end, supported by an iron bolt 10 inches long, and $\frac{1}{2}$ an inch in diameter, with a screw at one end passing through the side of the cooler. The heads of the bolts and the nuts at the bottom must both be completely sunk into the wood, or a band of wide iron hooping may clasp the end of each piece instead of having the bolts.

25, 26. Four Fermenting Tuns.-Made 3 inches wider at bottom than at top. For the size of them, see page 4. Made of the best well-seasoned oak, $1 \frac{1}{2}$ inch thick, with four hoops to each like those on the mash-tun. A lid to each tun, made of inch deal, and with handles. Each lid may be in two parts.

The largest of the fermenting tuns (see Diagram 3, page 7) is placed on a square frame made of oak 4 inches square, standing on blocks 4 inches high. Each of the other fermenting tuns may stand on three pieces of 4-inches-square oak, laid on the floor without any cross pieces, which might exclude air, and also prevent examination as to leakage.

For elevations of the fermenting tuns, see page 7. The front of the large fermenting tun projects at bottom 9 inches, in front of the cooler 
and the others, 6 inches. See Diagram 1, page 2.

There will be 16 inches clear between the fermenting tuns and the frame supporting the lower cooler, and 20 inches between the large tun and that of the upper cooler. Each fermenting tun must have a fall of not more than $\frac{1}{2}$ an inch towards a waste vent $1 \frac{1}{2}$ inch in diameter, bored close to the bottom in the centre of the front part. These vents are stopped with bungs and pieces of wrapper. The slope of the pavement will perhaps give the desired fall.

27. Cleansing Pipes.-A leaden pipe $1 \frac{1}{2}$ inch diameter inside must be fixed firmly into the bottom of each of the fermenting tuns 4 inches from one side of them, and raised a $\frac{1}{4}$ of an inch above the bottom, see page 84 . Into each pipe a wooden plug must fit well and firmly. These plugs, when fixed, should be 2 inches below the top of the tuns, for fear of being disturbed by the lids. One pipe will do for two tuns. The two pipes from the fermenting tuns may lie on the pavement. They run into a main pipe, see No. 27 on Diagram 1st, which enters the floor of the brewhouse at a distance of 6 feet 6 inches from the wall, and then descends to the cellars. 
This pipe and one of its taps and also the yeast receiver are shown on Diagram 3, page 7. The exact position of the pipe and tap would however be on Diagram 2, page 5. This main pipe is continued through the parting wall into the other cellar. Avoid sudden turnings or contracting the bore of the pipe in any way. The object is to be able to convey the beer from all the fermenting tuns into either of the cellars. At the end of the pipe in each cellar is soldered a tap of $1 \frac{1}{4}$ inch diameter inside, and under it half a union screw. This union screw must not be less than 1 foot above the tops of the casks. The other half of the union screw is fixed in a patent webbing hose, without seam, $1 \frac{1}{2}$ inch diameter inside. Two 10-feet lengths will be required. They must occasionally form into one pipe, by means of the union screw fixed in them, in order to reach and descend into the casks farthest from the tap. Sometimes the hose is made of gutta percha or of leather.

To return to the brewhouse. Between the steps of the lower platform and the large copper three posts are fixed (see Diagrams 1 and 2, pages 2 and 5). On these a rail is fixed, 6 feet from the floor of the brewhouse. This rail is level with 
the top of the mash-tun, and the top of the upper cooler, and is required to support the shoot leading from the large copper to the mash-tun, as shown on Diagram 2, page 5, or that from the copper to the upper cooler.

Sundry Requisites for the Brewhouse.

Four moveable shoots are necessary, all made of $\frac{3}{4}$ inch deal, and well tongued at the joints, to prevent leakage. One of these is 3 feet long, with four sides, made 6 inches square inside, at the upper end, and 3 inches at the lower. By means of a strap at the largest end it can be hung on to the copper tap to guide the water downwards into any vessel on the floor, and to prevent its splashing over when running into the shoot leading to the mash-tun. The other three are open shoots, each of them made 6 inches wide inside at the upper end, and tapering to 4 inches at the lower. They should be 4 inches deep inside throughout. One, 7 feet 6 inches long, to reach from the copper to the mash-tun; another, 9 feet long, to convey the wort from the copper to the upper cooler, passing a foot over that vessel, in order to enter the horsehair hop-bag. By means of iron brackets, open in front, fixed underneath the coolers, these 
shoots are suspended, when requsite, under the coolers (as seen on Diagram 3, page 7) to convey the wort from the lower cooler to the fermenting tuns. One of the tuns being under the plug requires none; but the next, and the large tun, will require one or both of the shoots. The other tun will require a second shoot, about 5 feet long. These shoots will be useful in the cellars to support the cleansing hose while running the beer into the casks.

A leaden strainer in large copper is an indispensable utensil. Its use is to prevent the hops from leaving the copper, while the wort is running from that vessel. It is a round piece of stout lead, 18 inches in diameter, perforated every 2 inches each way, with a hole $\frac{3}{8}$ ths of an inch in diameter. Two-thirds of it is made to bulge out gradually, so that 6 inches diameter of the middle part stands out 4 inches from the moath of the tap tube; and another, 6 inches, projects less. The remainder forms a rim, 3 inches wide, which fits flat and close to the copper. When in use its own weight keeps it in its proper place.

A horse-hair bag is another requisite, for receiving any hops that may escape through the leaden strainer, 2 feet wide and 3 feet deep, with 
rings sewed on the mouth to receive a cord: a pulley is placed over the upper cooler and opposite the copper tap. By means of a line the bag is raised or lowered when required.

Next come two mashing rules, for stirring the malt when in the mash-tun. They must be made of ash, in the following form :-The centre rod is 6 feet 6 inches long, $1 \frac{1}{2}$ inch thick throughout, and $2 \frac{1}{2}$ inches wide at the lower end; where five round wooden bars, $\frac{3}{4}$ inch in diameter, and 3 inches apart, run through it, into, and through a piece 22 inches long, an inch thick, and $2 \frac{1}{2}$ inches wide, placed on each side. The side pieces are 10 inches apart at the upper end, and 6 inches at the lower. The upper end of the rod is reduced to $1 \frac{1}{2}$ inch square, and the edges rounded for the purpose of handling. The three pieces at the lower end are rounded, in order to glide along easily, when at the bottom of the mash-tun.

Two ladders, made light, one 13 feet long, to give access to the liquorback, will be wanted occasionally. The other, 6 feet 6 inches long, is necessary whenever the plugs in the coolers require moving.

A weighing machine and weights, up to two hundred weight. 
An iron rod, half an inch in diameter, and 6 feet long, will be a convenient poker for the furnace.

Another iron rod, 7 feet long, with one end shaped like a garden hoe, 4 inches wide and 3 inches deep, is also needed for the furnace, and also a common coal shovel.

Three 4-gallon pails, made of $\frac{1}{2}$ inch oak, with iron hoops.

Three 3-gallon ditto, ditto.

A 4-gallon garden watering-pot, with rose.

Three or four stone bottles, holding 2 or 3 gallons each, may sometimes be wanted.

Several birch brooms, and two good scrubbing brushes, also a good mop.

A 4-inch square block, 1 foot long, is placed on the railing under the copper tap, when the shoot leading to the mash-tun is in use, to give it the requisite fall.

Stirring-rod, for copper, 6 feet long, $2 \frac{1}{2}$ inches diameter. If there is no tap to the small copper, a small pail with a long handle fixed to its side, called a jut, will be required.

\section{Description of the Casks.}

These are what are called 'bell-shaped.' The inside measurement is given at page 5 . The 
outside dimensions are 4 feet high, 3 feet wide at the top, and 2 feet 6 inches at the bottom. They will hold about 120 gallons each. Made of the very best well-seasoned English or Hamburgh oak, $1 \frac{1}{4}$ inch thick, with seven iron hoops, $1 \frac{1}{2}$ inch wide, and $\frac{1}{10}$ th of an inch thick. The heads $1 \frac{1}{4}$ inch thick, and made to fit with great accuracy, a groove cut $\frac{3}{8}$ ths of an inch wide, and $\frac{1}{4}$ of an inch deep. In the head, 9 inches from the front, is the bunghole, $2 \frac{1}{2}$ inches in diameter outside, and $2 \frac{1}{4}$ inches inside; and to the right of it is an air vent, $\frac{3}{8}$ ths of an inch in diameter outside, and $\frac{1}{4}$ of an inch inside. A similar peg-hole is bored in the middle of a stave, on the right hand side of the front of the cask, just below the second hoop from the top. A vent $1 \frac{1}{2}$ inch diameter outside, but tapering to $1 \frac{1}{4}$ inch inside, must be bored in front of the cask, close under the head. This is intended for the escape of the yeast, and as the cask is never filled above this opening, the contents of it will never be more than about 117 gallons. The slope of the pavement will give the casks a very slight incline forward, which is desirable, provided it does not exceed an inch (see page 9). Two tap-holes, 1 inch diameter, tapering to $\frac{3}{4}$ inch inside, one just below the fourth hoop from the top, and the 
other 3 inches above the inside of the bottom, or about 5 inches from the bottom, outside. The casks should be perfectly smooth in every part of the inside. Very porous oak is wholly unfit for casks. Instructions for keeping casks sweet, and detecting those that are not so, are given at pages 82 and 83.

\section{Sundry Requistres for use in the Cellar.}

Three or four yeast receivers. One of these is seen on Diagram 3, p. 7, made of well-seasoned inch deal; the joints extremely well tongued. It stands on four legs of deal 2 inches square, and is strengthened by cross pieces. The inside measurement is 5 feet 6 inches long, 9 inches deep, and 18 inches wide; it will hold about a barrel; the top is 2 feet 9 inches from the ground. A $\frac{3}{4}$ inch tap-hole bored in the centre of one end $\frac{1}{2}$ inch from the bottom.

Two 3-quart bowls, made of oak.

Four round open tubs holding 9 or 10 gallons each, made of oak $\frac{3}{4}$ inch thick with iron hoops; inside measurement, $9 \frac{1}{2}$ inches deep, and $17 \frac{1}{2}$ inches in diameter.

Eight yeast conductors made and used as follows :-A tin tube 4 inches long, $1 \frac{1}{4}$ inch diameter at one end, and $1 \frac{3}{4}$ inch at the other, is placed 
tightly in the yeast vent in front of the cask, so as not to enter the cask much beyond the wood; at the other, or largest end of this tube, a piece of tin is soldered to conduct the yeast downwards, this is in the form of a scoop 2 inches deep, 3 inches wide, and 9 inches long, the upper end fixed an inch above the tube, and is rounded at both ends.

A funnel, holding about 3 gallons, made of $\frac{1}{2}$ inch oak about 16 inches in diameter inside at bottom, and 14 inches at top, 5 inches deep; but a hollow cut in the top to rest a pail upon reduces the depth at that part to 4 inches; an iron pipe, 4 inches long and 1 inch diameter inside, is fixed in a hollow in the centre of the bottom.

Four tilters made of ash, $1 \frac{1}{2}$ inches thick, 3 feet 6 inches long, and the lower half 4 inches wide. Commencing 6 inches from the lower end, cut four notches in a foot 2 inches deep; the part of the notch against which the cask presses must be quite flat. The upper end reduced to 2 inches wide for convenience of handling.

Two stools made of oak, 2 feet long, 9 inches wide, and 2 feet high, with four legs.

Two pair of pinchers made thus :-A foot long 
with the ring 2 inches in diameter inside, and a stem 2 inches in length fixed on the under part of the ring. When the pinchers clasp the peg and the handle is pressed downwards, the stem presses on the cask and the peg is drawn easily.

Avoid porous bungs and old pegs. Use the best bungs cut an inch thick. Vent pegs of red willow cut smooth and even. Beer taps of $\frac{1}{2}$ inch diameter inside at the mouth; select those which by unscrewing underneath will allow the upright part to be taken out and oiled when necessary.

Two middle sized wooden mallets.

Two $\frac{1}{4}$ inch gimblets.

Before proceeding to give a precise account of his method of brewing, the author considers it requisite to refer to the ingredients employed, viz. :-Malt, Hops, Water, and Yeast. Also, to the instruments used: a Saccharometer and a Thermometer, which are necessary to the conducting of the process with precision, and certainty of success.

\section{MaLt.}

There are three kinds of malt made, viz., 'pale,' 'amber,' and 'brown' malt. The sac- 
charometer is a correct guide concerning the goodness of the malt, provided the mashing has been well conducted.

Purchase the best malt. A bushel of good malt will weigh from 41 to 43 lbs. Weight, however, is not always a criterion of value, for if a portion of the grain remains unmalted the weight will be increased, because a bushel of good malt when newly dried weighs about threefourths of a bushel of the raw grain.-See Making of Malt, page 147.

Good malt is made only from the beginning of October to the beginning of May. Avoid that which is made in summer, and never use any which has not been kept perfectly dry, for dampness will injure its quality. Malt very recently made is not desirable for use; it requires an interval of a few weeks after leaving the kiln to cool and mellow it.

Obtain a sample of the malt before it is crushed. The grains should be pale and bright in colour, uniform in size, round, thin-skinned, break easily, and be full of a soft white flour, having a sweet, mellow, and very agreeable flavour. The grains should be as tender, and crumble as easily, at the ends as in the middle; and when 
broken and drawn on a board leave a trace similar to that made by a piece of chalk.

The sample should always be tested by throwing about a hundred grains into a tumbler of cold water: the well-malted grains will float on their sides on the surface of the water; the half-malted will float endways, and the unmalted will sink to the bottom of the glass. - See Making of Malt, page 148.

The author has seldom used malt in which about one-fifth of the whole did not either sink or float endways, it may be otherwise with the very finest samples: this test will not apply to the 'blown' malt (a kind of brown malt) sometimes used for brewing stout and porter, for that will always swim on the water, in consequence of the greater abundance of air inside the husk, caused by the great and sudden application of heat when on the kiln.

The malt should be crushed by the mill: crushing is preferable to grinding; examine closely samples taken from each sack, to see that none of the grains remain unbroken, those which are so being valueless. If the grains are of unequal size the lesser ones will pass the roller without being broken, or else the larger corns will be 
crushed to powder; there will, however, be some flour, but the less the better, provided every grain is cracked.

The malt should not be crushed longer than a day or two before it is used. For the method of making malt, see pages 135--148.

\section{Hops.}

The fine, warm, aromatic, bitter flavour peculiar to the best hops is mild and grateful to the palate, and perfectly free from the rank and nauseous bitter flavour produced in malt liquor by the use of inferior hops: the sort called 'Golding's' are decidedly the best flavoured; they are grown at Farnham in Surrey, and in East Kent and Mid Kent: they have the smallest flower of any kind of hops, and give a rich and delicate flavour to the ale. The author has found the kind called 'Jones's,' being a mild hop, answer very well when picked in excellent condition.

Much care must be taken to procure hops which were picked in good condition: those picked too soon, or unripe, look green in the sample, and the brown-coloured or over-ripe were picked too late in the season; both of these 
will be very defective in quality, a uniform bright pale yellow is the proper colour; when rubbed on the hand they should leave it clammy, with an extremely fragrant odour, and perfectly free from rankness; there should be no leaves or pieces of branches mixed with the hops. The finer sorts of hops are packed in large sacks called ' pockets,' holding about $1 \frac{1}{2}$ cwt. each, the other kinds are pressed into what are called 'bags', made of a coarser material and holding about 3 cwt. each.

Sometimes, what is called the 'mould' infects the flower of the plant before it is picked; such hops must be carefully avoided, for they will be nearly destitute of the valuable yellow powder called 'condition.'

Hops are generally picked in September; they may be used immediately after they are picked and dried, with or without an admixture of older hops. Hops should not be kept longer than one or two years; age decreases their value because of the evaporation of the aroma.

\section{WATER.}

The author has almost always brewed with ' hard,' that is, well or spring water, and generally with that which contained carbonate of 
lime (chalk). Boiling softens such water: after boiling some time, if it was allowed to stand till cool, a chalky sediment would be seen at the bottom of the copper, and the water would be more transparent than it was before: it is his practice always to boil the water 10 or 15 minutes before using it for the first mashing. Rain water being softer than any other, is considered best by some, but the supply is generally precarious, and when obtained from the roofs of houses, a quantity of dust and blacks from chimneys accompanies it into the cistern. These impurities will subside to the bottom if left a sufficient time undisturbed, but they may injure the flavour of the water. It is highly requisite that the water used in brewing should be almost, if not perfectly, clear, and utterly free from the least unpleasantness in taste or smell.

\section{YEAST.}

It is of much importance that the yeast used in brewing should be extremely fresh and good. The colour should not be at all dark, but of a light brownish grey. If there is the slightest acidity in the flavour, reject it. It should be so thick as barely to retain the liquid state; and it 
must always be used by weight, not by measure. Keep it in a cool place.

The method of fermentation recommended in this work is such as will always ensure an abundant supply of the very best yeast after the first or second brewing in the season.

\section{The Thermometer.}

This instrument is so generally known, that a description of it is unnecessary. The most convenient size for brewing purposes is about 14 inches long, with each line on the plate indicating two degrees of heat. The case is of japanned tin, and the part of it which protects the bottom or bulb of the glass should not leak. Two thermometers will be required. They cost $4 s$. or 5 s. each.

\section{The Saccharometer.}

This instrument is made of glass. The price varies from $5 s$. to $7 s$. $6 d$. The diagram on the next page represents the saccharometer at about half its actual size. At the bottom is some quicksilver enclosed in a round bulb about $\frac{3}{4}$ inch in diameter, and a little above it is another bulb slightly elongated, about as large again in diameter. 
The remainder or upper part of the instrument consists of a hollow stem $\frac{1}{4}$ inch in diameter,

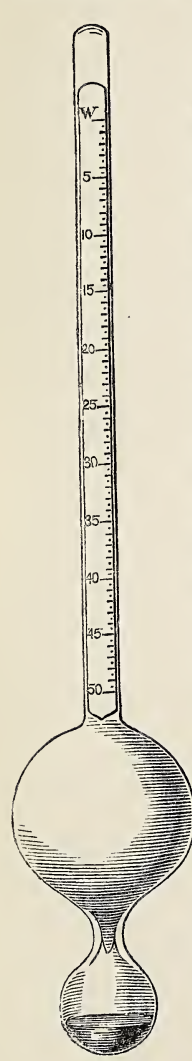
and about 6 inches in length. Inside of this stem there is fixed a white plate, on which is marked figures or lines successively from one to fifty. The latter number is nearest the large bulb, and the former near the top of the stem next to the letter W, which indicates the gravity of water. The saccharometer is sold in a tin tube which holds nearly a pint, and which must be soldered if it leaks. It can be purchased in London of Messrs. Dring and Fage, 19 Tooley Street, near London Bridge; or of Mr. Long, 20 Little Tower Street; or of Mr. Cox, 100 Newgate Street. There are metal saccharometers of several kinds. They cost four and a-half, or five guineas each. The author has still in his possession a glass one which he purchased above twenty years ago. He has always found the glass ones answer his purpose. 
The use of the saccharometer is to show the difference between water and malt liquor, when the extract from the necessary ingredients is combined with the water. The word 'saccharometer' signifies ' a measure of sweetness.'

When the glass instrument is put into the water at a temperature of $55^{\circ}$ by the thermometer it sinks down till the surface of the water cuts the stem at the point marked 0 (nought) or $\mathrm{W}$ (water). Wort, which is the liquid extract drawn from malt after its infusion in hot water, may be considered a mixture of sugar and water. The saccharometer shows how much of this sugar the wort contains. The more there is of this sugar in the wort, the stronger and better will be the beer, provided it is well managed in every part of the brewing process. When the saccharometer is placed in wort, it will only partly sink; and should the top of the fluid cut the stem at the figures 10 or 20 , it would be called respectively a $10 \mathrm{lb}$. or a $20 \mathrm{lb}$. wort, the latter being just double the gravity of the former.

A barrel of water weighs $360 \mathrm{lbs}$. and a barrel of wort, which shows a gravity of 20 lbs. by the saccharometer, weighs $380 \mathrm{lbs}$, that is $20 \mathrm{lbs}$. per barrel more than water. Both wort and 
water will weigh lighter if warmer than 55 , because of the expansion or increase in bulk which heat occasions. They also weigh heavier when colder than the temperature 55, to which the instrument is adjusted.

It will often be convenient to use the saccharometer without waiting for the wort to cool to 55 , therefore the following scale is needful, in order to show how much to allow when the temperature exceeds 55 :-

\begin{tabular}{|c|c|c|c|c|c|c|}
\hline Temperature & 55 & 65 & 75 & 85 & 95 & 105 \\
\hline $\begin{array}{c}\text { Allow lbs. per } \\
\text { barrel }\end{array}$ & 0 & $\frac{1}{4}$ & $\frac{3}{4}$ & $1 \frac{1}{4}$ & $1 \frac{3}{4}$ & $2 \frac{1}{2}$ \\
\hline
\end{tabular}

Thus if the instrument swims in a wort at 85 degrees of heat, and it cuts the stem at $16 \mathrm{lbs}$, the actual gravity of that wort is $17 \frac{1}{4} \mathrm{lbs}$., as would be seen on cooling it to 55, and immersing the saccharometer in it again.

The above scale is intended for worts up to 25 lbs. per barrel, but when the wort under examination weighs more than 25 lbs. a quarter of a pound is to be allowed in addition to what is shown in the scale. Thus, a wort of $30 \mathrm{lbs}$. at 85 temperature would be $31 \frac{1}{2}$ lbs. not $31 \frac{1}{4}$. 
Care must be taken to wipe the instrument very clean after using it, for if any of the wort dries on and adheres to it the glass will be heavier and larger in bulk than it ought to be, and therefore inaccurate. This is especially necessary when ascertaining whether the adjustment of the instrument agrees with the water used in brewing. If after repeated trials at a temperature of 55 it is found that the saccharometer is adjusted to show a $\frac{1}{2} \mathrm{lb}$. more or a $\frac{1}{2} \mathrm{lb}$. less than the water used, a proportionate addition or deduction of gravity can be easily made. Thus a wort showing $30 \mathrm{lbs}$. would be called either $29 \frac{1}{2}$ or $30 \frac{1}{2}$ lbs. See page 59 .

The saccharometer enables the brewer to judge of the value of the malt used by ascertaining its produce per quarter. The method of making the calculation is very easy, but will be better understood after the brewing process has been fully explained. See page 110.

The word 'density' means compactness or closeness. The richer the wort is before fermentation the more dense or close it will be. Weak wort is thinner or less dense. The word 'gravity' means weight. The greater the density of the wort the greater will be its weight; 
and the saccharometer shows the additional weight per barrel more than water.

An important use of the saccharometer consists in its being such an unerring guide concerning the progress of the fermentation of the wort. By means of fermentation a great part of the malt sugar in the wort is gradually changed into spirit (alcohol), and then the liquid is called ale or beer. As the spirit forms the wort is attenuated, that is becomes lighter, which is seen on trying it by the saccharometer at different periods of the fermentation. The great utility of the indications of this instrument will fully appear when fermentation is treated of.

There should always be a second saccharometer provided in case of an accident happening to the one in use.

The brewer who is willing to follow the plain directions given in the following pages will find no difficulty in using this instrument, and he will have the guidance of one who has practised many years and experienced much anxiety, -and many failures before he succeeded in acquiring the practical knowledge he is now desirous of imparting without any reservation.

All that the brewer has to do is to fill the 
tin tube, which contained the instrument when purchased, with wort a few times during the process of brewing, and dip the saccharometer into the liquid, observing at which figure or line the surface of the wort cuts the stem.

It would be impossible to give clear and precise rules for brewing without the aid of a thermometer and saccharometer. Probably nearly every public brewer uses them, and every private brewer ought to do so, for they are as useful to one as the other; enabling the brewer, if he has attained the mastery of the art, to conduct his process with such never varying precision as to ensure the same result in every instancethe production of a pure, bright, agreeable, wholesome, sound-keeping beverage.

\section{Quantity of Malt and Hops Required.}

Every family that wishes to have excellent ale and good table beer, should use two quarters of malt for the production of $3 \frac{1}{2}$ barrels of ale, and the same quantity of table beer.

The proportion of hops may be thus regulated :- 
Ale to be kept

Months

1 .

$4 . \quad \cdot \quad \cdot \quad \cdot \quad . \quad 11 \mathrm{~b}$.

8 . . . . . . . . $1 \frac{1}{2} \mathrm{lbs}$.

12 of Malt

- 2 lbs.

Hops to each Bushel

Brown stout (see page 123) must have the same proportion of hops.

For bitter ale (see pages 118 and 121) allow from $\frac{1}{2}$ to $1 \mathrm{lb}$. more hops to each bushel of malt than is recommended above. Hops certainly tend to keep the beer mild, but if the quantities mentioned above make it more bitter than is approved of, less may be used without material injury to the keeping properties of the beer.

The author has now (June 1859) excellent ale and table beer in cask, which were brewed by him sixteen months ago, and had only $1 \frac{1}{2} \mathrm{lb}$. of hops to each bushel of malt.

As the table beer will keep mild and sound like the ale, it proves that alcohol or strength is not essential to the production of beer that will keep good a long time; but, doubtless, the larger proportion of spirit aids in preserving it mild, as well as improving its flavour.

The author has now table beer quite sound which was bottled eight years ago at fourteen months old. He brewed it after bitter ale (see 
page 122). Its original gravity was only $10 \mathrm{lbs}$. It was bottled at $1 \mathrm{lb}$. gravity, and is of the same gravity now.

\section{REMARKS.}

The ale will be bright and fit for consumption in a fortnight if racked and fined with isinglass (see page 114). But it will be far better when it is three or four months old; it will then be clear and excellent, and never require the addition of finings.

Ale brewed in the spring will (from the warmth of summer) ripen rather faster than that which is brewed in the autumn.

It will be in its greatest perfection from six months to a year old (see page 91). By perfection is meant not only transparency and the effervescing quality called briskness or sparkling, but that peculiarly rich, soft, vinous, mellow flavour, and exhilarating property, which age, in conjunction with a sufficiency of the best malt and hops, and skill in the brewing process, produces.

Those who do not object to dormant capital, may keep it another year in the cask, and find it then free from hardness. Its exhilarating property will be increased thereby, and those who prefer old ale may consider the flavour improved. 
If bottled at six months old, it will keep mild and excellent for many years (see page 128).

A great quantity of beer, whether brewed by private families or by public brewers, becomes what is called 'hard' before it has been kept six months. Hard beer is both unpleasant and unwholesome, although it may be bright and free from that extreme hardness termed sourness. If hard beer is mixed with new beer only in the proportion of one-fifth of the hard, the unpleasant flavour of the latter will be readily detected. Sour beer should be thrown away forthwith.

With the two-quarter brewing plant which has been described, any butler of active habits, who is able and willing to devote a very considerable part of his time to the superintendence of the brewings, may brew four times in a week. If the first brewing is commenced on Monday morning, and the fourth on Thursday morning, the whole of the twenty-eight barrels of malt liquor will be in the casks in the cellars on the Saturday evening of the same week, and there will be nothing to do on the Sunday except a little filling up of the casks in the cellars.

The best time for brewing, taking a range of 
six weeks in the spring, and six weeks in the autumn, is to commence the beginning of March and the beginning of October. Clear, dry, windy weather is favourable for the cooling part of the process. The best temperature of the atmosphere is a mean of $46^{\circ}$, but it may range from $30^{\circ}$ to $65^{\circ}$, without the least evil resulting. In general, ' stock,' or keeping beers, should not be brewed in the months of June, July, or August. The author has sometimes brewed excellent stock beer when the temperature of the atmosphere was $70^{\circ}$ in the brewhouse, and $65^{\circ}$ in the shade outside of the building. The high temperature $\left(95^{\circ}\right)$ at which the worts are pitched prevents any difficulty in getting them quickly cooled.

\section{Cost of Brewing.}

16 bushels of malt at $8 s$. per bushel, or $64 s$.

$$
£ \text { s. } d \text {. }
$$
per quarter.

$25 \mathrm{lbs}$. of hops, at $1 s .2 d$. per lb.

Two labourers a day and a half each . $\quad$. $\begin{array}{llll}0 & 8 & 0\end{array}$

Cooper, for unheading, cleaning, and re-

heading two butts . $\quad . \quad$. 030

Coals .

$$
\begin{array}{rrr}
0 & 4 & 10 \\
\hline 8 & 13 & 0
\end{array}
$$

Deduct average value of grains, $4 d$. per bushel

$$
\begin{array}{rrr}
0 & 5 & 0 \\
\hline 8 & 8 & 0
\end{array}
$$


Produce of the Above.

126 gallons of ale at $11 d$. per gallon, the

original gravity being $28 \mathrm{lbs}$. per barrel $\quad 5 \quad 15 \quad 6$

126 gallons of table-beer, at $5 d$. per gallon, the original gravity being $12 \frac{1}{2}$ lbs. per barrel

$$
\mathscr{L} \text { s. } d \text {. }
$$

- \begin{tabular}{rrr}
$212 \quad 6$ \\
$£ 8 \quad 8 \quad 0$ \\
\hline
\end{tabular}

\section{PRACTICAL INSTRUCTIONS.}

Example $\left\{\begin{array}{l}16 \text { bushels of pale malt }\} \\ 25 \text { lbs. of the best hops }\end{array}\right\} 3 \frac{1}{2}$ brls. of ale.

Brewing consists of six processes, which succeed each other in the following order:-
Mashing,
Boiling,
Cooling,
Fermenting
Cleansing,
Cellaring.

Much care is requisite in order to have every vessel in the brewhouse perfectly clean, especially when they have not been used for some time. They should be cleaned with warm water, and afterwards rinsed with hot water. Avoid running 
water quite boiling into the coolers if they are lined with lead (page 23). Pump clean water from the underback to cleanse the pipe of the wort pump. The copper should be cleaned to brightness, and this cleaning should be repeated every second brewing. Any mould or dirt adhering to any of the vessels would be likely to taint the wort, and spoil the flavour of the beer.

The malt can be weighed by the machine. Deducting the weight of the sacks, and dividing by 16, the weight per bushel is ascertained.

Eighteen lbs. of the best fresh yeast will be required.

Weigh 22 lbs. of hops, leaving the three remaining pounds to be added to the casks hereafter (see pages 87 and 107). Loosen the flakes of the hops before adding them to the wort in the copper.

\section{Mashing.}

Fill the seven-barrel copper with water or 'liquor' (as it is technically called in the brewhouse), and let it boil a quarter of an hour. Then let $\frac{3}{4}$ of a barrel of it into the mash-tun. Fill up the copper, and as soon as the liquor is within $10^{\circ}$ of the boiling heat (212) by the thermometer, 
run the whole into the mash-tun, making $7 \frac{3}{4}$ barrels of liquor in that vessel. As a future guide, mark the mash-tun at the surface of the liquor, just before the malt is put in. As soon as the liquor has cooled to a temperature of $178^{\circ}$, add the malt to it. While the malt is running from the sacks (which should not occupy more than ten minutes) let it be thoroughly stirred about with one or both of the mashing rules (see page 30 ), to prevent its forming into balls, and that every grain may be wet.

The stirring must be continued for twenty minutes longer, making half an hour altogether, when the mash-tun lid is to be put on, and its contents, which are now called 'the goods,' are to be left in a state of repose for three hours. At the close of the stirring, endeavour to leave the malt (which will be inclined to sink) nearly level in the mash-tun.

In every case before the copper is emptied cover the fire completely with cinders and ashes, so that no red part of the fire, or any flame, be seen. Also, partly close the damper in the flue.

Four and three quarters of a barrel of liquor, at a temperature of 186 , will be required for the second mashing. It need not be made to boil. 
Let the liquor commence running from the liquorback to the copper directly it is emptied for the first mashing.

A slight variation may be made in the temperature of the liquor for the first mashing according to the coldness or warmth of the weather; but it must never be used colder than 176 , or warmer than 180. The malt will probably vary in temperature from 50 to 65 , and the atmosphere out of doors from 30 to 65 . In the warmest weather mash at 176, and in the coldest at 180. In general the brewhouse will be from 5 to 10 degrees warmer than the outer air.

Neither stout nor bitter ale will require any variation in the first mashing heat from the rule just laid down (see pages 122 and 124).

As soon as the 16 bushels of malt are added to the $7 \frac{3}{4}$ barrels of liquor, the temperature of the whole will be about 160 or 162 , and when the stirring is finished, it will be about 154 or 158 .

At the end of three hours from the time of covering up, the wort must commence running from the mash-tun. This is called 'setting the tap.' 'Turn the tap of the mash-tun a little way, and draw out into a bowl 2 or 3 quarts of the wort, by which time it will run tolerably clear. 
Empty the bowl slowly into the mash-tun, and let the wort continue running into the underback. In ten minutes the tap will bear a little more turning, as far perhaps as one quarter of its bore, if it is of the size which has been recommended at page 21. In half an hour the tap may be turned half way, and in an hour three quarters of the way. The wort will run tolerably clear the whole time, but it will not be perfectly transparent. There will not be the slightest taste of sourness in it, and it will have a fine white frothy head on its surface when in the underback.

The wort should be about an hour and three quarters running from the mash-tun. If it much exceeded that time, acidity might ensue in the goods, and spoil the second wort or table beer.

When the tap has been running (called 'spending') about an hour, the wort will probably be escaping at a temperature of 152. It should never exceed that heat by more than 2 or 3 degrees; nor at any time be lower than 144, except at the beginning or end of running, when it will be a few degrees colder.

The reasons for slow drawing out from the mash-tun, as well as for using so much liquor, 
and allowing it to stand so long on the malt, are now given.

When the goods are left in repose, the malt subsides towards the bottom of the mash-tun, leaving a considerable quantity of liquid above it, - probably three barrels. This liquid gains no increase of gravity during the three hours. If examined at the time of covering up, and again at setting the tap, it will generally be found to be one-fourth less gravity than the wort is when it is all in the copper; if the latter is $25 \mathrm{lbs}$. the former will not be more than 18 lbs. Moreover, at the setting of the tap, this top liquid will have lost from 15 to 20 degrees of heat, while that which flows from the tap does not lose more than from 5 to 10 degrees during its stay in the mash-tun. By allowing the tap to spend slowly, this volume of colder and weaker wort above gradually sinks into the malt, driving the richer wort downwards, and occupying its place in the goods. When the tap is spent, the goods will perhaps be at a mean temperature of 125 , and their depth about 1 foot.

The wort, when all in the underback, will probably be at about 135 . The quantity of wort will be about $5 \frac{1}{4}$ barrels. The body of wort 
above the malt prevents contact with the atmosphere and causes a retention of heat, so that it not only expels the richer fluid, but causes the latter to become such by allowing it to remain longer in contact with the malt, without running into acidity through a too great loss of heat.

The long time of standing on the goods, and the slow drawing therefrom, promotes the clearness of the wort.

The use of so large a quantity of liquor enables the brewer to restrict his ale to the first wort only.

Dr. Thomson, F.R.S. (in the supplement to the Encyclopædia Britannica, page 474, article Brewing) says, "The flavour and beauty of the ale is increased if we take only the wort that runs first off, and throw away the last drawn worts, or employ them only in the manufacture of small beer.'

If the wort was allowed to run off rapidly, some of the upper portion would probably find its way to the tap without sufficiently rinsing the malt in its progress, or displacing that which, as already stated, is one-fourth stronger, thereby weakening the ale wort.

The 16 bushels of malt will absorb and retain 
$2 \frac{1}{2}$ barrels of liquor in the first mashing, or about $5 \frac{1}{2}$ gallons each bushel.

There must be no delay between the close of the mash-tun tap spending and the second mashing. Run the $4 \frac{3}{4}$ barrels of liquor at 186 through the upright shoot in the mash-tun, that the liquor may rise up into the goods through the holes in the false bottom. It may run out in ten minutes; that the loss of heat in going along the cross shoot from the copper may not be more than a degree or two. The goods must be well stirred as before for half an hour, and then covered up and left to repose for one hour.

Directly the copper is empty, pump the wort from the liquorback into it, observing whether the leaden strainer in the copper covers the mouth of the tap-tube. Renew the fire, and open the damper. Take about 3 half-pints of wort from the copper, and put it into a bowl to cool. When it has cooled to 55, fill the tin case of the saccharometer with the wort, and stand it in a flatbottomed pint jug so that the case may remain quite upright. Put the saccharometer into the wort, and if the malt was very good, the gravity will be 25 lbs. The stem of the instrument 
should always be made to sink, then take its indication after it rises out of the liquid. Be careful to prevent anything from getting into the sample of wort before it is weighed by the saccharometer, and allow the steam to escape freely from it.

Malt badly made, or malt weighing perhaps not more than 38 lbs. per bushel, made from light and inferior barley, will reduce the gravity of the ale wort at least 2 lbs. per barrel.

After the goods have remained quiet one hour, run off the second wort, which should occupy about an hour and a half, the same care being requisite as before to get it off fine. The temperature of the goods at covering up, and that of the wort when flowing from the tap, will be about the same as with the first mash. The same process of expulsion by colder wort above takes place during the running of the second wort; but there will be no difference of gravity between the wort above the malt and that which flows from the tap.

The mash-tun tap should be spent about the time that the copper is empty, and ready to receive the wort in consequence of the ale wort being in the coolers. A sample of the second 
wort taken from the underback and cooled to 55, will show 8 lbs. gravity if the first wort was 25 lbs.

When the second wort ceases running, draw the mashing rule lightly over the surface of the goods, in order to disturb the pasty sediment which may cover them in places. This arises from the flour of the malt which mingles with and then subsides from the wort above the goods. If there is too much flour from the crushing of the malt, the abundance of this paste would prevent the upper portion of both worts from sinking equally all over, and thoroughly searching the goods.

Having stopped the mash-tun tap, pour half a barrel of cold liquor equally all over the goods, from the rose of a watering pot; this is called 'sparging.'

In half an hour set the mash-tun tap, run it off fine into the underback, and add it immediately to the second wort in the copper. Taste each of the worts, to ascertain that they are perfectly free from the least sourness in their flavour.

There will be no loss of liquor in the second mashing, nor yet from the sparging, so that the second and third worts will be equal in quantity 
to the first wort, that is $5 \frac{1}{4}$ barrels ; the third wort will be of a 7 lbs. gravity.

The residue of the malt is now called ' grains.' They should be removed from the mash-tun within a few hours, lest they become sour, and taint that vessel. They are valuable as food for cows and pigs. If the mashing has been efficiently conducted, the grains will have no sweetness whatever in their flavour.

\section{Summary of the Mashing.}

The following is a summary of the process of mashing, and drawing off the worts. It occupies about nine hours and a half.

6.0 a.m. $\left\{\begin{array}{r}\text { First mash : }-16 \text { bushels of malt to } 7 \frac{3}{4} \\ \text { barrels of liquor, at } 178 \text { temperature. }\end{array}\right.$

6.30 a.m.-Mash-tun covered.

9.30 a.m.-Det tap.

$11 \cdot 15$ a.m. -Tap spent.

11.30 a.m. $\left\{\begin{array}{c}\text { Second mashing: }--4 \frac{3}{4} \text { barrels of liquor, } \\ \text { at a temperature of } 186 .\end{array}\right.$

12.0 noon.-Mash-tun covered.

1.0 p. m. -Set tap.

2.30 p.m. $\left\{\begin{array}{l}\text { Tap spent. } \\ \text { Sparge with } \frac{1}{2} \text { barrel of cold liquor. }\end{array}\right.$

2.45 p.m.-Finished sparging.

3.15 p.m.-Set tap.

3.30 p.m. - Tap spent. 
For the boiling process in accordance with the above, see page 68 .

\section{BoILING.}

The first wort will take about a quarter of an hour in being pumped into the copper. See that no sour wort from a former brewing is in the pipe of the wort pump. Measure the distance between the surface of the wort and the top of the copper, in order to be able to regulate the evaporation. 22 lbs. of the $25 \mathrm{lbs}$. of hops are to be added without delay. If the furnace draws properly, and the fire is well managed, the wort will be boiling in an hour. The hops will float on the top of the wort, until the boiling commences, and then they may be stirred in. When they have sank further stirring is useless; avoid displacing the leaden strainer while using the stirring rod.

The lid of the copper must be kept off all the time the worts are boiling. Have a good body of fire under the copper, at the commencement of the boiling, that the evaporation may proceed evenly, and with sufficient rapidity, without much stirring of the fire, or frequent addition of coals. The boiling is to be continued for one hour, and 
during that time there must be half a barrel of wort boiled away, through the escape of steam.

The boiling increases the strength or gravity of the wort, because it is the water, and not the sugar, that evaporates. The time of boiling and the quantity evaporated decide the rapidity; it will boil at a brisk pace.

Guard against an overflow of the wort. This is likeliest to happen just before the boiling commences. The rising foam will subside when disturbed by the stirring rod. The boiling can be slackened by opening the furnace-door, which permits a current of air to pass over the fire; partly closing the damper also retards the boiling.

When the 22 lbs. of hops have sunk into the $5 \frac{1}{4}$ barrels of wort, the copper (if of the dimensions recommended at page 4) will want about 6 inches of being full; the hops having added nearly $\frac{3}{4}$ of an inch to the wort. The evaporation of half a barrel by boiling will (tried when the boiling has ceased) increase the vacant space above to 8 inches, which is about 5 inches lower than the top of the flue. It would burn the copper to attempt to boil much less wort in it than this, which fills it to about three-fourths of 
its depth, at the end of the boiling. Less fire is desirable towards the close.

On causing the boiling to cease, let the wort remain a quarter of an hour longer in the copper, before running it along the cross shoot into the upper cooler.

The horse-hair bag which is suspended over the upper cooler (see page 29) must be lowered, and cover one end of the cross shoot, in order to receive the few hops which may escape from the copper.

See that the plugs are fixed in the coolers; open all the windows and the doors; then run the wort slowly from the copper to the upper cooler. It may take three-quarters of an hour to run out.

The size of the tap is given at page 21. The wort should run nearly transparent the whole time. Put a little of it to cool, and at $55^{\circ}$ the gravity will be about 28 lbs., having gained 3 lbs. Quite a quarter of a pound of gravity will be derived from the $22 \mathrm{lbs}$. of hops, and two and three quarter pounds from the evaporation of half a barrel of wort.

During the boiling the wort 'breaks,' as it is called, that is, a portion of the mealy or floury 
parts of the malt, which was extracted along with the sugar, and intimately blended with the wort, now separates in fleecy particles, and floats about therein. When the boiling ceases, these coagulated particles sink to the bottom of the copper, together with a certain quantity of what is called 'hop-dreg;' or very minute particles of hop. By running out the wort somewhat slowly, the greater part of these impurities remains in the copper with the hops; if not left there they would form a grey, slimy sediment at the bottom of the coolers, and afterwards, in running the wort into the fermenting tun, it would be very difficult to leave this sediment behind, because of the extreme facility with which it mixes with the wort.

In public breweries it is separated from the wort in a vessel called the 'hopback,', which is a needless and inconvenient appendage to the small brewing plants of private families, and entails the labour of carrying the hops back to the copper.

The second wort will cease running from the mash-tun at the same time that the copper is

* It is a kind of cooler with a double bottom, the upper one being full of holes, through which the wort drains from the hops. 
cleared of the first wort, and therefore ready to receive it. If the second wort was to remain longer in the underback, it might become sour, from loss of heat, and contact with the atmosphere. Take a sample of it from the underback; when cooled to $55^{\circ}$ it will show 8 lbs. gravity.

The speedy addition of the wort will prevent the hops from burning at the bottom of the copper. There being no loss in the second mashing, or in the sparging, the second and third worts will be $5 \frac{1}{4}$ barrels, but after they are pumped up there will be about $5 \frac{3}{4}$ barrels of wort, because the 22 lbs. of hops will have retained nearly half a barrel of the first wort, after the copper tap is spent. This addition of strong wort will increase the gravity of the whole to $9 \frac{1}{2} \mathrm{lbs}$.

The boiling must continue for two hours, and the evaporation proceed at the same rate as before, because a harrel must be boiled away in the two hours. This will increase the gravity to $12 \frac{1}{2}$ lbs., which is a very good strength for table beer: run it into the upper cooler with the same care that was used with the ale wort.

Clear the furnace entirely, and beware lest the body of cinders and ashes in the ash-pit should continue burning; drench them with water, and 
examine them afterwards. Let some cold liquor on to the hops in the copper to cool it.

The boiling process is thus arranged, supposing that the mashing proceeded as arranged at page 62 .

Summary of the BoIling.

11.30 a.m.-First wort in copper.

12.30 p.m. - Began boiling.

1.30 p.m.-Finished boiling.

1.45 p.m.-Set copper tap.

2.30 p.m.-Copper tap spent.

2.45 p.m.-Second wort in copper.

3.30 p.m.-Third wort added.

3.45 p.m.-Began boiling.

5.45 p.m.-Finished boiling.

6.0 p.m.- Set copper tap.

6.45 p.m.-Copper tap spent.

The mashing and boiling occupies nearly 13 hours.

\section{Cooling.}

Under this head will also be included the 'pitching' of the worts: that is, adding yeast to them in order to cause fermentation. The two coolers are supposed to be of the dimensions given at page 5 . If the weather is cool and some wind stirring, the first or ale wort will all 
be cool, and in the fermenting tun, within two or three hours of the time it first began to run from the copper. The same will be the case with the table beer wort. It is desirable that in no case should more than four hours elapse between the time of the wort leaving the copper and of its entering the fermenting tun.

The sooner the wort is spread thinly, and the quicker it is cooled, the better it will be for the beer. The wort should not be deeper than $\mathbf{3}$ inches in the coolers. Let some of the hot wort run into the fermenting tun to warm it, and to assist in cooling the wort.

When the copper tap is spent, suspend the horsehair bag again. There will be $4 \frac{1}{4}$ barrels of each wort enter the coolers; but during the cooling, each wort will lose by evaporation about half a barrel or one-eighth, so that there will be only $3 \frac{3}{4}$ barrels enter each fermenting tun. If there is less than that quantity in the fermenting tun, there will not be enough to fill up the cask during the throwing off the yeast, which would be a serious evil. The cask, when filled to the yeast vent (see page 32), is supposed to hold $3 \frac{1}{4}$ barrels.

The means of conveying the wort into the 
fermenting tuns is seen on Diagram 3, p. 7, and referred to at pp. 27, 28.

Yeast has been already adverted to at pages 40 and 53. If the yeast used is the production of your own brewing, and obtained in accordance with the directions at page 89,10 lbs. will be sufficient for the strong wort, and $8 \mathrm{lbs}$. for the table beer. But allow 2 lbs. more to each wort if compelled to use inferior yeast. The preference is always to be given to yeast produced from ale. If that from table beer is used from necessity, it should be employed only for the weaker wort. The light impurities such yeast contains is very likely to prevent the beer from becoming spontaneously bright.

Put a gallon of wort, at the temperature of $100^{\circ}$, into the pail containing the yeast and stir it. The outside of the pail being perfectly clean, it may stand inside the fermenting tun. In a very short time the yeast will begin to rise up and flow over the pail. It is then ready to be added to the portion of wort (perhaps a barrel), which has by that time been cooled, and let into the tun. The rest of the wort is to be added by degrees from the lower cooler as it cools. The worts are to be at a temperature of $95^{\circ}$ 
when all together in their respective tuns. As they will lose a little heat in running from the coolers, watchfulness is required not to let the $3 \frac{3}{4}$ barrels, with the yeast added thereto, be colder than $95^{\circ}$. This temperature of the wort is adapted to any temperature of the atmosphere, which may vary from $30^{\circ}$ to $65^{\circ}$, without affecting the process of fermentation.

It was only after long and close observation that the author became convinced of the necessity and advantage of employing the heat, and conducting the fermentation in the way he recommends. He has no hesitation in affirming positively, that if this part of the practical instructions is disregarded, he has little hope of much benefit being derived from all that has preceded it. That is, if the object is to produce sound-keeping 'stock' beers. On the other hand, he is doubtful whether his method of fermentation would answer if the preceding instructions on mashing, boiling, and cooling were not attended to.

He does not presume to say that excellent beer may not be brewed by other methods, although he has not succeeded in discovering them. Those who can produce a beverage giving perfect satisfaction to their employers, will do well 
to proceed on their successful course. There are many persons who do not so succeed. On such of these as may read this work, and are willing to give the method of brewing which it recommends a fair trial, the author would urge the necessity (as far as their means and appliances will admit) of adopting his method, in all its parts, for they are connected like the links of a chain, and therefore would be injured by separation. Much might be written in proof of this if brevity was less his aim, and the main object of this work had not been practical instruction, rather than a full exposition of the theory on which, nevertheless, the practice recommended can be justified and defended in all points.

Success, from attending to the rules he has given, will be the most powerful argument in their favour. By that test the author's method of brewing must stand or fall.

But to proceed. Refrigerators or pipes laid in the coolers, having cold water running through them to hasten the cooling of the wort, will not be needed if the extent of cooler surface recommended at page 5 is provided. The four fermenting tuns are shown on Diagram 3, page 7, and their dimensions are given at page 4 . 
One of the fermenting tuns is larger than the others, in order to enable the brewer to ferment both worts together in one tun, so as to produce a beer of intermediate strength called table ale. For the process in that case, see pages 116-118.

This medium strength is, of course, easily produced by mixing ale and table beer as they are drawn from the casks: this tun, however, is not so large but that it may be used when required, with the same quantity of wort as the other tuns. Two instead of three tuns may be sufficient (in addition to the larger one) for the purpose of brewing four times in a week if the fermentation proceeds with sufficient rapidity, as will generally be the case, but a third tun may sometimes be requisite.

\section{Fermentation.}

When the $3 \frac{3}{4}$ barrels of wort is in either of the three smaller fermenting tuns, it will be at a depth of about 16 inches, and there will be nearly 1 foot clear above, between the wort and the lid. Keep the lids of the tuns on all the time the worts are in them: if the lid is in two parts it will be less cumbersome, and will open readily, 
to allow the wort to be examined by the saccharometer.

Stir the wort well at adding the yeast, and also when the whole is together; but afterwards the wort in the fermenting tuns will not require any stirring.

If through inadvertence the wort has been allowed to cool much below $95^{\circ}$, fill two or three stone bottles (holding two or three gallons each) with boiling water, and stand them in the tun for 20 minutes, which will raise the temperature $3^{\circ}$ or $4^{\circ}$. Repeat the filling and immersion of the bottles if requisite.

Before fermentation, the saccharometer (see page 43) tells the strength or value of the wort, but as a $30 \mathrm{lb}$. and a $20 \mathrm{lb}$. wort may both be fermented down to $10 \mathrm{lbs}$. or less, it will be seen that the instrument is not intended to give the strength or value of wort after it is fermented and become ale or beer. But it will be of great use as a means of ascertaining with accuracy the progress of the fermentation and the period at which the beer is ready to go into the cellar.

At page 43 it was said that the wort consists of sugar and water; it also contains a considerable quantity of an ingredient called gluten, which 
is derived from the malt, along with the sugar. When the yeast is mixed with the wort in the fermenting tun at the temperature already mentioned, it puts the wort, which was before tranquil, into a state of motion or disturbance, in consequence of which, what is called the 'vinous fermentation' takes place in the liquid; that is, a quantity of spirit (alcohol) and of carbonic acid is formed by the decomposition of the sugar. Part of the carbonic acid remains in the wort, but a good deal of it flies away in the form of gas, causing the suffocating smell, to be mentioned presently. A portion of the sugar changes into spirit and carbonic acid, and a portion of the gluten changes into yeast.

Alcohol is the intoxicating principle of beer, wine, and the different sorts of spirits. Spirit of wine is alcohol and water.

Carbonic acid does not add to the strength of malt liquor, but is the cause of the lively pungent taste which is so much admired in them, and without which they are flat and unwholesome: it was called 'briskness' at page 49 .

Another effect of the fermentation of the wort is the formation of fresh yeast from the gluten mentioned above. The very eminent German 
chemist, Baron Liebig, says, 'Wort is proportionally richer in gluten than in sugar, so that during its fermentation in the common way, a great quantity of yeast is formed as a thick scum. The carbonic acid evolved during the process attaches itself to the particles of the yeast by which they become specifically lighter than the liquid in which they are formed, and rise to its surface. Gluten in the act of oxidation comes in contact with the particles of the decomposing sugar in the interior of the liquid. The carbonic acid from the sugar, and insoluble ferment from the gluten, are disengaged simultaneously and cohere together.'-Organic Chemistry, p. 295.See on page 97 .

\section{Fermentation of the Ale while in the Tun.}

This process will generally occupy about 18 hours; and (provided the fermentation is vigorous) a few hours longer or shorter time is not of much importance. It has been mentioned (page 74) that fermentation decreases the gravity of the wort. To ascertain the progress of the fermentation take out a sample of the wort, and having first warmed the case of the saccharometer with 
some of the wort; fill it, and continue to add to it until clear wort is seen on the surface, and the yeast or froth is gone off: then immerse the saccharometer, and whatever gravity is shown on the stem of the instrument, add $1 \frac{3}{4} \mathrm{lb}$. thereto, that is, supposing the wort to be at a temperature of $95^{\circ}$, see the scale given at page 44 . At page 71 the $3 \frac{3}{4}$ barrels of ale wort was directed to be placed in the fermenting tun at a temperature of $95^{\circ}$, the gravity being $28 \mathrm{lbs}$. In general, if the yeast acts readily and efficiently, the temperature will remain at $95^{\circ}$ throughout the 18 hours. Sometimes it may rise or fall $2^{\circ}$ or $3^{\circ}$, but it is desirable that it should never rise above $100^{\circ}$ or fall below $90^{\circ}$ during the time it remains in the tun.

Whether the temperature of the brewhouse is $35^{\circ}$ or $65^{\circ}$ is not of any consequence to the brewer, who employs the high temperature and the rapid fermentation which the author recommends. Such an one escapes happily from the train of evils that result from the slow process of fermentation when adopted with the small quantity of wort a two-quarter brewing plant supplies.

While the wort is in the tun, the following 
appearances will indicate that the fermentation is healthy and vigorous. Within the first 2 hours after pitching, there will be a fine creamy head on the surface of the wort of a brownish white colour, and resembling a cauliflower. At the end of the first 6 hours the head of yeast on the wort will perhaps be 6 inches high, and be uneven and rocky in appearance, with clusters of transparent bladders filled with carbonic-acid gas, rising in different parts of the head. The smell from the wort should now partake of that sound, pungent, fragrant aroma, well known to brewers. At the end of a second 6 hours the light yeasty head will have fallen 2 or 3 inches, and there will be large and small clear bladders all over the surface of the wort, and bursting incessantly. The escaping carbonic-acid gas will be found very suffocating if closely inhaled.

If the surface of the wort under the light yeasty head is closely examined, myriads of exceedingly small bladdery particles or yeast cells, the size and shape of small pins' heads, will be seen rising rapidly to the surface, and instantly expanding, forming a white froth floating on the wort. A continuous hissing noise accompanies the fermentation when in full force, arising from 
the effervescence caused by the escape of carbonicacid gas from the wort. This noise will be heard less distinctly when there is a large quantity of yeast on the surface of the wort. At the expiration of 18 hours from the time of pitching, it is probable that the attenuation of the wort (see page 46) will have proceeded from the original gravity, 28 lbs., down to from 18 to 14 lbs. The appearance of the wort will perhaps remain as before, if the fermentation is still active; but if it has become weak, the light yeasty and bladdery head, of 3 inches high, will have dropped entirely, leaving minute particles of yeast or sediment which, with blistery bubbles, are seen floating on the surface of the wort. The gas will now be seen rising with much less force, the sweet taste of the wort will be considerably lessened, and the liquid will have a vinous and spirituous taste and smell.

About this time (18 hours) the energy of the fermentation will probably greatly slacken, so that there will be scarcely any gas escaping; and the saccharometer will show that the attenuation is proceeding very slowly, perhaps only at the rate of $\frac{1}{2} \mathrm{lb}$. in two or three hours. The temperature of the ale will also begin to lower in consequence 
of the languor of the fermentation. Maintaining the temperature by means of the bottles filled with hot water (see page 74) would not prevent this languid or naturally spent state of the fermentation.

Whenever the ale has reached this comparatively inert state of fermentation, which (as already stated) it may be expected to do in about 18 hours after pitching, it must, without much delay, be run into the cask in the cellar by means of the pipe and hose, mentioned at pages 26 and 27, and seen on Diagram 3, page 7 . This, in the language of the brewhouse, is called ' cleansing.'

If the above-mentioned languid state of fermentation should occur before the 18 hours have expired, the ale must nevertheless be cleansed forthwith. But if at that period the attenuation has not reached 18 or $14 \mathrm{lbs}$., and is proceeding at the rate of $\frac{1}{2} \mathrm{lb}$. per hour, a few more hours may be allowed before it is cleansed.

If it is kept in the tun after the active fermentation has ceased, the head of yeast on the surface might sink into the ale and injure it. Skimming it off while the fermentation is weak, exposes the ale to contact with the air of the 
brewhouse, which is not desirable. By delaying the cleansing, a loss of heat would also ensue, and the action of the gas in the ale becomes so feeble, that it would not throw off the yeast after it is in the cask with the vigour and to the extent the author deems indispensable.

It will be observed that $18 \mathrm{lbs}$. is almost twothirds, and $14 \mathrm{lbs}$. one-half of the original gravity. As a general rule, the cleansing gravity for ale should not be heavier than two-thirds, or lighter than one-half of the original gravity. It may be mentioned here by anticipation, that the fermentation will proceed after the ale is in the cask, so that in a few days it will perhaps be attenuated down to $12 \mathrm{lbs}$., or even to $7 \mathrm{lbs}$., the latter being onefourth of the original gravity. It is immaterial which of the two gravities the ale is bunged down at. The attenuation at the bunging down of the ale in the cask will be in relative proportion to its gravity at cleansing. See page 87.

\section{Clenansing of the Ale.}

It is a matter of great importance that the yeast which is formed from the gluten (see page 76), and suspended in the ale at the time it enters the cask, as well as that which is formed 
subsequently, should be extracted therefrom. The term cleansing indicates this process.

The cask must be perfectly sweet and sound. If a cork or chip is left in the cask it will obstruct the yeast vent.

The cask has been minutely described at pages 31 and 32. The head will require to be taken out for the purpose of cleaning, and generally the cask should be dry when the head is replaced, lest the vessel should become mouldy before it is used, an evil that might occur in a few days. Every part of the inside of the cask must be thoroughly scrubbed, and afterwards rinsed with clean hot water.

To ascertain the sweetness of the cask, blow into it through the vent, place a finger for a minute on it, then remove the hand and smell the air as it rushes out of the vessel. If it smells musty or unpleasant, reject it, or use it only for table-beer. If the sweetness of a cask is suspected, chip a piece off the inside of the bottom, and if the cask is tainted the piece will smell so; it is seldom that any amount of cleaning will remedy the evil. To have beer tasting of the cask is an evil every brewer should most strenuously endeavour to avoid. 
Those who have the casks under their own control can always keep them perfectly sweet, even if out of use six months or longer, by leaving: a gallon or two of beer along with the hops and sediment, called 'grounds,' remaining at the bottom of the cask, and keeping it well closed, so as to prevent any admission of air.

The pure and delicate nature of malt liquor renders it very susceptible of becoming ill-flavoured from any of the following five causes: the use of bad malt, or rank and ill-conditioned hops; or employing stale, bad-flavoured yeast; or from the want of cleanliness in the brewing utensils; or storing it in a cask not perfectly sweet.

The casks should stand clear of each other, and not touch the wall of the cellar. Screw on the portable hose to the tap of the cleansing-pipe in the cellar (see Diagram 3, page 7), and let the other end of the hose enter two-thirds down the cask, in order to lessen the froth. Fix the tin tube, or yeast conductor (described at page 33) tightly into the yeast vent in front of the cask (see page 32 ), and place the yeast receiver under it; the latter vessel is described at page 33, and seen on Diagram 3, page 7. See that the plugs are in their sockets in the fermenting tuns; open half way

G 2 
the tap in the cleansing-pipe in the cellar, to prevent the air in the pipe forcing itself into the tun, and disturbing the ale; then draw the plug of the tun to be emptied.

The ale may be twenty or thirty minutes running into the butt, and will lose one or two degrees of heat by the removal. The socket which holds the plug at the end of the cleansingpipe in the bottom of the fermenting tun, should be a quarter-of an-inch higher than the part surrounding it, so that the sediment in the tun may not draw into the pipe.

Put a pound of wheat flour, and half-a-pound of salt into a pail, and well mix them with a quart or two of the ale, by means of a small birch whisk, to break the lumps; then add two gallons of the ale, and repeat the stirring. When the cask is about three-fourths full, pour the mixture into it by means of the funnel (page 34); it will increase the energy of the fermentation, and thereby cause more yeast to flow from the ale.

The advantages of the cleansing-pipes are fourfold: they save labour, they prevent the loss of much heat during removal, they preserve the ale from contact with the atmosphere between the tun and the cask, and they enable it to be re- 
moved without disturbing either the sediment of yeast at the bottom of the tun, or the head of yeast that floats on the surface of the ale.

When the cask is so full that ale (not merely froth) runs out at the yeast-vent, put in the bung and vent-peg in the head of the cask. They must be kept closed, or the yeast will not flow out at the yeast-vent.

The remainder of the ale in the tun (nearly half a barrel) should be run into two of the nine-gallon open tubs mentioned at page 33 . Hang up the cleansing-hose, that it may drain dry. There will be a gallon or two of thick ale and yeast in the tun, which must be thrown away.

Wash out the tun with cold liquor, run out at the front waste-vent (see page 26), having first fixed the plug to prevent its entering the cleansing-pipe. If a piece of birch was to enter the cleansing-pipe, it might give much trouble.

The yeast will begin to flow out directly, or sometimes it may not do so for several hours. The cask must be filled up every three or four hours from the ale in the open tubs. Be careful to skim off the yeast from the surface of the ale 
before dipping the bowl into it for the purpose of filling up the cask, and do not put in the sediment at bottom, if there is any.

A caution must here be given, inattention to which would ruin the ale. Never, on any account, use the least portion of the beer that works out into the yeast-receiver, for the purpose of filling up the cask. If, through inadvertence, there is not enough left for the purpose, the cask must be filled up with some bright and mild ale from one of the casks in the store. This should not be done except of necessity, because it may check the fermentation, and thereby hinder the flowing out of the yeast, through suddenly lessening the gravity, and lowering the temperature of the ale.

During the first 12 hours, about 18 gallons of light yeast and ale will work out of the cask; and perhaps 10 gallons of ale will have been required to fill it up. During the next 12 hours, about 6 gallons of more solid yeast and thick ale will flow out; and the remaining few gallons of ale will have been used to fill up the cask.

The cask must be filled up to the yeast-vent. If more than the half-barrel, reserved, is wanted, use bright and sound ale, or table-beer for the 
purpose. By this time (24 hours) the active working out of yeast will have nearly ceased, but the ale will continue to throw off yeast slowly and sparingly for perhaps 48 hours longer, and should be filled up every 6 or 8 hours. When the escape of yeast has ceased entirely for about 12 hours, the cask may be bunged down.

By this time ( 84 hours) the temperature of the ale will probably be reduced to $65^{\circ}$, and its gravity to nearly one-third, or sometimes one-fourth of the original gravity. In general, the decrease of gravity by attenuation, during the first few days that the ale is in the cask, will be about $6 \mathrm{lbs}$. Thus ale cleansed at 16 lbs. will generally be bunged down in the cask at about 10 lbs. gravity.

The temperature of the cellar will probably range between $50^{\circ}$ and $60^{\circ}$, and it is not material which of those two temperatures prevails. The ale will soon cool to the temperature of the cellar after the cask is bunged down.

Take out the tin yeast-conductor, and drive in a good sound bung in its place. Wipe the head of the butt clean and dry. Put the 2 lbs. of unboiled hops, reserved (see page 53), into a clean pail, and by means of the pinchers (page 34) draw the peg at the side of the cask (page 32), and 
run sufficient of the ale on to the hops to saturate them well. Having stirred them till all are wetted, put them into the cask. Part of them will remain on the surface of the ale for some time, and, together with the thin head of yeast also thereon, will form a barrier to contact with the air. The vacant space, perhaps an inch, between the ale and the head of the cask, will always be filled with carbonic acid gas, which also prevents contact with the air of the cellar.

After the hops are put in, drive in the bung into the head of the cask; it should fit extremely tight, and not be less than an inch thick. Avoid hard, coarse, porous bungs.

Put in loosely the vent-peg in the head of the cask, but tighten it in two days : after it has been tightened 24 hours, loosen it for a moment to let out any undue accumulation of gas, and tighten it again directly. If there is too much of the gas, it may hinder the ale from getting clear, by preventing the remaining yeast suspended in the liquid from sinking to the bottom of the cask. Repeat this loosening of the vent-peg every few days for a fortnight, after which, it may be done once a month, or less frequently, always closing it again directly. It is seldom that there 
will be any rushing out of gas when the peg is loosened.

At page 86 it was said that in the first 24 hours after the ale enters the butt in the cellar, about 24 gallons of froth, yeast, and ale will flow therefrom into the yeast receiver. In another 24 hours skim off the yeast carefully from the ale in the yeast receiver. This yeast, taken from the surface, must be kept in a cool place, to be used for pitching the next gyle (as the contents of a fermenting tun is called). It should be kept covered up, and not be stirred. In general, it should be used without being kept longer than two or three days. There will perhaps be from $16 \mathrm{lbs}$. to $20 \mathrm{lbs}$. of it, varying in bulk from 4 gallons to 8 gallons.

After the yeast is removed from the surface, draw off the ale from the yeast receiver as clear as possible, by means of the tap at the end, and put it into a cask kept expressly for the purpose of receiving the remnants of each brewing. There will be about 9 gallons of this ale. Its flavour will be less pure than that which remains in the butt, and in general it will require the aid of finings and racking before it is drank. It should not be kept more than a few months, lest 
it should get hard, which is the more likely to happen if the cask is not filled. It will have a somewhat rankish bitter taste.

There will be a thick glutinous sediment at the bottom of the yeast receiver, chiefly gluten, extracted from the ale; it will be of the consistence of thin treacle, and must be thrown away. The yeast taken from the surface of the ale that has worked out has a portion of carbonic acid gas in it, which makes it lighter and more lively and effective. If the sediment just mentioned is mixed up with the yeast it will impair its efficiency, and moreover, introduce impurities into the ale fermented with it, which may prevent its becoming transparent.

The yeast is supposed to be skimmed off the ale in the yeast receiver, about 48 hours after the cask began to throw out the yeast. This frothy yeast, however, may be used a few hours after its ejection, and will be very effective. It will then probably take six gallons to weigh 10 lbs. Stirring will probably be required (after taking it from the yeast receiver) to reduce its bulk to six gallons. 


\section{CELLARING.}

The butt of ale, if racked into another, and fined with isinglass (see page 115), may be drank at three or four weeks old, or sooner, provided the proportion of hops mentioned at page 48 has not been exceeded; otherwise, it might be unpleasantly bitter: or the finings (though in that case less effective because of the disturbance of the sediment) may be added without racking into another cask, and thus prevent flatness. See page 95. If the ale is allowed to remain three or four months in the butt, it will not require fining, but will get clear, and become mellow, and improved in flavour.

At six or eight months old, the ale in the butt will probably arrive at its greatest perfection, being mild, bright, rich-flavoured, brisk, and exhilarating. By that time the attenuation will have proceeded down to $5 \mathrm{lbs}$. or $6 \mathrm{lbs}$, , or about one-fifth of its original gravity.

The author has kept ale of this strength (28 lbs. original gravity) two years in the cask, and then found it 'sound old,' not having degenerated into hardness or acidity; in general, however, it is not desirable to keep it longer than six months, 
or a year, unless perhaps when stored in larger casks than butts. See page 49 .

A loss of 3 or 4 gallons in a butt may be expected in a year; this arises from evaporation during storage.

The ' condition' of the ale is easily ascertained by drawing a wine-glassful from the peg hole in front of the cask. Clearness is a good guarantee for the ale remaining sound, although the temperature of the cellar should be as high as $65^{\circ}$, or warmer. Stock ales which have been brewed and managed in accordance with the preceding directions, are deprived in a great degree of the gluten and yeast which causes the early decay of a vast quantity of beer, where an incorrect principle of mashing, and a less vigorous and inefficient method of fermentation is adopted. See pages 97 and 98 .

Beer which tastes of the cask will readily impart its ill-flavour to any new beer, if mixed therewith.

Ale which has been attenuated to only half of its original gravity at the time of being bunged down in the cask, will generally be found in six months to have become attenuated to one-fifth of its original gravity, similarly to that which was bunged down at one-third or one-fourth. 
The additional gravity, or sweetness, is not needed (as some suppose it to be) in order to ' feed' the ale while in store. If so much as one-half of the original gravity remains unattenuated at the time of closing the cask, the ale will not generally prove so good, or keep so well, as that which is more attenuated.

The vacant space (about an inch or two) above the ale in a butt, will allow about 2 quarts to run out without giving vent; if more than that quantity will run out while the vent-peg is tight, it is a proof that the head of the cask is not sound: probably the cooper might have prevented the evil if he had put a piece of rush in the groove at the defective part. Dry sand spread an inch thick over the head of the bell-shaped butts, will aid in the exclusion of air, if the cask is old; wet sand will decay the wood.

As the beer is drawn out, and more vacant space is obtained in the cask, of course more ale will run out, without letting air in, and the less the vent-peg is opened the better it will be for the ale.

Exposure to air in an open vessel placed in a very warm temperature, changes beer into a kind of vinegar. The alcohol changes into acetic acid : 
the latter being of a greater gravity, the liquid will show considerably more gravity by the saccharometer after this change has taken place.

The following particulars are derived from entries in the author's brewing memorandums :-

In August, 1851, the author placed an uncorked bottle, filled about two-thirds with ale, on a kitchen shelf, where the temperature was frequently as high as $80^{\circ}$; the ale was brewed in the preceding March; it was bright and mild, and of $6 \mathrm{lbs}$. gravity; the original gravity was $29 \mathrm{lbs}$. In 10 weeks this part of a bottle of ale had increased in gravity from 6 lbs. to 13 lbs.; it was clear, and seemed excellent vinegar; it had become much darker in colour.

A bottle of the same ale, well corked, was filled at the same time, and placed in the same warm situation as the other ; it remained there about 9 months, and was subsequently kept in a cellar for above a year. In June, 1853, it was opened; it was then brilliant, mild, fine flavoured, pale in colour, and had a fragrant odour; it effervesced well when poured out, and was of $5 \frac{1}{2}$ lbs. gravity; there was a considerable deposition in the bottle; it had been kept lying down during the 22 months. See page 128. 
The author recently placed a pint of ale, an inch deep, in an uncovered jug, and kept it where the temperature was frequently $75^{\circ}$; the ale was 16 months old, clear, mild, and pale, and of $5 \mathrm{lbs}$. gravity ; in about a week the absorption of oxygen from the air had caused it to become very sour, very cloudy, and of a dark colour; there was some sediment; the gravity had increased to $16 \mathrm{lbs}$; the original gravity was 28 lbs.

It is of great importance to avoid all needless exposure of the beer (especially in warm weather) to the baneful influence of atmospheric air, lest the decay above mentioned should take place in an incipient form.

If the new ale is racked into a butt, for the purpose of fining it for immediate consumption, place a short length of the portable hose, or else a leaden pipe, into the bung-hole, letting it reach three-fourths down the vessel; they may be supported by a rim attached to them, resting on the head of the cask; place the funnel-tube (see page 34 ) into the pipe, and pour the ale into the funnel; this method will prevent much froth from forming, and thereby hinder considerably the disengagement and loss of carbonic acid gas. In drawing ale into a jug avoid much frothing, 
but when a glass is filled for drinking, some frothing is desirable, to disengage a portion of the gas, which will be seen rising up through the ale in great abundance, giving liveliness or briskness of flavour. Flat beer is insipid, and often unwholesome.

Tap the butt at first half-way down. Be careful not to draw out the ale close enough to break the head upon it, which might cause foulness in the liquid. The part of the ale near the surface in a cask is generally rather clearer, and tastes older than that in the lower part. The quantity of carbonic acid gas is greater when the pressure arising from the height of the liquid is two feet than when it is only a few inches; hence the ale becomes less brisk as its depth in the cask above the tap decreases.

The necessary admission of air into the cask before the ale will escape at the tap, and the increased empty space in the vessel, tends to lessen the briskness of ale long in draught; but at the same time the transparency increases, and the ale will continue mild, lively, and sparkling even if the butt should be some months in draught. The hops put in at bunging down the cask will aid in the preservation of the ale while a remnant. 
The flavour of pure malt liquor is clean and delicate on the palate. If the malt is pale, and the hops not brown, the ale will be the colour of pale sherry. If it is racked into another cask the exposure to the air will darken its colour a little.

It will have been observed (page 86), that within twenty-four hours after the ale is in the cask (which holds $3 \frac{1}{4}$ barrels) about 24 gallons of yeast and ale are expelled at the yeast vent. This vigorous fermentation and great expulsion of the yeast, or oxidized gluten (see pages 76 and 90), are absolutely necessary, in order to lessen the quantity of soluble gluten, which afterwards remains dissolved in the ale; and also because there would otherwise be a great quantity of yeast (or gluten in an insoluble state) settle at the bottom of the cask. In a few months this sediment would probably rise up and mingle with the ale, causing foulness.

Immediately following the quotation already given at page 76, Professor Liebig says: 'A great quantity of gluten remains dissolved in the fermented liquid, even after the transformation of the sugar is completed, and this gluten causes the conversion of the alcohol into acetic acid, on account of its strong disposition to attract oxygen, 
and to undergo decay.'-Organic Chemistry, p. 295.

When yeasty or oxidized glutinous particles float in beer they render it turbid, and give it a mawkish, unpleasant taste, proportioned to the extent of their prevalence.

The shaking of the cask from a shock of thunder, or any other cause, and also any considerable increase of temperature, is likely to cause the sediment alluded to, to rise up and produce foulness in the liquid. If not prevented from undue accumulation, this sediment will rise up even when the temperature of the cellar has not exceeded $50^{\circ}$, and without any shaking of the cask from thunder or any other cause.

At pages 66 and 85 instructions were given as to preventing the mucilaginous impuitiers from the copper (consisting of hop-dregs and maltdregs) or the sediment of spent yeast at the bottom of the fermenting tun, from being mixed up with the ale. Inattention to this will be likely to add to the sediment in the cask, and thereby increase the liability to the evil alluded to. The use of yeast containing impurities (see pages 90 and 106) will also tend to add to the objectionable sediment. 
After the cask is bunged down a gradual depuration or clearing of the ale goes on, and the yeast left suspended in the liquid or subsequently forming therein, subsides to the bottom of the cask, forming what are called the 'dregs' of the beer. Table beer will not become spontaneously clear so readily as ale.

If ale or table beer is stored in smaller casks than butts they will sometimes get clear sooner, and that in proportion to the shallowness of the malt liquor in the cask, the greater depth sometimes requiring longer time for depuration. But it must be remembered that the greatest depth gives most briskness (page 96), and that for storage for six months, or longer, a but is as small a cask as is generally desirable. Some use barrel-shaped butts, and lay them on their sides, but that requires more cellar room, and while the beer is in draught a large surface of it is exposed to the deleterious effects of atmospheric air, producing flatness, especially if the beer is a long time in draught.

These barrel-shaped butts answer very well if stood on one end, although, being largest in the middle, they necessitate some expansion of the head on the surface of the beer while it is in draught, which is not desirable. 
Racking the ale into another cask (without disturbing the bottom) a week or two after it is brewed, would free the ale from much of the objectionable sediment repeatedly mentioned; but that course entails labour, and exposes the ale to air, which is always best avoided. Malt liquor is always more perfect when it can be drawn for consumption from the cask into which it was put when removed from the fermenting tun. The 'dregs' which subside to the bottom of the cask ought not to be sufficiently abundant to cause the sudden cloudiness or turbidity mentioned at page 97.

Sometimes a very slight cloudiness will occur in ale (which had become clear) from a cause apparently independent of any sediment in the cask. It seems to be the effect of an oxidation of part of the soluble or dissolved gluten (page 97) which remains in the beer. The author thinks that this evil, however, will not occur if the cask is sound, and due attention is paid to the instructions which have been given for conducting the various processes brewing consists of. A gradual oxidation and deposition of gluten seems to be constantly proceeding in all beers, perhaps for a year (if not a much longer 
period) after it is in the cask, but the process should not materially injure the clearness of the beer, and it ultimately considerably promotes its brilliancy. It is probable that racking beer, whether into casks or bottles, causes an absorption of oxygen from the air, and hence results a more rapid if not a greater amount of oxidation of part of the remaining gluten than would otherwise take place.

It will often give much satisfaction to draw ale a year old, and mix with it an equal portion of that which has been brewed but a few months.

Experience has convinced the author that any kind of malt liquor brewed in accordance with the directions given in this work, will continue mild and excellent after being racked into smaller casks and sent a distance of many miles in the midst of summer. This racking for sending the beer elsewhere may take place at any time from a week to six or nine months after the ale has been bunged down in the butt. Though less desirable, it may be racked when much older if required, or be mixed with new beer to improve the latter.

Put a $\frac{1}{4} \mathrm{lb}$. of unboiled hops into each half barrel. The author has found it answer very well 
(when requisite) to run the beer from the fermenting tuns into half-barrel casks, and as soon as the throwing off the yeast has completely ceased (see page 134), to bung down the casks and remove them at once to their destination. After removal they will require vent at the peg-hole for a few hours, or longer if any yeast appears. The beer will be much improved by remaining some months before it is tapped.

The author has tried running some of the ale from the fermenting tun at cleansing into a butt half filled with bright and sound old ale, but it did not answer satisfactorily: see page 86 . When the ale is comparatively new it will recover more quickly from the flatness racking produces.

The beer may, if desired, be racked at a fortnight old, and stored in half barrels or lesser casks for several months previous to their being removed to their destination. The deposit from the depuration which will have gone on in that period being disturbed by the removal, will make the ale cloudy, but transparency will again ensue in a short time.

It is, however, best to give all malt liquors three months' storage in the butts prior to racking them for sending elsewhere, in order to increase 
their purity, and lessen the subsequent depuration in the smaller casks. Fining (page 114) will not be necessary, and is always best avoided in beers intended for keeping six months or a longer period. Be careful never to rack close enough to disturb the sediment at the bottom of the butt, or the head on the surface of the liquid. With new beer in warm weather allow about half a pint to each half barrel for vacancy needed for gas pressure and expansion of the beer from an increase of temperature.

The author has repeatedly found that malt liquor removed from the fermenting tun into casks, and then emptied into a butt at a distance from the brewhouse, occupying an hour in the removal, has proved very excellent 'stock' ale. The loss of temperature, however, during removal, ought not to exceed $10^{\circ}$, so that it may be at a temperature not lower than $85^{\circ}$ in the butt. Nevertheless, the removal of ale by cleansing pipes (see page 84) without exposure to air or loss of heat, is to be preferred.

Fermentation of the Table-Beer.

At page 67 it was said that there was $4 \frac{3}{4}$ barrels of the second wort, of 8 lbs. gravity; and $\frac{1}{2}$ a 
barrel of the third wort; of 7 lbs. gravity; which, added to $\frac{1}{2}$ a barrel of wort of $28 \mathrm{lbs}$. gravity retained by the hops, made $5 \frac{3}{4}$ barrels at $9 \frac{1}{2} \mathrm{lbs}$. gravity. Having boiled away one barrel in two hours,- lost in cooling $\frac{1}{2}$ a barrel,- - and the hops retaining $\frac{1}{2}$ a barrel, leaves $3 \frac{3}{4}$ barrels of tablebeer wort to enter the fermenting tun.

At page 70, 8 lbs. of yeast was mentioned as the requisite quantity for the table-beer; and in that and the following page, the method of pitching the ale wort was given. The same course must be taken with the table-beer; and it must. be pitched at the same temperature as the ale. There will be in the fermenting tun $3 \frac{3}{4}$ barrels of table-beer wort, at $12 \frac{1}{2}$ lbs. gravity, at a temperature of $95^{\circ}$, having 8 lbs. of good yeast wellstirred into it.

In a short time a thin white, creamy froth will cover the surface of the wort, indicating that fermentation has commenced. As soon as the attenuation has proceeded down to $8 \mathrm{lbs}$., or about two-thirds of the original gravity only remains, it must be run into the butt in the cellar. In general it will be ready to go into the cellar in about nine hours after pitching. During this period the temperature will remain at $95^{\circ}$, or perhaps fall 
$2^{\circ}$ or $3^{\circ}$. The light yeasty head on the surface will rise 2 or 3 inches, but will probably fall again to half an inch.

There will be the same kind of aromatic odour, with escape of carbonic acid gas, causing a suffocating smell, which was observed in the ale wort, but in a much less degree. Transparent bladders, filled with carbonic acid gas, will be seen rising up and bursting all round the edge of the tun, and some in other parts of the surface of the wort. A gentle, continuous, hissing sound will be heard.

The depth of liquid in the tun is supposed to be 16 inches, as the ale was. If the depth is much more than 16 inches, the table-beer wort will probably have a boiling appearance partly round the edge of the tun. This boiling appearance is, however, no detriment whatever to the beer. For further reference to this 'boiling: fermentation,' see page 119. Put into the butt $\frac{1}{2} \mathrm{lb}$. of flour, and $\frac{1}{4} \mathrm{lb}$. of salt; or half as much as directed for the ale. The gravity being lowered from $12 \frac{1}{2}$ lbs. to 8 lbs., run the table-beer through the cleansing-pipe into the cask in the cellar, and proceed with it precisely as directed for the ale. See pages 85 to 90 . 
Yeast will begin in a short time to flow out, and the butt will at first require filling up every four hours from the half-barrel reserved for the purpose from the tun. Twelve gallons of yeast and thick beer will probably work out of the butt, which is about half the quantity thrown off from the butt of ale; page 86 . There will be a loss of a gallon or two in the fermenting tun, and nearly 16 gallons will be required to fill up the cask, which is supposed to hold $3 \frac{1}{4}$ barrels.

The table-beer will cease to throw off yeast in about twenty-four hours, and by that time the gravity will be reduced to $4 \mathrm{lbs}$. or $3 \mathrm{lbs}$., or about one-third or one-fourth of the original gravity.

The caution given (page 86) must be repeated here-never to use any portion of the beer which works out to fill up the cask. The light feculencies floating in this ejected table-beer will render any beer turbid that it is mixed with. It must be drawn off as clear as it can be from the yeast, and put into a cask kept to receive the table-beer remnants. There will be about 9 gallons of it. Its flavour will be less pure than the table-beer in the cask from which it was ejected, and it will not keep sound many months. This remnant will 
probably require to be submitted to the action of finings to render it clear.

The yeast skimmed off from this ejected tablebeer may be used for pitching table-beer if no ale yeast is to be had; but the thick yeast or rather mucilaginous deposit settled at the bottom of the yeast receiver must never be used. This deposit is more impure and pernicious than the glutinous deposit directed to be thrown away from the yeast receiver containing ale. If either of these sediments is mixed up and used with the yeast to pitch a gyle of beer with, much of it will be found deposited at the bottom of the fermenting tun, probably not having aided the fermentation, but causing light impurities which separate from it to be suspended in the beer, and which may cause durable cloudiness.

On no account mix the table beer separated from the yeast with any fresh gyle of beer, lest it should cause durable foulness to the whole.

When the table-beer has ceased to throw off the yeast for twenty-four hours put in a pound of unboiled hops (reserved, see page 53) wetted with some of the beer, and drive in the bung, leaving the vent-peg loose till the following day, when it should be tightened. It may again be loosened 
occasionally as directed for the ale, page 88 , but there will seldom be any undue accumulation of carbonic acid gas.

In general the table-beer may be bunged down in about sixty hours after it enters the cask. After six months' storage it will probably be about $2 \frac{1}{2} \mathrm{lbs}$. gravity, or that much per barrel heavier than water. It will be excellent in about four or six months, and will keep sound for a year or two years if a good proportion of hops was used. If required for consumption at a month or two months old it should be fined (see page 115), to make it clear (whether with or without previous racking is optional). To prevent too much bitterness at this early age, remove part of the hops from the copper before the second wort is pumped into it, unless the ale wort had a small quantity of hops only.

Any remnants of ale or table-beer which have not been ejected with the yeast may, if thought more convenient than being stored in a separate cask, be mixed with the next gyle. Such mixture should not be in a larger proportion than $\frac{1}{6}$ th of fermented beer to $\frac{5}{6}$ ths of unfermented wort, lest the action of fermentation should be retarded or prevented. 
The beer thus added should be removed clear from any sediment, and put first into the fermenting tun, and sufficient wort at a temperature of about $140^{\circ}$ be mixed with it, so as to have the temperature at $95^{\circ}$ on adding the yeast or ' pitching,' as it is called.

Of course the addition of a lighter fluid will tend to make the fermentation less vigorous; the result of a proportionable diminution of sugar in the wort indicated by the decrease of gravity as shown by the saccharometer. It is scarcely necessary to say that if the original gravity of the beer (whether old or new) thus added to the gyle is equal to that of the wort it is mixed with, the beer will not be reduced in strength.

\section{QUANTITY OF WATER USED AND ACCOUNTED FOR.}

In the preceding example 2 quarters, or 16 bushels, of malt and $22 \mathrm{lbs}$. of hops were used to brew 7 barrels of beer. To produce that quantity, 13 barrels of liquor (water) was required, used thus:-

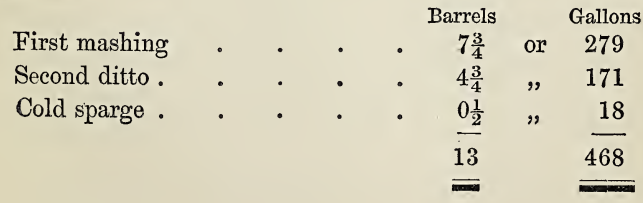


Accounted for as follows :-

\begin{tabular}{|c|c|c|c|}
\hline Ale in cask & $\begin{array}{l}\text { Barrels } \\
\quad 3 \frac{1}{4}\end{array}$ & or & $\begin{array}{l}\text { Gallons } \\
117\end{array}$ \\
\hline Table-beer in ditto & $3 \frac{1}{4}$ & , & 117 \\
\hline $\begin{array}{l}\text { Liquor absorbed and retained by } \\
\text { the malt (including loss by eva- } \\
\text { poration in mash-tun and under- } \\
\text { back), about } 5 \frac{1}{2} \text { gals. per bushel }\end{array}$ & $2 \frac{1}{2}$ & $"$ & 90 \\
\hline $\begin{array}{l}\text { Decrease during the boiling of the } \\
\text { ale wort . }\end{array}$ & $0 \frac{1}{2}$ & $"$ & 18 \\
\hline $\begin{array}{l}\text { Decrease during the boiling of the } \\
\text { table-beer wort }\end{array}$ & 1 & $"$ & 36 \\
\hline $\left.\begin{array}{c}\text { Decrease by evaporation during } \\
\text { cooling of the worts }\end{array}\right\}$ & 1 & $"$ & 36 \\
\hline Transferred to remnant ale cask & $0 \frac{1}{4}$ & $"$ & 9 \\
\hline Ditto to table-beer cask. & $0 \frac{1}{4}$ & ", & 9 \\
\hline * Retained in the copper by the hops & $0 \frac{1}{2}$ & $"$ & 18 \\
\hline $\left.\begin{array}{l}\text { Loss accounted for by the yeast } \\
\text { produced, and the waste from } \\
\text { very thick beer }\end{array}\right\}$ & $\frac{1}{2}$ & $"$ & 18 \\
\hline & 13 & 9 & 468 \\
\hline
\end{tabular}

\section{Method of ascertaining the Produce of the Màit.}

The following is the method of ascertaining by calculation the quality and goodness of the malt used. The quantities of wort should be reckoned when they are altogether in the fermenting tuns. If they are taken according as the

* Probably the retention by $22 \mathrm{lbs}$. of hops is a few gallons less. 
quantities appear in the underback or copper, the result will not be accurate, because the decrease in quantity, while the worts are cooling, will not be allowed for:-

\section{Barrels of wort in}

fermenting tun Gravity

$3 \frac{3}{4}$ at $28 \mathrm{lbs}$. is $105 \mathrm{lbs}$.

$3 \frac{3}{4} \quad$ " $12 \frac{1}{2} \mathrm{lbs}$. " $47 \mathrm{lbs}$. discarding fractions.

Divide by the number of

quarters of malt used $\}^{2)} \underline{152}$

Produce . . . 76 each quarter.

If the malt is very superior, the ale wort may be $1 \mathrm{lb}$. more in gravity, and the table-beer half as much, which would make the produce $78 \frac{3}{4} \mathrm{lbs}$. per quarter. Where a larger quantity of malt is used, a greater produce per quarter is sometimes obtained by sparging the goods (after the second wort is drawn off) to a greater extent than is here recommended. By that means a wort of 3 or $4 \mathrm{lbs}$. gravity, called a 'return,' is obtained, and used at the next brewing instead of liquor at mashing ; but it is of a very inferior quality, and liable to get acid if not used soon. It should be used for a second mashing rather than for ale.

In mashing larger quantities of malt than 2 quarters, the loss in mashing is somewhat less than $5 \frac{1}{2}$ gallons per bushel from the depth of 
the malt being greater, and consequently a greater pressure above as the wort drains out. This decrease of loss in mashing would of course increase the produce per quarter.

'Pale' malt, provided it is well ' cured,' that is, sufficiently dried on the kiln, is preferable to malt which is very highly dried (i. e. more brown), not only on account of the superior flavour pale malt imparts, but also because more wort of a given strength can be extracted from it in the mashing process than can be obtained from the same quantity of brown or 'blown' malt; because a part of the sugar in the latter kind is destroyed by the heat applied to the malt while on the kiln. See page 148.

The produce of good 'amber'-coloured malt will be nearly, if not quite, equal to 'pale,' but the colour and flavour are not so well suited for ales. 'Amber' is the medium between 'pale' and 'brown.' See pages 37, 123, and 148, for brown and blown malt.

It will have been observed that in producing $3 \frac{1}{2}$ barrels of ale, each bushel of malt yielded $1 \frac{3}{4} \mathrm{lb}$. to the gravity, and the table-beer average gravity was about $\frac{3}{4} \mathrm{lb}$. per bushel. Thus each bushel of malt gave on the whole $2 \frac{1}{2} \mathrm{lbs}$. per 
bushel, exclusive of the loss of beer by fermentation and cleansing.

\section{Finings.}

It will have been observed that transparency has been sought after in the various processes already mentioned.

1st. In running the wort tolerably clear from the mash-tun. It will appear more clear by daylight than it does if looked at with a lighted candle held on the opposite side of the glass containing the sample.

2nd. In getting it bright from the hops in the copper.

3rd. In using yeast free from mucilaginous impurities likely to remain permanently suspended in the malt liquor. These are most abundant in yeast which is obtained from beer the produce of a second mashing. See page 107.

4th. In running it clear from the separated yeast in the fermenting tun.

5th. But the great auxiliary to transparency is throwing out the yeast vigorously and abundantly from the cask, and not using the beer which flows out with the yeast to fill up the cask.

To make a gallon of pure and effective finings. 
-Take 1 ounce of the best isinglass, add to it a pint of the best vinegar, which will dissolve the isinglass almost, directly, and the whole will become like stiff glue; in an hour add a quart of clear old table-beer, not hard or sour, and stir it; in a few hours the mixture will become very thick again, and then another quart of the table-beer should be added, and the stirring repeated; nearly 2 quarts more of the table-beer is to be added as the whole thickens.

When the above mixture has stood twenty-four hours, and been stirred at intervals, it will be of the consistence of thin treacle, and will be nearly transparent; rub and strain any part not dissolved through a fine wire sieve; it is then ready for use, and this quantity, about a gallon, will be required for fining a butt of ale or table-beer.

Finings should, of course, only be used when necessary.

When the ale or table-beer is to be fined, it may be drawn off into a clean dry butt, being careful not to disturb the sediment at the bottom of the cask or the head on the beer. It is, however, not necessary to draw the beer off into another cask, for although it will be clearer, yet it loses much of its gas or briskness by racking, 
and the trouble of the process is best avoided generally.

The addition of finings is thus managed:-Put about 6 quarts of the beer to be fined into a pail with the gallon of finings, and stir it into a froth with a small whisk made of birch; put a stout stick into the bung-hole of the butt (letting it enter two-thirds down the cask), and stir the beer two or three minutes; then pour the finings into the cask, and repeat the stirring for several minutes; drive in the bung, and tighten the ventpeg immediately. In twenty-four hours the beer will be fine, and will increase in brightness during several days.

If the beer has been racked, a week or two should be allowed for it to recover from the flatness caused thereby, or a longer time will be required if the beer is more than a month old.

The minute particles of the dissolved isinglass unite with the fine feculencies floating in the ale; the union makes them heavier than the liquid, and they fall to the bottom of the cask, leaving the beer transparent. Sometimes, some of the united particles rise to the surface of the liquid, but the beer is equally clarified. The more completely the isinglass is dissolved, and the less 
turbidity or cloudiness there is in the beer, the more effective the finings will prove. Any part of the isinglass that is not dissolved will not answer the purpose, viz. attracting and uniting with the particles which caused the turbidity.

If due attention is paid to the method of brewing recommended in this work, the beer will never be what is called 'stubborn;' that is, refuse to yield to the action of finings prepared and applied as above directed. In stubborn beer, the finings appear to remain floating in and mingled with the liquid.

\section{TABLE-ALE.}

Sixteen bushels of malt, and $25 \mathrm{lbs}$. of hops, will produce 7 barrels of beer. This is merely a mixture of the ale and table-beer worts together in the larger fermenting tun. See page 73.

Having proceeded with the mashing and boiling as directed, pages 53-68, the cooling may be accelerated by allowing two-thirds of the strong wort to remain in the coolers until the weaker wort has ceased boiling. When about a barrel of the wort is in the fermenting tun, at a temperature of $95^{\circ}$, stir in $16 \mathrm{lbs}$. of yeast. When the coolers are wanted for the contents of the second copper, 
run the rest of the ale wort (perhaps then cooled to $75^{\circ}$ ) into the fermenting tun. Then add a sufficient quantity of the weaker wort when cooled to $120^{\circ}$, to raise the temperature to $95^{\circ}$; and add the rest when cooled to that temperature.

There will be $7 \frac{1}{2}$ barrels of wort in the fermenting tun, at a temperature of $95^{\circ}$, and the gravity will be about $20 \frac{1}{4} \mathrm{lbs}$. The worts need not be stirred together, as it would disturb, unnecessarily, the head of yeast already formed on the ale wort. The strong wort being heavier, will be likely partly to remain at the bottom of the fermenting tun. In taking out samples for testing the average gravity, this imperfect mixing of the worts prevents, at first, accuracy in the apparent results, as given by the saccharometer with respect to it.

The fermentation having commenced in the stronger wort, will also prevent the average gravity from being correctly ascertained. The tun will be filled all but 3 or 4 inches, and the depth of wort about 26 inches, or 10 inches deeper than the ale was. See page 73. In about six hours, there will be a yeasty and bladdery head, of 2 or 3 inches high, on the wort; and the attenuation will probably have lowered the gravity from $20 \frac{1}{4}$ 
to 16 lbs. There will be the hissing noise and pungent smell mentioned at page 78. In this gyle of table-ale, there will sometimes be seen a boiling appearance, partly or all round the edge of the tun. This peculiar action of the wort will be adverted to under the next head.

The lid of the tun may be left off, as it might obstruct the rising of the yeast on the wort. The wort will probably keep at the temperature of $95^{\circ}$. In twelve hours after it is all in the tun, it may be run into the two butts in the cellar.

The gravity at cleansing will be about 12 lus., the attenuation having averaged $\frac{3}{4}$ of a lb. per hour, while the wort was in the tun. Cleansing, at a pound heavier or lighter, is not of any importance.

There will be an abundance of good yeast (though inferior to ale yeast) ejected from the casks. The gravity of the table-ale at being bunged down will be about 4 or 5 lbs.; that is, one-fourth or one-fifth of its original gravity. If fined and drank at a month old, it will be a good sample of bitter ale.

By using 2 or 4 bushels more of malt, and 9 or 18 gallons more of liquor, a table-ale of $22 \frac{1}{2}$ or $25 \mathrm{lbs}$. original gravity would be produced; and if 
to the latter gravity $2 \mathrm{lbs}$. of hops instead of $1 \frac{1}{2} \mathrm{lb}$. per bushel is used, and the beer is kept five or six months, it will be a very good bitter ale.

\section{The Boiling Fermentation.}

The appearances of wort during fermentation vary with the gravity of the wort subjected to the process, as will have been seen by comparing the ale and table-beer fermentations already described. But the quantity, and more especially the depth of the wort, greatly influence the appearance on its surface.

At page 118 it was stated that in the gyle ( $7 \frac{1}{2}$ barrels) of table-ale there would be seen a boiling appearance, partly or all round the edge of the tun, and extending about 3 inches from the sides of the vessel. The wort in these instances was about 26 inches deep, while the ale and table-beer was 16 inches, being 10 inches less, and the boiling appearance has never been seen in either of the latter, where $3 \frac{3}{4}$ barrels only was fermented.

The author cannot concur in the opinion which has been advanced, that the boiling appearance is occasioned by electricity. The carbonic acid gas and yeast rise with increased rapidity through 
the larger quantity, and greater depth, accelerated also by the comparative lightness of the wort, which is of so much less gravity than ale wort. The greater heat of the wort may also tend to produce the appearance, but he has seen it in wort at a temperature of $68^{\circ}$. See next page.

The author has discovered that the boiling motion will cease if about one-third of the wort is drawn from the tun, thereby reducing the depth from 26 to 16 inches. The boiling appearance is probably the result of the accumulation of gas round the sides of the vessel while the wort is in active fermentation. The gas perhaps presses in an horizontal as well as in an upward direction, and meeting with resistance at the sides, rises with greater force at that part to the surface. Also, the tun being 3 inches narrower at top than at bottom, the contraction probably condenses the rising gas by forcing it out of a perpendicular ascent to the surface at the part next the sides of the vessel.

The following particulars are derived from an entry in the author's brewing memorandums :-

On October 9th, 1852, he cleansed some tablebeer at a temperature of $78^{\circ}$ and at $8 \mathrm{lbs}$. gravity. The temperature of the atmosphere out of doors 
was $48^{\circ}$. The depth of the wort in the tun was 14 inches, and no boiling appearance was seen during the fermentation. Having nearly a barrel more than the butt would hold, he ran it into an open tub holding 30 gallons, shaped like a barrel cask, being 4 inches narrower in diameter at the top than in the middle: the wort was 20 inches deep in it when full. In about eight hours he observed a gentle but decided boiling appearance; on reducing the depth to 14 inches, the boiling ceased: in half an hour the wort taken out was added again, and in a quarter of an hour the boiling appearance again commenced. The temperature of the wort was then $68^{\circ}$. The cellar in which it was placed was at a temperature of $54^{\circ}$.

Experience has convinced the author that not the slightest harm results in any way to beer (brewed in accordance with his method) from this 'boiling fermentation,' and that neither it nor the weak head of yeast on weak wort proceeds from any ' unsoundness' in the worts.

\section{Superior Bitter ALE.}

Two kinds of bitter ale have been mentioned. See pages 118 and 119. 
Barrels

14 bushels of pale malt . . $33 \frac{1}{2}$ bitter ale.

32 lbs. of best hops . . . $\} 3 \frac{1}{2}$ table-beer.

The only variations requisite from the practical instructions already given respecting ale and table-beer are these:- Use $7 \frac{1}{2}$ barrels of liquor in the first mashing instead of $7 \frac{3}{4}$ barrels, in consequence of 2 bushels less of malt being used. The increased quantity of hops will not affect the fermentation.

Pitch the $3 \frac{3}{4}$ barrels of wort in the fermenting tun with $9 \mathrm{lbs}$. of yeast instead of $10 \mathrm{lbs}$. The gravity of this bitter ale will be $24 \frac{1}{2} \mathrm{lbs}$. after boiling, and that of the table-beer, $11 \mathrm{lbs}$. Cleanse in about eighteen hours, when the gravity will be from $12 \mathrm{lbs}$. to $16 \mathrm{lbs}$. See pages 80 and 81 .

The quality of the ale will be superior in consequence of being restricted to the first wort drawn from the mash-tun. See page 58. The flavour derived from the hops will be much better because they are boiled but one hour. The second boiling extracts an inferior bitter flavour.

This bitter ale may be drank in four or six months notwithstanding the quantity of hops used. At about nine months or a year old, the rich, warm, 
aromatic bitter imparted by the hops will considerably diminish, leaving a bitter flavour of a more simple and less agreeable kind, which, however, will still aid in keeping the ale mild.

\section{Brown Stout.}

$\left.\begin{array}{l}10 \text { bushels of pale malt } \\ \begin{array}{l}5 \text { ditto of brown malt } \\ \frac{1}{2} \text { bushel of patent or black malt } \\ 28 \text { lbs. of the best hops } \\ .\end{array}\end{array}\right\} \begin{aligned} & \cdot \\ & 3 \frac{1}{2} \text { of stout. } \\ & 3 \frac{1}{2} \text { of table-beer. }\end{aligned}$

The 'brown' malt imparts a flavour which cannot be dispensed with in this kind of malt liquor. The partial destruction of the malt sugar by the great heat this malt is subjected to on the kiln, lessens its comparative produce per quarter. See page 112. It is often made from inferior barley, and will be usually several pounds per bushel lighter than pale malt.

A good sample of patent or black malt should be selected. When it is improperly reduced by the roasting to a condition which may be called 'cindery,' it will impart an ill flavour to the beverage. It should be of a dark chocolate colour, and must be crushed finer than the other malts, and kept separate from them. It is used chiefly to give stout or porter a dark 
colour, but a larger proportion than here recommended injures the flavour.

When fit for consumption, or six months old, the stout should be of the colour of port wine, and nearly or quite as clear. The brown, as well as the black malt, can generally be procured at any brewery in the country districts.

Forty-seven years ago (1817), Dr. Thompson, F.R.S. remarked, 'One of the best brewers in London uses two parts of pale malt to one of brown.' *

Proceed with the mashing as directed for ale (page 54), with $7 \frac{3}{4}$ barrels of liquor at $178^{\circ}$. As soon as the pale and brown malts are added to the liquor in the mash-tun, sprinkle in the black malt while the stirring is going on. As part of it will be reduced to powder by the crushing, it is liable to form into balls if not sprinkled on.

No other variation is required from the minute directions already given concerning ale and tablebeer. The original gravity of this stout will be about $25 \frac{1}{2} \mathrm{lbs}$. and that of the table-beer, $11 \frac{1}{2} \mathrm{lbs}$. Another bushel of pale malt might be added with advantage, which would increase the gravity

* Supplement to the Encyclopedia Britannica, art. 'Brewing.' 
of the stout to about $27 \frac{1}{4} \mathrm{lbs}$, and the table-beer to $12 \frac{1}{4} \mathrm{lbs}$.

Pitch the $3 \frac{3}{4}$ barrels of stout at a temperature of $95^{\circ}$ with $10 \mathrm{lbs}$. of excellent yeast. Cleanse in about eighteen hours, at a gravity between $13 \mathrm{lbs}$. and 17 lbs. The discharge of yeast from the butt must be vigorous and abundant. See page 86 .

This stout will be fit for consumption in five or six months, although the quantity of hops used is more than is recommended for ale to be drank at that age (page 48). Stout intended for exportation to the colonies should not have less than 2 lbs. of hops to each bushel of malt.

\section{Porter.}

$\left.\begin{array}{rcc}12 \text { bushels of pale malt } & . & . \\ 6 \text { ditto of brown malt } & \cdot & \cdot \\ 1 \text { ditto of black malt } & \cdot & \cdot \\ 32 \text { lbs. of hops . } & \cdot & \cdot\end{array}\right\} 7$ barrels of porter.

Use 8 barrels of liquor at $178^{\circ}$ temperature in the first mashing, and sprinkle in the black malt as directed at page 124. Ferment both worts together, as directed for table-ale, page 117 , pitching the $7 \frac{1}{2}$ barrels of wort, at a temperature of $95^{\circ}$, with $16 \mathrm{lbs}$. of yeast. The average gravity will be about 22 lbs. 
The boiling appearance already adverted to (page 119) will be seen here also, and will be equally harmless as in the table-ale. Cleanse in about twelve hours after it is all in the tun; the gravity will then probably be about $13 \mathrm{lbs}$. and the temperature still $95^{\circ}$. See page 118 .

It will be ready for consumption in four or five months, and its gravity will then be about $4 \frac{1}{2} \mathrm{lbs}$. Its flavour will be inferior to the brown stout, because of the addition of the second and third worts, and the bitter of the hops of the second boiling, and also from its lesser original gravity.

\section{Brewing from Malt and Stgar.}

There is no economy in using sugar with malt unless the malt is of the high price of $11 \mathrm{~s}$. per bushel, and the sugar not more than $44 s$. per cwt. The author made two brewings in 1847, using the following proportions of malt, sugar, and hops each time : -12 bushels of pale malt at $11 s$. per bushel; 96 lbs. of moist sugar, at $4 \frac{3}{4} d$. per 1b. ; and 32 lbs. of hops. The sugar was well mixed with 4 gallons of wort, and added to the first wort in the copper half an hour before the boiling 
ended, stirring it well to prevent the sugar from subsiding and burning the copper.

The 96 lbs. of sugar was equivalent to 5 bushels of malt in the ale wort, and the cost of it was $6 s$. less than four bushels of malt. But the table-beer was of course one-fourth weaker from the deduction of 4 bushels of malt. The keeping properties of this ale proved equal to that brewed from malt only, but the sugar gave it a peculiar flavour, and partially deprived it of the pure and delicate flavour it would have had if it had been brewed from malt only. The sugar gave a deep amber colour to the ale. Perhaps a higher priced sugar might not give the objectionable flavour.

Some of this ale bottled at a year old, and kept in bottle eleven years, is still perfectly sound, but has not wholly lost the peculiar flavour imparted by the sugar. The original gravity was $30 \mathrm{lbs}$. It was bottled at $2 \frac{1}{2} \mathrm{lbs}$. gravity, and is of the same gravity now.

\section{BotTling.}

Great care should be taken to have the bottles perfectly clean. Use shot in cleaning them, and rinse them repeatedly afterwards with clean water. Let them drain dry. Use the best corks, and 
drive them in as soon as the bottles are filled. Quite three-fourths or more of the length of the cork should enter the neck of the bottle: they will enter more easily if they are dipped into some of the ale; press the corks in a cork squeezer before using them; leave half an inch clear space between the cork and the ale; use a funnel with a bent tube, which will prevent frothing, by leading the ale to the side of the bottle. Frothing the ale should be avoided, as it causes a loss of carbonic acid gas. Ale is best bottled between five and nine months old. The author has kept ale bottled at six months old for ten years, and then found it mild and in great perfection, and weigh. ing $5 \mathrm{lbs}$, or one-sixth of its original gravity. The bottles were kept in an upright position the greater part of the time. It was bottled at $6 \mathrm{lbs}$. gravity; the hops used were $2 \mathrm{lbs}$. to each bushel of malt. In general, ale should become attenuated to one-fifth of its original gravity before bottling; it is seldom, then, that any reduction of gravity will occur after the ale is bottled. Those who prefer ale of a sweet flavour can bottle it sooner, and at a heavier gravity. The bottles should be kept standing upright in the cellar. When opened, be careful not to disturb the sedi- 
ment at the bottom of the bottle; it may be racked clear into a jug a short time before it is drank, leaving a wine-glassful in the bottle.

It should be bottled at least 3 months before it is drank; when opened it should be highly charged with gas, but not violently so, lest it cause a disturbance of the sediment at the bottom of the bottle. The remnant of ale in a cask is not so well adapted for bottling if it has become at all flat.

\section{Unmalted Barley with Malt.}

The author has never tried a mixture of malted and unmalted barley in brewing; as the latter requires to be ground finer than malt, there would be more flour, which settling on the sunken goods would prevent the upper portion of the wort from running into them, and displacing the stronger. wort. See page 58. If by any contrivance the wort was drawn from the top such wort would be less pure than that which is filtered through the goods. The raw grain will yield sugar, and consequently spirit or strength, but the flavour of such beer must be inferior to that brewed from malt only. 


\section{Drugs in Beer.}

Various drugs and other ingredients have been recommended for improving the flavour or increasing the intoxicating quality of beer. Some of these may be harmless, but are all quite unnecessary. Others are highly poisonous, especially those intended to add to the strength of the beer. Nor will any of the malt liquor require the poisonous auxiliary sometimes used to give it a frothy top in the jug or glass.

Brewing from a Quarter (8 bushels) of Malt.

A smaller brewhouse fitted up with vessels half the size of those belonging to the two-quarter brewing plant, which has been described in this work, would be adapted for producing $3 \frac{1}{2}$ or 4 - barrels of beer from any quantity of malt, varying from five to ten bushels.

The casks should be hogsheads, of a bell shape, and holding about 60 gallons each, having a yeast-vent in front, and two tap-holes, similar to the butt mentioned at page 32 .

To brew 67 gallons of strong wort, and the 
BREWING FROM TWO AND A HALF BUSHELS. 131

same quantity of weaker wort, to enter the fermenting tuns :-

The processes of mashing, boiling, and cooling have been fully described at pages 53 to 69 . Add the 8 bushels of malt to 140 gallons of liquor, at a temperature of $180^{\circ}$; stir it well for 20 minutes, and then cover the mash-tun closely. Let it remain 2 hours, and then draw out the wort carefully. Its temperature should be about $150^{\circ}$.

For the second mashing, use $2 \frac{1}{2}$ barrels of liquor, at a temperature of $186^{\circ}$. See page 59. Let the goods remain 1 hour, and then set the tap. Sparging with cold liquor may be dispensed with. Boil the first wort 1 hour, and the second wort 2 hours. Pitch both worts at a temperature of $95^{\circ}$, using $6 \mathrm{lbs}$. of yeast for the stronger, and $4 \mathrm{lbs}$. for the weaker wort. Keep the fermenting tuns well closed. Ample instructions for the management of the fermenting; cleansing, and cellaring processes have been given. See pages 73 to 108 .

\section{Brewing from $2 \frac{1}{2}$ Bushels of Malt.}

The copper should not bold more than 36 gallons. The additional 5 gallons of liquor 
required for the first mashing can be heated elsewhere. See page 64 .

The diameter of the bottom of the mash-tun should not be more than 2 feet. One of the bellshaped hogsheads, mentioned at page 130, will answer the purpose.

Have a false bottom fitted and placed 1 inch above the real one. Have a large sized beer-tap (with the end-piece of the strainer removed) driven in at the front, just under the false bottom. The vessel should be raised an inch behind. The vessels used for cooling need not be more than 6 inches in depth. There should be a large-sized beer-tap in each, that the wort may be drawn off tolerably clear from the sediment which will be in them if the copper has no tap, nor leaden strainer. See p. 29. If there is no tap to the copper, the worts must be run through a sieve, or horse-hair bag, or wicker basket, to separate them from the hops.

To produce 20 gallons of strong, and the same quantity of weaker wort, to enter the fermenting tuns. For the proportion of hops, see page 48 . Put 41 gallons of boiling liquor into the mashtun, and as soon as the temperature is reduced to $180^{\circ}$, which will probably be immediately, add the $2 \frac{1}{2}$ bushels of malt. Stir it well for a quarter 
of an hour. Cover it closely, and let it remain an hour and a half; then run it off carefully. The wort should run off in 1 hour. There will be a loss of about 14 gallons in the first mashing, leaving 27 gallons of strong wort, to be boiled with the hops 1 hour, losing by evaporation about $2 \frac{1}{2}$ gallons in that period. There will be a further reduction of $2 \frac{1}{2}$ gallons during the cooling, and the hops will retain 2 gallons, leaving 20 gallons to enter the fermenting tun.

Use $27 \frac{1}{2}$ gallons of liquor, at $190^{\circ}$, for the second mashing, and stir it well for 10 minutes. In 1 hour set the mash-tun tap. There will be $27 \frac{1}{2}$ gallons of the weaker wort. Boil it 2 hours with the hops, and reduce it by evaporation to $22 \frac{1}{2}$ gallons. Cooling will diminish the quantity $2 \frac{1}{2}$ gallons, so that only 20 gallons will remain. The worts should not be deeper than 4 inches while cooling.

Pitch both worts at a temperature of $95^{\circ}$, using 2 lbs. of the best fresh yeast (see page 40) for the stronger wort, and $1 \frac{1}{2} \mathrm{lb}$. for the weaker. The fermenting tuns should be about 2 feet in depth. There should be a large-sized beer-tap in each, that the ale and table-beer may be drawn off clear (but not too slowly) from the sediment at bottom and the head of yeast on the surface of the beer. 
The small quantity of the worts will prevent their retaining the temperature of $95^{\circ}$, although covered up, but they must not be allowed to get colder than $85^{\circ}$ while in the tuns. To prevent this, fill a gallon stone bottle with boiling water, and immerse it in the ale wort (see page 74) and do the same to the table-beer wort: the ale must not remain longer than 18 hours in the fermenting tun: it will then probably have become attenuated to two-thirds or one-half of its original gravity; that is, from $28 \mathrm{lbs}$. to $18 \mathrm{lbs}$ or $14 \mathrm{lbs}$. See p. 80.

The table-beer may be cleansed in about eight or nine hours; it will then probably have attenuated from $12 \frac{1}{2}$ lbs. to $8 \mathrm{lbs}$. See page 105. Put each wort into an 18 gallon cask; turn the cask a little on one side that the yeast may flow out on one side of the bunghole, putting them level again when the yeast ceases to How out. It is very desirable that the beer should enter the casks at a temperature not under $85^{\circ}$. A $\frac{1}{4} 1 \mathrm{~b}$. of flour and $2 \mathrm{oz}$. of salt to the strong wort, and half as much to the weaker wort, may be used at cleansing. See page 84 . There will be 2 gallons of each wort left to fill up the casks with: carefully avoid filling them up with any portion of 
that which works out with the yeast. See pages 86 and 106. If both worts are fermented together, use $3 \mathrm{lbs}$. of yeast. The mash-tun with the false bottom taken out, would answer for fermenting them in. For cleansing, follow the directions given concerning table-ale. See page 118.

\section{Making of Malt.}

The author is unable, from his own experience, to say anything concerning the art of making malt, but he trusts the following description of the process will be interesting and useful. It consists of extracts from an elaborate article on Brewing and Malting, in the Supplement to the Encyclopædia Britannica, written by Dr. Thomson, F.R.S., published in 1817 : together with a few extracts (marked in parentheses) from a Report on Malting, \&c., drawn up by Dr. Thomson, in conjunction with Drs. Hope and Coventry, ordered by the House of Commons to be printed. Dr. Thomson says :-

'We shall now describe the process of malting as it is practised by the best informed maltmakers in Great Britain.

'Malting consists of four processes, which 
follow each other in regular order; namely, steeping, couching, flooring, and kiln-drying.

- 1st. The steep is a square cistern, sunk at one end of the malt-barn, lined with stone, and of a sufficient size to hold the whole barley that is to be malted at a time: the barley is put into this cistern with the requisite quantity of pure water to cover it: it is laid as evenly as possible upon the floor of the cistern; here it must remain at least forty hours, but in Scotland, especially when the weather is cold, it is customary to allow it to remain much longer. We have seen barley steeped in Edinburgh for a hundred and twelve hours by one maltster, and by another, usually ninety-eight or ninety-two hours: it is the common practice to introduce the water into the cistern before the barley, and it is usually once drawn off, and new water added during the steeping.

' The quantity of moisture imbibed by the barley varies according to the goodness of the barley, and the length of time during which it is allowed to remain in the steep. The swell of the grain in the steep obviously depends upon the quantity of water absorbed; but it is not so great as that absorption, scarcely ever exceeding one-fifth of the original bulk of the barley, while the increase of 
weight amounts to nearly one-half of that of the original weight of the grain.

'2. The Couch.-When the barley is judged by the maltster to have remained long enough in the steep, which is the case when its two ends can be easily squeezed together between the finger and the thumb, the water is let off and the grain allowed to drain. It is then thrown out of the cistern upon the malt-floor, where it is formed into as regular a rectangular heap * as possible, which is called the couch.

' While in this position it is gauged by the exciseman, and if it measure more than it did in the steep, he is at liberty to charge the duty upon the quantity to which the grain now amounts. The grain is allowed to remain in the couch without any alteration for about twenty-six hours.

'3. Flooring.-If we plunge a thermometer into the grain and observe it from time to time, we shall find that the barley continues for some hours without acquiring any perceptible increase of heat. During this period the moisture on the surface of the corns gradually exhales, or is absorbed, so that they do not perceptibly moisten the hands. But at last the thermometer begins

* The form of the couch-frame is now prescribed by law. 
to rise, and continues to do so gradually till the temperature of the grain is about 10 degrees higher than that of the surrounding atmosphere.

'This happens usually in about ninety-six hours after it has been thrown out of the steep. It now exhales an agreeable odour which has some resemblance to that of apples. If we thrust our hand into the heap, we shall find it to feel warm, while at the same time it has become so moist as to wet the hand. The appearance of this moisture is called sweating by the maltster, and it constitutes a remarkable period in the process of malting; - we have reason to believe that $a$ little alcohol is at this period exhaled by the grain.

'(When the roots have acquired some length (which usually happens in one, two, or three days after their appearance, according to circumstances), the apple-like smell goes off, and is succeeded by another not unlike that of the common rush when newly pulled. This smell continues during the whole time that the malt is on the floor, unless it be overpowered by a peculiar mouldy smell, which happens only when the grain is bad, and contains seeds incapable of germinating; or when a part of the malt has been bruised during the turning from the carelessness of the workmen.) 
'If we examine the grains in the inside of the heap at the time of sweating, we shall perceive the roots beginning to make their appearance at the bottom of each seed; at first they have the appearance of a white prominence which soon divides itself into three rootlets. In big, the number of rootlets seldom exceed three, but in barley they frequently amount to five or six. These rootlets increase in length with great rapidity unless their growth be checked by artificial means, and the principal art of the maltster is directed to keep them short till the grain is sufficiently malted.

' (Some maltsters allow the roots to get to seven-eighths of an inch long, others never wish to see them above half that length. As the roots are afterwards separated from the malt and thrown away, and as their length does not contribute to the progress of malting, the latter method seems preferable.)

' The writer of this article has seen them increase in length nearly to two inches in the course of a single night; and when he purposely favoured the growth, in order to ascertain the effect upon the malt, he has seen them get to the length of three inches, or more. In such cases, the heat 
of the grain rose very rapidly, and on one occasion was little inferior to $80^{\circ}$. Indeed it is probable that, if not checked, the temperature would rise sufficiently high to char the grain, if not to set it on fire.

' The too great growth of the roots, and the too high elevation of temperature, is prevented by spreading the grain thinner upon the floor, and carefully turning it over several times a day. At first the depth is about 16 inches; but this depth is diminished a little at every turning, till at last it is reduced to 3 or 4 inches. The number of turnings is regulated by the temperature of the malt; but they are seldom fewer than two each day. In Scotland, the temperature of the grain is kept as nearly as possible at $55^{\circ}$; but in England, we have generally found the temperature of the grain on the malt-floor about $62^{\circ}$. It has been generally supposed that the Hertfordshire method of making malt is the best; but after a very careful comparison of the two methods, we were unable to perceive any superiority whatever in the English mode.

'Acrospire.-About a day after the sprouting of the roots, the rudiments of the future stem begins to make its appearance. This substance is 
called by maltsters the acrospire. It rises from the same extremity of the seed with the root, and advancing within the husk, or skin, would at last (if the process were continued long enough) issue from the other extremity in the form of a green leaf; but the process of malting is stopped before the acrospire has made such progress.

' (The progress of the acrospire is at first very rapid, like that of the roots; by the eighth day after "casting," it will have usually reached rather more than one-half the length of the grain, but after this time its progress becomes much more slow, so that frequently another week elapses, or even more, before it has made its way to near the end of the seed, when it is understood to be proper to finish the malting.)

6 While the grain is on the malt-floor, it has been ascertained that it absorbs oxygen gas, and emits carbonic acid gas, but to what amount the absorptions and emissions take place has not been ascertained; they are certainly small, for the average loss which the grain sustains when on the malt-floor is only 3 per cent., a considerable portion of which must be ascribed to roots broken off, and grains of barley bruised, during the turning. As the acrospire shoots along the grain, the, 
appearance of the kernel, or mealy part of the corn, undergoes a considerable change. The glutinous and mucilaginous matter in a great measure disappears, the colour becomes whiter, and the texture so loose that it crumbles to powder between the fingers. The object of malting is to produce this change; when it is accomplished, which takes place when the acrospire has come nearly to the end of the seed, the process is stopped altogether.

'(It is the common opinion of maltsters that this change of the grain always keeps pace with the acrospire, each seed being altered as far as the point of the acrospire extends, and no farther; and this opinion has been rather confirmed by our observation. . . The loss of weight, as well as the progress of the malting, depends much upon the temperature, two things respecting which require attention. First, to keep it as equal as possible; and, second, to keep it at the proper pitch, neither too high nor too low. Unless the first precaution be attended to, the progress of the malt is very unequal, some parts being fully ready before others have advanced half-way; this inequality is attended with great loss of weight, because many of the farthest advanced corns must 
be sacrificed to the progress of the rest; it is chiefly prevented by keeping the thickness of all parts of the malt as equal as possible, and by turning it over without delay, whenever an inequality of temperature can be detected in any portion of it.

'A high temperature is more injurious at the beginning of the "flooring" than after the malt has made some progress. Should the heat be in excess, the radicles advance too rapidly, while the kernel does not undergo the wished-for change, but becomes clammy like bird-lime, a condition which is most apt to supervene in the early stage of the process, when the grain is very moist; hence the proper temperature may be judged of pretty correctly from the rootlets; if they be pretty equal, and do not exceed half an inch in length, we may consider the temperature as having been proper, but when they lengthen suddenly and unequally, there must have been an excess of heat.)

'The time during which the grain continues on the malt-floor varies according to circumstances; the higher the temperature at which the grain is kept, the more speedily is it converted into malt; in general, 14 days may be specified as the period 
which intervenes in England from throwing the barley out of the steep till it is ready for the kiln; while in Scotland it is seldom shorter than 18 days, and sometimes 3 weeks. This no doubt is an advantage in favour of English malting, as every thing which shortens the progress, without injuring the malt, must turn out to the advantage of the manufacturer.

'4th. Kiln-drying.-The last part of the process is to dry the malt upon a kiln, which stops the germination, and enables the brewer to keep the malt for some time without injury.

'The kiln is a chamber, the floor of which usually consists of iron plates, full of holes, and in the roof there is a vent to allow the escape of the heated air and vapour. Under this room is a space in which a fire of charcoal or coke is lighted; the heated air which this fire supplies, passes up through the holes in the iron plates, and makes its way through the malt, carrying off the moisture along with it. At first the temperature of the malt is not higher than $90^{\circ}$, but it is elevated very slowly to $140^{\circ}$, or even bigher; we believe that in many cases it rises at last almost as high as $212^{\circ}$, though we have never witnessed any such high temperature ourselves, but we have seen pale 
malt dried at a temperature of $175^{\circ}$, without any injury whatever.

'The great secret in drying malt properly consists in keeping the heat very low at first, and only raising it very gradually, as the moisture is dissipated. For a high temperature applied at first would infallibly blacken or even char the malt, and would certainly diminish considerably the quantity of soluble matter which it contains.

'(The malt is spread upon the kiln floor to the depth of from 3 to 6 inches, and a very moderate fire of charcoal is kindled in an apartment below it.)

' The old malt-kilns had a bottom of hair-cloth instead of the iron plates full of holes, which constitute a more recent improvement. We have seen the thermometer in such a kiln, when the bulb touched the hair-cloth, rise as high as $186^{\circ}$. In general the temperature of the malt-kiln is very carelessly regulated. We have seen malt for the very same purpose dried at a temperature which never rose higher than $136^{\circ}$, while a portion of the very same malt, put into another kiln, was heated as high as $186^{\circ}$. But such a careless mode of drying malt is reprehensible, and must be more or less injurious to the brewer. 
'In general, the more rapidly malt is dried, the more does its bulk increase. This method accordingly is practised by those who malt for sale, as is the case with most of the English maltsters, because malt is always sold by measure and not by weight. The brewers would find it more for their interest to buy malt by weight than by measure. In that case the maltsters would dry their malt at as low a temperature as possible. But this would signify very little, or rather would be advantageous to the brewer, because dried malt soon recovers the moisture lost on the kiln kept for some time in sacks ; and when malt is dried at a low temperature, we are sure that none of it is injured by the fire. It will therefore go farther in the production of beer.

'The time of kiln-drying varies considerably according to the quantity of malt exposed to the action of the heat. But when that quantity is not too great, we may estimate the time of kilndrying in general at two days. After the fire is withdrawn, the malt is allowed to remain on the kiln till it has become nearly cold.

' (The time during which the malt is on the kiln varies with the temperature and the quantity of malt dried from forty to eighty hours, which 
were the extremes in our experiment. While upon the kiln the malt is occasionally turned.)

' By the kiln-drying, the roots of the barley, or, as the maltsters call them, the comings, are dried up and fall of. They are separated from the malt by passing it over the surface of a kind of wire screen, which allows the comings to drop through, while the wires are too near each other to permit the grains of malt to pass.

' (While still warm upon the kiln, it is usually trodden upon by the workmen to separate the rootlets which are at that time brittle, but soon become tough by absorbing moisture.)

'If $100 \mathrm{lbs}$. of barley malted in this manner, with all the requisite care, be weighed just after being kiln-dried and cleaned, they will be found on an average to weigh $80 \mathrm{lbs}$.

' (In general a bushel of good malt, when newly dried, weighs about three-quarters of a bushel of the raw grain.)

' It is probable that an additional portion of the kernel would be dissolved if the malt were ground finer than it is customary to do. The reason for grinding it only coarsely is to render it less apt to set. But this object might be accomplished equally well by bruising the malt 
between rollers, which would reduce the starchy part to powder without destroying the husk. This method indeed is practised by many brewers, but it ought to be followed by all.

'Though the specific gravity of a malt corn be greater than that of water, yet if it be thrown into that liquid it always swims. The reason is, that between the skin and the kernel there is lodged a quantity of air, which it is not easy to drive away. Accordingly brewers are in the habit of judging of the goodness of malt by throwing a certain quantity of it into water, and reckoning the grains which fall to the bottom. These indicate the proportion of unmalted grain which the malt contains. Of course the more of them that exist in any given quantity of malt, the worse must the malt be considered.

'When malt became high priced in consequence of the heavy taxes laid upon it, and the great increase in the price of barley, which took place during the war of the French revolution, the brewers found out that a greater quantity of wort of a given strength could be prepared from pale malt than from brown malt.'

PRINTED BY SPOTTISWOODE AND CO., NEW-STREET SQUARF, LONDON. 


\section{GENBRAL LIST OF WORKS}

PUBLISHED BY

\section{MEssrs. LONGMANS, GREEN, AND CO.} PATERNOSTER ROW, LONDON.

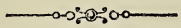

\section{History, Politics, Historical Memoirs, \&c.}

The IIISTORY of INNGLAND from the Fall of Wolsey to the Defeat of the Spanish Armada. By Jayrs AxTHONY Froude, M.A. late Feilow of Exeter College, Cxford.

LrBRARY EDITION, Twelve Volumes, 8vo. price \&s. $18 s$.

CABINET Edrtion, Twelve Volumes, crown Svo. price $72 s$.

The ENGLISH in IRELAND in the EIGHTEENTH GENTURY. By James ANTHony Froude, M.A. late Fellow of Exeter College, Oxford. VoL. I. Svo. price $16 s$.

ESTIMATES of the ENGIISE KINGS from WIIIIAM the CONQUEROR to GEORGE III. By J. LANGTON SANFOnD. Crown 8vo.12s. 6d. The HISTORY of ENGLAND from the Accession of James II. By Lord MLACAULAY.

STUDENT's EDiTION, 2 vols. crown 8 ro. $12 s$.

PEOPLE's EDITION, 4 vols. crown 8vo. $16 s$.

CABLNET EDITION, 8 vols. post 8 vo. $48 s$.

LIBRARY EDITION, 5 vols. 8vo. $₫ 4$.

LORD MACAULAY'S WORXS. Complete and Uniform Library Edition. Edited by his Sister, Lady Trevelyan. 8 vols. 8 vo. with Portrait, price $£ \tilde{5} .5 s$. cloth, or £s. $8 s$. bound in tree-calf by Rivière.

On PARLIAMENTARY GOVERNMENT in ENGTAND; its Origin, Development, and Practical Operation. By ALPHEus ToDD, Librarian of the Legislative Assembly of Canada. 2 vols. 8vo. price $£ 1.17 s$.

The CONSTITUTIONAL FISTORY of RTGLAND, since the Accession of George III. 1760-1860. By Sir THOMIAS ERSKINE, MAX, C.B. The Third Edition, thoroughly revised. 3 vols. crown 8 vo. price $18 s$.

The FISTORY of ENGLAND, from the Earliest Times to the Year 1865. By C. D. YoNGk, B.A. Regius Professor of Modern History in Queen's College, Belfast. New Edition. Crown 8vo. price 7s. $6 d$.

ROYAL and REPUBLICAN FRANCE. A Series of Essays reprinted from the Edinburgh, Quarterly, and British and Foreign Reviews. By HENRY REEvE, C.B. D.C.I. 2 vols. 8 vo. price $21 s$.

CEAPTERS from FRENCE HISTORY; St. Louis, Joan of Arc Henri IV. with Sketches of the Intermediate Periods. By J. H. GURmaY, M.A New Edition. Fcp. 8vo. 6s. 6d. 
The OXFORD REFORMERS - John Colet, Erasmus, and Thomas More; being a History of their Fellow-work. By FreDERIC SEebohm. Second Edition, enlarged. 8vo. 14s.

LECTURES on the HISTORY of ENGLAND, from the Earliest Times to the Death of King Edward II. By William Longman. With Maps and Illustrations. 8vo. $15 s$.

The HISTORY of the LIFE and TIMES of EDWARD the THIRD. By Wilutam Longman. With 9 Maps, 8 Plates, and 16 Woodcuts. 2 vols. 8vo. $28 s$.

GAUL or TEUTON? Considerations as to our Allies of the Future. By Lord DunsanY. 8vo. price $10 s .6 d$.

LORD HATHERTON'S MEMOIR and CORRESPONDENCE relating to POLITICAL OCCURRENCES in June and July 1834. Edited by HENRX REEVE. 8 vo. price $7 s, 6 d$.

WATERL00 LECTURES ; a Study of the Campaign of 1815. By Colonel Charles C. Chesney, R.E., late Professor of Military Art and History in the Staff College. New Edition. 8vo. with Map, 10s. $6 d$.

The LIFE and TIMES of SIXTUS the FIFTH. By Baron HüBNER. Translated from the Original French, with the Author's sanction, by HUBERT E. H. JeRNINGHAMr. 2 vols. 8 vo. price $24 s$.

IGNATIUS LOYOLA and the EARLY JESUITS. By Stewart Rose. New Edition, revised. 8vo. with Portrait, price $16 s$.

The SIXTH ORIENTAL MONARCHY; or, the Geography, History, and Antiquities of Parthia. By George Rawlinson, M.A. Camden Professor of Ancient History in the University of Oxford. With Maps and Illustrations. 8vo. price 16 s.

A HISTORY of GREECE. From the Earliest Period to the Present Time. By the Rev. George W. Cox, M.A., late Scholar of Trinity College, Oxford; Author of 'The Aryan Mythology,' \&c. 4 vols. 8vo.

** The First and Second Volumes of this History, to be published in November, will comprise the historical narrative to the end of the Pelopponesian War, and will form in themselves a complete work, provided with a copious Index.

The History of GREECE. By C. Thirlwall, D.D. Lord Bishop of St. David's. 8 rols. fcp. 8 vo. price $28 s$.

GREEK HISTORY from Themistocles to Alexander, in a Series of Lives from Plutarch. Revised and arranged by A. H. Clougr. New Edition. Fcp. with 44 Woodcuts, $6 s$.

The TALE of the GREAT PERSIAN WAR, from the Histories of Herodotus. By GroRGE W. Cox, M.A. New Edition. Fep. 3s. $6 d$.

The HISTORY of ROME. By WILLIAM IhNe. English Edition, translated and revised by the Author. VoLs. I. and II. 8vc. price $30 s$.

HISTORY of the ROMANS under the EMPIRE. By the Very Rev. C. Merivale, D.C.L. Dean of Ely. 8 vols. post 8vo. 48 s.

The FALL of the ROMAN REPUBLIC; a Short History of the Last Century of the Commonwealth. By the same Author. $12 \mathrm{mo} .7 s .6 d$.

THREE CENTURIES of MODERN HISTORY. By ChaRLES DUKR YoNGE, B.A. Regius Professor of Modern History and English Literature in Queen's College, Belfast. Crown 8vo. price $7 s .6 d$. 
The STUDENT'S MANUAL of the HISTORY of INDIA, from the Earliest Period to the Present. By Colonel MEadows TaYLor, M.R.A.S. M.R.I.A. Second Thousand. Crown 8vo. with Maps, $7 s .6 d$.

The HISTORY of INDIA, from the Earliest Period to the close of Lord Dalhousie's Administration. By JoHN Crark Marshman. 3 vols. crown 8vo. 22s. $6 d$.

INDIAN POLITY : a View of the System of Administration in India. By Lieutenant-Colonel GEORGE CHESNEY, Fellow of the University of Calcutta. New Edition, revised; with Map. 8vo. price 21s.

The IMPERIAL and COLONIAL CONSTITUTIONS of the BRITANNIC EMPIRE, including INDIAN INSTITUTIONS. By Sir EDWARD CREASY, M.A. With 6 Maps. 8vo. price 15s.

REALITIES of IRISH LIFE. By W. SteuarT Trench, late Land Agent in Ireland to the Marquess of Lansdowne, the Marquess of Bath, and Lord Digby. Fifth Edition. Crown 8vo. price 6s.

The STUDENT'S MANUAL of the HISTORY of IRELAND. By MaRy F. Cusack. Crown 8vo. price $6 s$.

CRITICAL and HISTORICAL ESSAYS contributed to the Edinburgh Review. By the Right Hon. LoRd Macaulay.

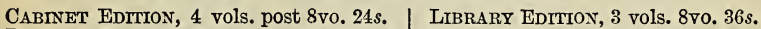

PEOPLE's EDITION, 2 vols. crown 8vo. 8s.

HISTORY of EUROPEAN MORALS, from Augustus to Charlemagne By W. E. H. LECKY, M.A. Second Edition. 2 тo s. 8vo. price $28 s$.

HISTORY of the RISE and INFLUENCE of the SPIRIT of RATIONALISM in EUROPE. By W.E. H. LECKY, M.A. Cabinet Edition being the Fourth. 2 vols. crown 8vo. price $16 s$.

GOD in HISTORY; or, the Progress of Man's Faith in the Moral Order of the World. By Baron BunSEN. Translated by Susanva WinkworTh, with a Preface by Dean STANLEX. 3 vols. 8 vo. price $42 s$.

The HISTORY of PHILOSOPHY, from Thales to Comte. By GEORGE HENRY LEWES. Fourth Edition. 2 vols. 8vo. 32s.

The MYTHOLOGY of the ARYAN NATIONS. By George W. Cox, M.A. late Scholar of Trinity College, Oxford, Joint-Editor, with the late Professor Brande, of the Fourth Edition of 'The Dictionary of Science Literature, and Art,' Author of ' Tales of Ancient Greece' \&c. 2 vols. 8vo.28s.

HISTORY of CIVILISATION in England and France, Spain and Scotland. By HENRY Thomas BuCKLE. New Edition of the entire Work, with a complete INDEX. 3 vols. crown 8 vo. $24 s$.

HISTORY of the CATHOLIC CHURCH of JESUS CHRIST from the Death of St. John to the Middle of the Second Century. By the Rev. T. W. MOSSMAN, B.A. 8ro. price 16 .

HISTORY of the CHRISTIAN CHURCH, from the Ascension of Christ to the Conversion of Constantine. By E. BurTon, D.D. late Prof. of Divinity in the Univ. of Oxford. New Edition. Fcp. $3 s .6 \dot{d}$.

SKETCH of the HISTORY of the CHURCH of ENGLAND to the Revolution of 1688. By the Right Rev. T. V. SHORT, D.D. Lord Bishop of St. Asaph. Eighth Edition. Crown 8vo. 7s,6d. 
HISTORY of the BARIY CHORCH, from the First Preaching of the Gospel to the Council of Nicæa, A.D. 325. By ELIZABETH M. SEwELL, Author of 'Amy Herbert.' New Edition, with Questions. Fcp. 4s. 6d.

The ENGLISH REFORMATION. By F. C. MassingBerd, M.A. late Chancellor of Lincoln and Rector of South Ormsby. Fourth Edition, revised. Fcp. 8vo. $7 s .6 d$.

MAUNDER'S HISTORICAI TREASURY ; comprising a General Introductory Outline of Universal History, and a series of Separate Histories. Latest Edition, revised and brought down to the Present Time by the Rev. GEORGE WILLIAMI Cox, M.A. Fcp. 6s. cloth, or 10s. calf.

CATES' and WOODWARD'S ENCYCLOP EDIA of CHRONOLOGY, HISTORICAL and BIOGRAPHICAL; comprising the Dates of all the Great Events of History, including Treaties, Alliances, Wars, Battles, \&c. ; Incidents in the Lives of Eminent Men and their Works, Scientific and Geographical Discoveries, Mechanical Inventions, and Social Improvements. 8vo. price $42 s$.

\section{Biographical Works.}

BIOGRAPHICAL and CRITICAI ESSAYS, reprinted from Reviews, with Additions and Corrections. Second Edition of the Second Series. By A. HAYWARD, Q.C. 2 vols. 8 vo. price $28 s$.

The LIFE of LIOYD, FIRST LORD KENYON, LORD CHIEF JUSTICE of ENGLAND. By the Hon. GEORGE T. KenYon, M.A. of Ch. Ch. Oxford. With Portraits. 8vo. price 14s.

MEMOIR of GEORGE EDWARD IYNCH COTTON, D.D. Bishop of Calcutta and Metropolitan. With Selections from his Journals and Correspondence. Edited by Mrs. CoTToN. Second Edition, with Portrait. Crown 8vo. price $7 s .6 d$.

MEMOIR of the LIFE of Admiral Sir EDWARD CODRINGTON. With Selections from his Public and Private Correspondence. Edited by his Daughter, Lady BourchIER. With Two Portraits, Maps, and Plans. 2 vols. 8vo. price $36 s$.

LIFE of ALEXANDER VON HUMBOLDT. Compiled in Commemoration of the Centenary of his Birth. Edited by Professor KARL BruHns, Director of the Observatory at Leipzig. Translated by JANE and CARoLINe LASSELL. 2 vols. Svo. with Three Portraits, price $36 s$.

MEMOIRS of BARON STOCKMAR. By his SoN, Baron E. VON STOCKMAR. Translated from the German by G. A. M. Edited by F. MaX MüLleR, M.A. 2 vols. crown 8vo. price 21s.

LORD GEORGR BENTINCK; A Political Biography. By the Right Hon. Benjamin DisRaeli, M.P. Eighth Edition, revised, with a New Preface. Crown 8vo. price 6s.

The IIFE OF ISAMBARD IINGDOM BRUNEL, Civil Engineer. By Isamband BRuNeL, B.C.L. of Lincoln's Inn; Chancellor of the Diocese of Ely. With Portrait, Plates, and Woodcuts. 8v0.21s.

The IIFE and JETTERS of FARADAY. By Dr. Bence JoNes, Secretary of the Royal Institution. Second Edition, thoroughly revised. 2 vols. 8vo. with Portrait, and Eight Engravings on Wood, price $28 s$. 
FARADAY as a DISCOVERER. By JoHN TYNDALI, LL.D. D.C.L. F.R.S. Professor of Natural Philosophy in the Royal Institution. Fcp. 8vo. $3 s .6 d$.

RECOLLECTIONS of PAST IIFE. By Sir HeNRY Holland, Bart. M.D. F.R.S. \&c. Physician-in-Ordinary to the Queen. Third Edition. Post 8 vo. price $10 s .6 d$.

The LIFE and LETTERS of the Rev. SYDNEY SMITH. Edited by his Daughter, Lady HoLLAND, and Mrs. Austiv. Crown 8vo. price $6 s$.

LEADERS of PUBLIC OPINION in IRELAND; Swift, Flood, Grattan, and O'Connell. By W. E. H. LECEY, M.A. New Edition, revised and enlarged. Crown 8vo. price 7s. $6 d$.

DICTIONARY of GENERAL BIOGRAPHY; containing Concise Memoirs and Notices of the most Eminent Persons of all Countries, from the Earliest Ages to the Present Time. Edited by W. L. R. CATES. 8vo. 21s.

IIVES of the QUEENS of ENGLAND. By AGNES STRICKLAND. Library Edition, newly revised; with Portraits of every Queen, Autographs, and Vignettes. 8 vols, post 8 vo. $7 s .6 d$. each.

IIFE of the DUKE of WELIINGTON. By the Rer. G. R. GLeIG, M.A. Popular Edition, carefully revised ; with copions Additions. Crown 8vo. with Portrait, $5 s$.

FELIX MENDELSSOHN'S LETTERS from Italy and Switzerland, and Letters from 1833 to 1847 , translated by Lady WALLACE. New Edition, with Portrait. 2 vols. crown $8 \mathrm{vo}$. $5 s$, each.

MEMOIRS Of SIR HENRY HAVELOCK, IR.C.B. By JoHN CLARK Marshman. Cabinet Edition, with Portrait. Crown 8vo. price $3 s .6 d$.

VICISSITUDES of FAMILIES. By Sir J. BerNard BuRKe, C.B. Ulster King of Arms. New Edition, remodelled and enlarged. 2 vols. crown 8 vo. $21 s$.

The RISE of GREAT FAIIIIES, other Essays and Stories. By Sir J. Bernard BURKe, C.B. Ulster King of Arms. Crown 8vo. price 12s, $6 d$.

ESSAYS in ECCLESIASTICAL BIOGRAPIIY. By the Right Hon. Sir J. STEPHEN, LU.D. Cabinet Edition, being the Fifth. Crown 8vo. 7s. $6 d$.

MAUNDER'S BIOGRAPHICAI TREASURY. Latest Edition, reconstructed, thoroughly revised, and in great part rewritten; with about 1,000 additional Memoirs and Notices, by W. L. R. CATES. Fep. 8vo. price 6s.

IETTERS and LIFE of FRANCIS BACON, including all his Occasional Works. Collected and edited, with a Commentary, by J. SpEDDING, Trin. Coll. Cantab. 6 vols. 8vo. price $₫ 312 s$. To be completed in One more Volume.

\section{Criticism, Philosophy, Polity, \&c.}

A SYSTEMATIC VIEW of the SCIENCE Of JURISPRUDENCE. By Sheldon Amos, M.A. Professor of Jurisprudence to the Inns of Court, London. 8vo. price 18s. 
The INSTITUTES of JUSTINIAN ; with English Introduction, Translation and Notes. By T. C. SANDARS, M.A. Barrister, late Fellow of Oriel Coll. Oxon. New Edition. 8vo. $15 s$.

SOCRATES and the SOCRATIC SCHOOLS. Translated from the German of Dr. E. ZELLER, with the Author's approval, by the Rev. OswaLd J. REICHEL, B.C.L. and M.A. Crown $8 \mathrm{vo} .8 s, 6 d$.

The STOICS, EPICUREANS, and SCEPTICS. Translated from the German of Dr. E. ZELLER, with the Author's approval, by OsWALD J. REICHEL, B.C.L. and M.A. Crown 8vo. price 14s.

The ETHICS of ARISTOTLE, illustrated with Essays and Notes, By Sir A. Gravt, Bart. M.A. LL.D. Third Edition, revised and partly rewritten.

[In the press.

The NICOMACHEAN ETHICS of ARISTOTLE newly translated into English. By R. Williams, B.A. Fellow and late Lecturer of Merton College, and sometime Student of Christ Church, Oxford. 8vo. 12s.

ELEMENTS of LOGIC. By R. Whately, D.D. late Archbishop of Dublin. New Edition. 8vo. 10s. 6d. crown 8vo. 4s. $6 d$.

Elements of Rhetoric. By the same Author. New Edition. 8vo. $10 s .6 d$. crown 8vo. $4 s .6 d$.

English Synonymes. By E. Jane Whately. Edited by Archbishop WhatelY. Fifth Edition. Fcp. 8vo. price $3 s$.

BACON'S ESSAYS with ANNOTATIONS. By R. Whately, D.D. late Arehbishop of Dublin. New Edition, 8vo. price 10s. $6 d$.

IORD BACON'S WORKS, collected and edited by J. SPEDding, M.A. R. L. Elits, M.A. and D. D. HeATH. New and Cheaper Edition. 7 vols. 8 ro. price £3. $13 s .6 d$.

The subJection of WOMEN. By John Stuart Mrle. New Edition. Post 8vo. 5s.

On RePREsentative govern ment. By John Stuart Mill. Crown 8vo. price $2 s$.

On LIBERTY. By John Stuart Mrux. Fourth Edition. Post 8vo. 7s. $6 d$. Crown 8vo. price $1 s .4 d$.

PRINCIPLES of POLITICAL ECONOMY. By the same Author. Seventh Edition. 2 vols. 8 vo. 30s. Or in 1 vol, crown 8vo. price $5 s$.

otilitarianism. By John Stuart Milc. Fourth Edition. 8ro. $5 s$

DISSERTATIONS and DISCUSSIONS, POLITICAL, PHILOSOPHICAL, and HISTORICAL. By JoHN STUART MILL. Second Edition, revised. 3 vols. 8 vo. $36 s$.

EXAMINATION of Sir. W. HAMILTON'S PHIIOSOPHY, and of the Principal Philosophical Questions discussed in his Writings. By JOHN STUAR'T Mrur. Fourth Edition. 8vo. 16s.

An OUTLINE of the NECESSARY LAWS of THOUGHT; a Treatise on Pure and Applied Logic. By the Most Rev. W. Thomson, Lord Archbishop of York, D.D. F.R.S. Ninth Thousand. Crown 8vo. price 5s. $6 d$.

PRIN CIPLES of ECONOMICAL PHILOSOPHY. By HenRy DunNing MACLEOD, M.A. Barrister-at-Law. Second Edition. In Two Volumes. VoL. I. 8 vo. price $15 s$. 
A SYSTEM of LOGIC, RATIOCINATIVE and INDUCTIVE. By JoHN STUART MILL. Eighth Edition. Two vols. 8vo. 25s.

The ELECTION of REPRESENTATIVES, Parliamentary and Municipal; a Treatise. By Thomas HARE, Barrister-at-Law. Fourth Edition, with Additions. Crown 8 vo. $7 s$.

SPEECHES of the RIGHT HON. IORD MACAULAY, corrected by Himself. People's Edition, crown 8vo. $3 s .6 d$.

Lord Macaulay's Speeches on Parliamentary Reform in 1831 and 1832. $16 \mathrm{mo} .1 \mathrm{~s}$.

A DICTIONARY of the ENGLISH LANGUAGE. By R. G. LATHAM, M.A. M.D. F.R.S. Founded on the Dictionary of Dr. SAMUEL JoHnson, as edited by the Rev. H. J. ToDD, with numerous Emendations and Additions. In Four Volumes, 4to. price $£ 7$.

THESAURUS of ENGLISH WORDS and PHRASES, classified and arranged so as to facilitate the Expression of Ideas, and assist in Literary Composition. By P. M. RoGET, M.D. New Edition. Crown 8vo. 10s. $6 d$.

LECTURES on the SCIENCE of LANGUAGE. By F. MAX MÜLLER, M.A. \&c. Foreign Member of the French Institute. Seventh Edition. Two vols. crown 8vo. price $16 s$.

IHANUAL of ENGLISH LITERATURE, Historical and Critical. By THOMAS ARNoLd, M.A. New Edition. Crown 8vo. $7 s .6 d$.

THREE CENTURIES of ENGLISH LITERATURE. By CHARLES DUKE YONGE, Regius Professor of Modern History and English Literature in Queen's College, Belfast. Crown 8vo. price 7s. $6 d$.

SOUTHEY'S DOCTOR, complete in One Volume. Edited by the Rev. J. W. WARTER, B.D. Square crown $8 \mathrm{vo} .12 s .6 d$.

HISTORICAL and CRITICAI COMMENTARY on the OLD TESTAMENT; with a New Translation. By M. M. KAlIsch, Ph.D. VoL. I. Genesis, 8vo. 18s. or adapted for the General Reader, 12s. Vol. II. Exodus, 15s. or adapted for the General Reader, 12s. VoL. III. Leviticus, I PART I. 15s. or adapted for the General Reader, 8s. VOL. IV. Leviticus, PART II. 15s. or adapted for the General Reader, $8 s$.

A DICTIONARY of ROMAN and GREEK ANTIQUITIES, with about Two Thousand Engravings on Wood from Ancient Originals, illustrative of the Industrial Arts and Social Life of the Greeks and Romans. By A. RICH, B.A. Third Edition, revised and improved. Crown 8 vo. price $7 s .6 d$.

A LATIN-ENGLISH DICTIONARY. By JoHN T. White, D.D. Oxon. and J. E. RIDDLE, M.A. Oxon. Third Edition, revised. 2 vols. 4 to. pp. 2,128 , price $42 s$. cloth.

WHITE'S COLLEGE LATIN-ENGLISH DICTIONARY (Intermediate Size), abridged for the use of University Students from the Parent Work (as above). Medium 8 vo. pp. 1,048 , price 18 s. cloth.

WHITE'S JUNIOR STODENT'S COMPLETE LATIN-ENGLISH and ENGLISH-LATIN DICTIONARY. New Edition. Square 12mo. pp. 1,058, price $12 s$.

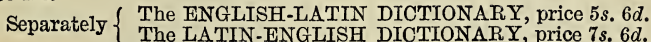

An ENGLISH-GREEK IEXICON, containing all the Greek Words used by Writers of good authority. By C. D. YoNGF, B.A. New Edition, 4to. price $21 s$. 
Mr. YONGE'S NEW LEXICON, English and Greek, abridged from his larger work (as above). Revised Edition. Square 12mo. price $8 s .6 d$.

A GREEK-ENGLISH LEXICON. Compiled by H. G. LiDDELL, D.D. Dean of Christ Church, and R. ScoTT, D.D. Dean of Rochester. Sixth Edition. Crown 4to. price $36 s$.

A Lexicon, Greek and English, abridged from LIDDELx and ScotT's Greek-English Lexicon. Fourteenth Edition. Square 12mo. 7s. 6d.

A SANSKRIT-ENGLISH DICTIONARY, the Sanskrit words printed both in the original Devanagari and in Roman Letters. Compiled by $T$. BENFEx, Prof. in the Univ. of Göttingen. 8vo. 52s. $6 d$.

A PRACTICAI DICTIONARY of the FRENCK and ENGLISH LANGUAGES. By L. ContanseaU. Fourteenth Edition. Post 8vo. 10s. $6 d$.

Contanseau's Pocket Dictionary, French and English, abridged from the above by the Author. New Edition, revised. Square 18mo. 3s. 6d.

NEW PRACTICAL DICTIONARY of the GERIIAF LANGUAGE; German-English and English-German. By the Rev. W. L. BlACKLFY, M.A. and Dr. Carl Martin FriedLäNDER. Post $8 \mathrm{vo} .7 s .6 d$.

The MASTERY of LANGUAGES; or, the Art of Speaking Foreign Tongues Idiomatically. By THOMAS PRENDERGAST, late of the Civil Service at Madras. Third Edition. 8vo. $6 s$.

\section{Miscellaneous Works and Popular Metaphysics.}

MISCELIANEOUS and POSTHUMOUS WORKS of the Late FENRY THOMAS BUCKLE. Edited, with a Biographical Notice, by HeLEN TAYLOR. 3 vols. $8 \mathrm{vo}$. price $52 s .6 d$.

In the MORNINGLAND; or, the Law of the Origin and Transformation of Christianity. By JoHx S. STUART-GLeNNIE, M.A. Barrister-at-Law. VoL. I. the New Philosophy of History and the Origin of the Doctrines of Christianity. 8vo. price 15s.

MISCELLANEOUS WRITINGS of JOHN CONINGTON, M.A. late Corpus Professor of Latin in the University of Oxford. Edited by J. A. SyMonds, M.A. With a Memoir by H. J. S. SMITH, M.A. LL.D. F.R.S. 2 vols. 8 vo. price 28 s.

SEASIDE MUSINGS ON SUNDAYS AND WEEK-DAYT. BY A. K. H. B. Crown 8 vo. price $3 s .6 d$.

Recreations of a Country Parson. By A. K. H. B. Frrst and SECOND SERIES, crown 8vo. $3 s$. $6 d$. each.

The Common-place Philosopher in Town and Country. By A. K. H. B. Crown 8 ro. price $3 s .6 d$.

Ieisure Hours in Town; Essays Consolatory, Esthetical, Moral, Social, and Domestic. By A. K. H. B. Crown 8vo. 3s. $6 d$.

The Autumn Holidays of a Country Parson; Essays contributed to Fraser's Magazine, \&c. By A. K. H. B. Crown 8vo. 3s. $6 d$.

The Graver Thoughts of a Country Parson. By A. K. H. B. First and SECOND SERIES, crown $8 \mathrm{vo} .3 s .6 d$. each. 
Critical Essays of a Country Parson, selected from Essays contributed to Fraser's Magazine. By A. K. H. B. Crown 8vo. 3s. $6 d$.

Sunday Afternoons at the Parish Church of a Scottish University City. By A. K. H. B. Crown 8vo. $3 s .6 d$.

Lessons of Middle Age; with some Account of various Cities and Men. By A. K. H. B. Crown 8 vo. $3 s .6 d$.

Counsel and Comfort spoken from a City Pulpit. By A. K. H. B. Crown 8vo. price 3s. $6 d$.

Changed Aspects of Unchanged Truths; Memorials of St. Andrews Sundays. By A. K. H. B. Crown 8vo. $3 s .6 a$.

Present-day Thoughts; Memorials of St. Andrews Sundays. By A. K. H. B. Crown 8 vo. $3 s .6 d$.

SHORT STUDIES On GREAT SURJECTS. By JAMES ANTHONY Froude, M.A. late Fellow of Exeter Coll. Oxford. 2 vols. crown 8vo. price $12 s$.

LORD MACAULAY'S HISCELLANEOUS WRITINGS :-

IJBRARY EDITION. 2 vols. 8vo. Portrait, $21 s$.

PeOPLE's EDITION. 1 vol. crown 8vo. $4 s .6 d$.

IORD MACAULAY'S MISCELIANEOUS WRITINGS and SPEECHES. STUDENT'S EDITION, in crown 8vo. price $6 s$.

The Rev, SYDNEY SMITH'S MISCELIANEOUS WORIS; including his Contributions to the Edinburgh Review. Crown 8vo. 6s.

The Wit and Wisdom of the Rev. Sydney Smith; a Selection of the most memorable Passages in his Writings and Conversation. 16ro. $3 s .6 d$.

The ECLIPSE of FAITH; or, a Visit to a Religious Sceptic. By HeNRY Rogrrs. Latest Edition. Fcp. 8vo. price $5 s$.

Defence of the Eclipse of Faith, by its Author; a rejoinder to Dr. Newman's Reply. Latest Edition. Fcp 8vo. price 3s. $6 d$.

CHIPS from a GERMAN WORKSFOP; being Essays on the Science of Religion, and on Mythology, Traditions, and Customs. By F. MAX MÜLLER, M.A. \&c. Foreign Member of the French Institute. 3 vols. 8 vo. $£ 2$.

ANALYSIS of the PEENOMENA of the FUMAN MIND. By JAMES MrLL. A New Edition, with Notes, Mllustrative and Critical, by Alexander BaIN, ANDrew Findlater, and George Grote. Edited, with additional Notes, by JoHN StUART MILL. 2 vols. 8 vo. price $28 s$.

An INTRODUCTION to MENTAL PHILOSOPHY, on the Inductive Method. By J. D. Morell, M.A. LL.D. 8vo. 12s.

ELEMENTS of PSYCEOLOGY, containing the Analysis of the Intellectual Powers. By the same Author. Post 8vo. $7 s .6 \mathrm{~d}$.

The SECRET of HEGEL; being the Hegelian System in Origin, Principle, Form, and Matter. By J. H. STIRLING, LL.D. 2 vols. 8vo. 28 s.

SIR WILLIAM HAMILTON; being the Philosophy of Perception : an Analysis. By J. H. STIRLING, LL.D. 8vo. 5s.

LECTURES on the PHILOSOPHY of LAW. Together with Whewell and Hegel, and Hegel and Mr. W. R. Smith; a Vindication in a PhysicoMathematical Regard. By J. H. STiRLING, LL.D. 8vo. $6 s$. 
As REgards PRotoplasm. By J. H. Stiring, LL.D. Second Edition, with Additions, in reference to Mr. Huxley's Second Issue and a new Preface in reply to Mr. Huxley in 'Yeast.' 8 vo. price $2 s$.

The SENSES and the INTrLIICT. By Alexander Bain, M.D. Professor of Logic in the University of Aberdeen. Third Edition. 8vo. 15s.

MENTAL and MORAL SCIENCE: a Compendium of Psychology and Ethics. By the same Author. Third Edition. Crown 8vo. 10s. 6d. Or separately: PART I. Mental Science, price 6s. 6d.; PART II. Moral Science, price $4 s .6 d$.

LOGIC, DEDUCTIVE and INDUCTIVE. By the same Author. In Two PARTS, crown 8vo. 10s. 6d. Each Part may be had separately :PART I. Deduction, 4s. PART II. Induction, $6 s .6 d$.

TIME and SPACE; a Metaphysical Essay. By Shadworth H. HoDGson. (This work covers the whole ground of Speculative Philosophy.) 8vo. price $16 s$.

The THEORY of PRACTICE ; an ETHICAL ENQUIRY. By the same Author. (This work, in conjunction with the foregoing, completes a system of Philosophy.) 2 vols. 8 vo. price $24 s$.

The PHILOSOPHY of NECESSITY; or, Natural Law as applicable to Mental, Moral, and Social Science. By Charles Bray. Second Edition. 8 vo. $9 s$.

A Manual of Anthropology, or Science of Man, based on Modern Research. By the same Author. Crown 8vo. price $6 s$.

On Force, its Mental and Moral Correlates. By the same Author. 8 vo. 5 s.

A TREATISE on HUMAN NATURE; being an Attempt to Introduce the Experimental Method of Reasoning into Moral Subjects. By DAvID HUME. Edited, with Notes, \&c. by T. H. GreEN, Fellow, and T. H. Grose, late Scholar, of Balliol College, Oxford. 2 vols. $8 \mathrm{vo}$.

[In the press.

ESSAYS MORAL, POLITICAI, and IITERARY. By David Hume. By the same Editors. 2 vols. 8 vo.

[In the press.

UEBERWEG'S SYSTEM of LOGIC and IIISTORY of LOGICAL DOCTRINES. Translated, with Notes and Appendices, by T. M. LINDSAY, M.A. F.R.S.E. 8vo. price $16 s$.

A Budget of Paradoxes. By Augustus De Morgan, F.R.A.S. and C.P.S. Reprinted, with the Author's Additions, from the Athenceum. 8vo. price $15 s$.

\section{Astronomy, Meteorology, Popular Geography, \&c.}

OUTLINES of ASTRONOMY. By Sir J. F. W. Herschel, Bart. M.A. Latest; Edition, with 9 Plates and numerous Diagrams. Square crown 8vo. price 12s.

ESSAYS on ASTRONOMY : a Series of Papers on Planets and Meteors, the Sun and Sun-surrounding Space, Stars and Star-Cloudlets; and a Dissertation on the approaching Transit of Venus : preceded by a Sketch of the Life and Work of Sir John Herschel. By Richard A. Proctor, B.A. Hon. Sec. R.A.S. With 10 Plates and 24 Woodcuts. 8vo. price $12 s$. 
The MOON ; her Motions, Aspect, Scenery, and Physical Condition. By Richard A. Proctor, B.A. Cantab. Hon. Sec. R.A.S. With Plates, Charts, Woodeuts, and Three Lunar Photographs by Rutherford, of New York. Crown 8vo. price $15 s$.

The SUN; RULER, LIGHT, FIRE, and LIFE of the PLANETARY SYSTEM. By RICHARD A. PRoctor, B.A. F.R.A.S. Second Edition, with 10 Plates ( 7 coloured) and 107 Figures on Wood. Crown 8vo. 14s.

OTHER WORLDS THAN OURS; the Plurality of Worlds Studied under the Light of Recent Scientific Researches. By the same Author. Third Edition, with 14 Illustrations. Crown 8vo. 10s. $6 d$.

The ORBS AROUND US; a Series of Familiar Essays on the Moon and Planets, Meteors and Comets, the Sun and Coloured Pairs of Stars. By the same Author. Crown 8vo. price 7s. $6 d$.

The STAR DEPTHS; or, Other Suns than Ours: a Treatise on Stars, Star-Systems, and Star-Cloudlets. By the same Author. Crown 8vo. with numerous Illustrations. [Nearly ready.

SATURN and its SYSTEM. By the same Author. 8vo. with 14Plates, 14s.

SCHELLEN'S SPECTRUM ANALYSIS, in its application to Terrestrial Substances and the Physical Constitution of the Heavenly Bodies. Translated by JANE and C. LASSELL; edited, with Notes, by W. HUGGINS, LL.D. F.R.S. With 13 Plates ( 6 coloured) and 223 Woodcuts. 8vo. price $28 s$.

A NEW STAR ATLAS, for the Library, the School, and the Observatory, in Twelve Circular Maps (with Two Index Plates). Intended as a Companion to 'Webb's Celestial Objects for Common Telescopes.' With a Letterpress Introduction on the Study of the Stars, illustrated by 9 Diagrams. By RICHARD A. Proctor, B.A. Hon. Sec. R.A.S. Crown 8 vo. $5 s$.

CELESTIAL OBJECTS for COMMON TELESCOPES. By the Rev. T. W. WEBB, M.A. F.R.A.S. Third Edition, revised and enlarged; with Maps, Plate, and Woodcuts. Crown $8 \mathrm{vo}$. price $7 s .6 d$.

AIR and RAIN; the Beginnings of a Chemical Climatology. By RoBERT Avgus SMITH, Ph.D. F.R.S. F.C.S. Government Inspector of Alkali Works. With 8 mlustrations. 8vo. price 24s.

NAUTICAL SURVEYING, an INTRODUCTION to the PRACTICAL and THEORETICAL STUDY of. By JOHN KNOX LAUGHTON, M.A. F.R.A.S. Small 8vo. price $6 s$.

MAGNETISM and DEVIATION of the COMPASS. For the Use of Students in Navigation and Science Schools. By JoHN MERRIFIeLd, LL.D. F.R.A.S. $18 \mathrm{mo}$. price $1 s .6 d$.

DOVE'S LAW of STORMS, considered in connexion with the Ordinary Movements of the Atmosphere. Translated by R. H. ScoTT, M.A. T.C.D. $8 \mathrm{vo} .10$ s. $6 d$.

KEITH JOHNSTON'S GENERAL DICTIONARY OF GEOGRAPHY, Descriptive, Physical, Statistical, and Historical ; forming a conplete Gazetteer of the World. New Edition, revised and corrected to the Present Date by the Author's Son, KeITH JOBNSTON, F.R.G.S. 1 vol. 8vo.

[Nearly ready.

The PUBLIC SCHOOLS ATLAS Of MODERN GEOGRAPHY. In 31 Maps, exhibiting clearly the more important Physical Features of the Countries delineated, and Noting all the Chief Places of Historical, Commercial, or Social Interest. Edited, with an Introduction, by the Rev. G. BUTLER, M.A. Imp. 4to. price 3s. $6 d$. sewed, or 5s. cloth. 
A MANUAL of GEOGRAPHY, Physical, Industrial, and Political. By W. HuGHES, F.R.G.S. With 6 Maps. Fep. $7 s, 6 d$.

MAUNDER'S TREASURY of GEOGRAPHY, Physical, Historical, Descriptive, and Political. Edited by W. HuGHeS, F.R.G.S. Revised Edition, with 7 Maps and 16 Plates. F'cp. 6s, cloth, or 10s, bound in calf.

\section{Natural History and Popular Science.}

TEXT-BOOKS of SCIENCE, MECHANICAL and PHYSICAI, Edited by T. M. GOODEVE, M.A. and C. W. MERrIEIELD, F.R.S.

1. GOODEVE'S Mechanism, $3 s .6 d$.

2. BLoxAM's Metals, $3 s, 6 d$.

3. MILLER's Inorganic Chemistry, $3 s .6 d$.

4. GRIFrin's Algebra and Trigonometry, 3s. $6 d$. Notes and Solutions to Algebra and Trigonometry, $3 s, 6 d$.

5. WATSON's Plane and Solid Geometry, $3 s .6 d$.

6. MAXWELL's Theory of Heat, $3 s .6 d$.

7. MERRIFIELD's Technical Arithmetic and Mensuration, $3 s .6 d$. HUNTER'S KEY to MERRIFIFLD's Arithmetic and Mensuration, 3s. $6 d$.

8. ANDERSON's Strength of Materials and Structures, $3 s, 6 d$.

9. JENKIN's Electricity and Magnetism, 3s. $6 d$.

10. SHELLEX's Workshop Appliances, $3 s .6 d$.

ELEMENTARY TREATISE on PHYSICS, Experimental and Applied. Translated and edited from GANoT's Éléments de Physique (with the Author's sanction) by E. ATkIsson, Ph.D. F.C.S. New Edition, revised and enlarged; with a Coloured Plate and 726 Woodeuts. Post 8vo. 15s.

NATURAL PHILOSOPHY for GENERAL READERS and YOUNG PERSONS; being a Course of Physics divested of Mathematical Formulæ, expressed in the language of daily life. Translated from GANoT's Cours de Physique (with the Author's sanction) by E. Atkrssox, Ph.D. F.C.S. Crown 8 vo. with 404 Woodcuts, price $7 s .6 d$.

HELMHOLTZ'S POPULAR IECTURES ON SCIENTIFIC SUBJECTS. Translated by E. ATkInson, Ph.D. F.C.S. Professor of Experimental Science, Staff College. With an Introduction by Professor TrNDALL. 8vo. with numerous Woodcuts, price $12 s .6 u$.

IIIS. MARCET'S CONVERSATIONS ON NATURAL PHILOSOPHY. Revised by the Author's Son, and augmented by Conversations on Spectrum Analysis and Solar Chemistry. With 36 Plates. Crown 8vo. price 7s. $6 d$.

SOUND: a Course of Eight Lectures delivered at the Royal Institution of Great Britain. By JOHN TrNDACr, LL.D. D.C.L. F.R.S. New Edition, crown 8vo. with Portrait of M. Schladni and 169 Woodcuts, price $9 s$.

HEAT a MODE of HOTION. By Professor John Trndall, LL.D. D.C.L. F.R.S. Fourth Edition. Crown 8vo. with Woodcuts, 10s. 6d.

CONTRIBUTIONS to MOLECULAR PHYSICS in the DOMAIN of RADIANT HEAT; a Series of Mernoirs published in the Philosophical Transactions and Philosophical Magazine, By JOHN TrNDALL, LL.D. D.C.L. F.R.S. 'With 2 Plates and 31 Woodcuts. 8vo, price $16 s$.

RESEARCHES on DIAMAGNETISMI and MAGNE-CRYSTALLIC AOTION ; including the Question of Diamagnetic Polarity. By the same Author. With 6 plates and many Woodcuts. 8 ro. price $14 s$. 
NOTES of a COURSE of SEVEN LECTURES On ELECTRICAL PHENOMENA and THEORIES, delivered at the Royal Institution, A.D. 1870. By Jomn TrNDALL, LL.D. Crown 8vo. $1 s$. sewed, or $1 s$. $6 d$. cloth.

ELEMENTARY TREATISE on the WAVE-THEORY of IIGHT. By HuMPHREY LLOYn, D.D. D.C.L. Provost of Trinity College, Dublin. Third Edition, revised and enlarged. 8vo. price $10 s .6 d$.

LECTURES on IIGHT delivered in the United States of America in the Years 1872 and 1873. By JoHN TrNDalL, LL.D. D.C.L. F.R.S. With Frontispiece and Diagrams. Crown 8vo. price $7 s, 6 d$.

NOTES of a COURSE of NINE IECTURES on IIGES delivered at the Royal Institution, A.D. 1869. By the same Author. Crown 8ro. price 1s. sewed, or $1 s .6 d$. cloth.

FRAGMENTS of SCIENCE. By JOHN TYNDALL, LL.D. D.C.L. F.R.S. Third Edition. 8ro. price 14s.

LIGHT SCIENCE for IEISURE HOURS; a Series of Familiar Essays on Scientific Subjects, Natural Phenomena, \&c. By R. A. Рroctor, B.A. F.R.A.S. Second Edition, revised, of the First Series. Crown 8vo. price 7s. 6d.-SECOND SERIES, including a Sketch of the Life of Mary Somerville. Crown 8vo. price $7 s, 6 d$.

The CORRELATION of PFISICAL FORCES. By Sir W. R. GRove, Q.C. V.P.R.S. Fifth Edition, revised, and followed by a Discourse on Continuity. 8vo. 10 s. $6 d$.

Professor OWEIN'S LECTURES on the COMPARATIVE ANATOMY and Physiology of the Invertebrate Animals. Second Edition, with 235 Woodcuts. $8 \mathrm{vo} .21 s$.

The COMPARATIVE ANATOMY and PHYSIOIOGY of the VERTEBRATE ANIMALS. By RICHARD OWEN, F.R.S. D.C.L. With 1,472 Woodcuts. 3 vols. 8 vo. $£ 3.13 s .6$ d.

PRINCIPLES of ANIMAL MECHANICS. By the Rev. S. HAUGHTON, F.R.S. Fellow of Trin. Coll. Dubl. M.D. Dubl. and D.C.L. Oxon. 8vo. with 111 Figures on Wood, price $21 s$.

The ANCIENT STONE IMPLEMENTS, WEAPONS, and ORNAMENTS of GREAT BRITAIN. By JoHN EvAxs, F.R.S.F.S.A. With 2 Plates and 476 Woodcuts. 8vo. price $28 s$.

The ORIGIN of CIVILISATION and the PRIMITIVE CONDITION of MAN ; Mental and Social Condition of Savages. By Sir JoHN LUBBock, Bart. M.P. F.R.S. Second Edition, with 25 Woodcuts. 8vo. price 16s.

The PRIMITIVE INHABITANTS of SCANDINAVIA: containing a Description of the Implements, Dwellings, Tombs, and Mode of Living of the Savages in the North of Europe during the Stone Age. By SNev Nulsson. With 16 Plates of Figures and 3 Woodcuts. 8vo. 18s.

BIBLE ANIMALS; being a Description of every Living Creature mentioned in the Scriptures, from the Ape to the Coral. By the Rev. J. G. WOOD, M.A. F.L.S. With about 100 Vignettes on Wood. 8vo. $21 s$.

HOMES WITHOUT HANDS; a Description of the Habitations of Animals, classed according to their Principle of Construction. By the Rev. J. G. WOOD, M.A. F.L.S. With about 140 Vignettes on Wood. 8 ro. $21 s$. 
MANKIND, their ORIGIN and DESTINY. By an M.A. of Balliol College, Oxford. Containing a New Translation of the First Three Chapters of Genesis ; a Critical Examination of the First Two Gospels ; an Explanation of the Apocalypse ; and the Origin and Secret Meaning of the Mythological and Mystical Teaching of the Ancients. With 31 Illustrations. 8vo. price 31s, $6 d$.

INSECTS AT HOME; a Popular Account of British Insects, their Structure, Habits, and Transformations. By the Rev. J. G. WooD, M.A. F.L.S. With upwards of 700 Illustrations engraved on Wood ( 1 coloured and 21 full size of page). $8 \nabla 0$. price $21 s$.

INSECTS ABROAD; being a Popular Account of Foreign Insects, their Structure, Habits, and Tranformations. By J. G. Wood, M.A. F.L.S. Author of 'Homes without Hands,' \&c. In One Volume, printed and illustrated uniformly with 'Insects at Home,' to which it will form a Sequel and Companion.

[In the press.

STRANGE DWELLINGS; a description of the Habitations of Animals, abridged from 'Homes without Hands.' By the Rev. J. G. WooD, MI.A. F.L.S. With about 60 Woodcut Illustrations. Crown 8vo. price $7 s .6 d$.

A FAMILIAR HISTORY of BIRDS. By E. STANLEY, D.D. F.R.S. late Lord Bishop of Norwich. Seventh Edition, with Woodcuts. Fcp. 3s. $6 d$.

The HARMONIES of NATURE and UNITY of CREATION. By Dr, GEORGE HARTWIG. 8vo. with numerous Illustrations, $18 s$.

The SEA and its IIVING WONDERS. By Dr. George Hartwig. Latest revised Edition. 8vo. with many Illustrations, 10s. $6 d$.

The TROPICAI WORLD. By Dr. George Hartwig. With above 160 Illustrations. Latest revised Edition. 8vo. price 10s. $6 d$.

The SUBTERRANEAN WORLD. By Dr. George Hartwig. With 3 Maps and about 80 Woodcuts, inclading 8 full size of page. 8 vo. price $21 s$.

The POLAR WORID, a Popular Description of Man and Nature in the Arctic and Antarctic Regions of the Globe. By Dr. GeORgE HaRTwrG. With 8 Chromoxylographs, 3 Maps, and 85 Woodeuts. 8 vo. 21 s.

KIRBY and SPENCE'S INTRODUCTION to ENTOMOLOGY, or Elements of the Natural History of Insects. 7th Edition. Crown 8vo. 5s.

MAUNDER'S TREASURY of NATURAL HISTORY, or Popular Dictionary of Birds, Beasts, Fishes, Reptiles, Insects, and Creeping Things. Latest revised Edition, with above 900 Woodcuts. Fcp. $8 \nabla 0$. price $6 s$. cloth, or 10 s. bound in calf.

HANDBOOK of HARDY TREES, SHRUBS, and HERBACEOUS PLANTS, containing Descriptions, Native Countries, \&c. of a Selection of the Best Species in Cultivation; togethér with Cultural Details, Comparative Hardiness, Suitability for Particular Positions, \&c. By W. B. HEMsLEX, formerly Assistant at the Herbarium of the Royal Gardens, Kew. Based on DECAISNE and NAUDIN's Manuel de l'A mateur des Jardins, and including the 264 Original Woodcuts. Medium 8ซo. 21s.

A GENERAL SYSTEM of BOTANY DESCRIPTIVE and ANALYTICAL. I. Outlines of Organography, Anatomy, and Physiology ; II. Descriptions and Illustrations of the Orders. By E. LE MAOUT, and J. DECATSNE, Members of the Institute of France. Translated by Mrs. HookER. The Orders arranged after the Method followed in the Universities and Schools of Great Britain, its Colonies, America, and India, with Additions, an Appendix on the Natural Method, and a Synopsis of the Orders, by J. D. Hooker, F.R.S. \&c. Director of the Royal Botanical Gardens, Kew. With 5,500 Woodcuts. Imperial 8vo. price $52 s .6 d$. 
The TREASURY of BOTANY, or Popular Dictionary of the Vegetable Kingdom; including a Glossary of Botanical Terms. Edited by J. LINDLEY, F.R.S. and T. MoORE, F.L.S. assisted by eminent Contributors. With 274 Woodcuts and 20 Steel Plates. Two Parts, fep. 12s. cloth, or 20s. calf.

The ELEMENTS of BOTANY for FAMILIES and SCHOOLS. Tenth Edition, revised by THomas Moore, F.I.S. Fcp. with 154 Woodcuts, $2 s .6 d$.

The ROSE AMATEUR'S GUIDE. By Thomas Rivers. Fourteenth Edition. Fep. $4 s$.

LOUDON'S ENCYCLOP EEDIA of PLANTS ; comprising the Specific Character, Description, Culture, History, \&c. of all the Plants found in Great Britain. With upwards of 12,000 Woodcuts. 8yo. $42 s$.

MAUNDER'S SCIEIVTIFIC and IITERARY TREASURY. New Edition, thoroughly revised and in great part rewritten, with above 1,000 new Articles, by J. Y. JoHNson, Corr. M.Z.S. Fep. 6s. cloth, or 10s. calf.

A DICTIONARY of SCIENCE, IITERATURE, and ART. Fourth Edition, re-edited by W. T. BRANDE (the original Author), and GÉRGE W. Cox, M.A., assisted by contributors of eminent Scientific and Literary Acquirements. 3 vols. medium 8vo. price 63s. cloth.

\section{Chemistry, Medicine, Surgery, and the Allied Sciences.}

A DICTIONARY of CHEMISTRY and the Allied Branches of other Sciences. By HENRY WATTS, F.R.S. assisted by eminent Contributors. Complete in 6 vols, medium 8vo. price $\$ 8.14 s .6 d$.

ELEMENTS of CHEMISTRY, Theoretical and Practical. By W. ALLEN MILLER, M.D. late Prof. of Chemistry, King's Coll. London. New Edition. 3 vols. 8vo. £3. Part I. ChEMTCAL Physics, 15s. PART II. Inorganic Chemistry, 21s. Part III. Organic Chemistry, 24s.

A Course of Practical Chemistry, for the use of Medical Students. By W. OdLING, F.R.S. New Edition, with 70 Woodeuts. Crown 8vo. 7s. 6d.

A MANUAL of CHEMICAL PHYSIOLOGY, including its Points of Contact with Pathology. By J. L. W. ThUdrchum, M.D. With Woodeuts. 8 vo. price $7 s, 6 d$.

SELECT METHODS in CHEMICAL ANALYSIS, chiefly INORGANIC. By WILLIAM CROoKES, F.R.S. With 22 Woodcuts. Crown 8vo. price $12 s .6 d$.

CHEMICAL NOTES for the LECTURE ROOM. By Thomas Wood, F.C.S. 2 vols. crown 8 ro. I. on Heat, \&zc. price 5s. II. on the Metals, $5 s$.

The HANDBOOK for MIDWIVES. By HeNRY FLY SMith, B.A. M.B. Oxon. M.R.C.S. late Assistant-Surgeon at the Hospital for Women, Soho-square. With 41 Woodeuts. Crown 8vo. 5s.

The DIAGNOSIS, PATHOLOGY, and TREATMENT of DISEASES of WOMEN ; including the Diagnosis of Pregnancy. By GRAILY HEw]TT, M.D. Third Edition, partly rewritten ; with several additional Illustrations. 8vo. price $24 s$. 
On SOME DISORDERS of the NERVOUS SYSTEM in CHILDHOOD ; being the Lumleian Lectures delivered before the Royal College of Physicians in March 1871. By Charles West, M.D. Crown 8vo. price of

LECTURES on the DISERSES of INEANCY and CEILDTOOD. By Charles West, M.D. \&c. New Edition, revised and enlarged. 8vo. 16s.

The SCIEYCE and $\triangle R T$ of SURGERY; being a Treatise on Surgical Injuries, Diseases, and Operations. By JoHN ERIC ERICHswe, Senior Surgeon to University College Hospital, and Holme Professor of Clinical Surgery in University College, London. A new Edition, being the Sixth, revised and enlarged; with 712 Woodcuts. 2 vols. 8 vo. price $32 s$.

A SYSTEM of SURGERZ, Theoretical and Practical. In Treatises by Various Authors. Edited by T. HoLmes, M.A. \&c. Surgeon and Lecturer on Surgery at St. George's Hospital, and Surgeon-in-Chief to the Metropolitan Police. Second Edition, thoroughly revised, with numerous Illustrations. 5 vols. 8 vo. $£ 5.5 s$.

The SURGICAL TREATMENT of CHILDREN'S DISEASES. By T. Holmes, M.A. \&c. late Surgeon to the Hospital for Sick Children. Second Edition, with 9 plates and 112 Woodcuts. $8 \mathrm{vo} .21 s$.

IECTORES on the PRINCIPLIS and PRACTICE of PHYSIC. By Sir Thomas Watson, Bart. M.D. Fifth Edition, thoroughly revised. 2 vols. 8vo. price $36 s$.

IECTURES on SURGICAL PATHOLOGY. By Sir JANES PAGET, Bart. F.R.S. Third Edition, revised and re-edited by the Author and Professor W. Turver, M.B. 8vo. with 134 Woodcuts, $21 s$.

COOPER'S DICTIONARY of PRACTICAI SURCERY and Encyclopædia of Surgical Science. New Edition, brought down to the present time. By S. A. LAXE, Surgeon to St. Mary's Hospital, assisted by various Eminent Surgeons. 2 vols. 8 vo. price $25 s$. each.

On CHRONIC BRONCHITIS, especially as connocted with GOUT, EMPHYSEMA, and DISEASES of the HEART. BY $E$. HEADLAM GreENHow, M.D. F.R.C.P. \&c. 8vo. $7 s .6 d$.

The CLIMATE of the SOUTE of FRANCE as SUITED to INVAIIDS ; with Notices of Mediterranean and other Winter Stations. By C. T. WruLIA MS, M.A. M.D. Oxon. Physician to the Hospital for Consumption at Brompton. Second Edition. Crown 8vo. $6 s$.

PULMONARY CONSUMPTION; its Nature, Varieties, and Treatment: with an Analysis of One Thousand Cases to exemplify its Duration. By C. J. B. WilitaMs, M.D. F.R.S. and C. T. WilliaMs, M.A. M.D. Oxon. Post 8vo. price $10 s .6 d$.

The SKIM-NILK TREATMENT Of DIABETES and BRIGHT'S DISEASE; with Clinical Observations on the Symptoms and Pathology of these Affections. By ARTHUR ScotT DoNkin, M.D. \&c. Crown 8vo. price $10 s$. $6 d$.

QTJAIN'S ELEMINTT edited by W. ShatPEY, M.D. F.R.S. AlLeN Thonpson, M.D. F.R.S. and J. CletaNd, M.D. With upwards of 800 Engravings on Wood. 2 vols. 8 vo. price $31 s .6 d$.

ANATOMY, DESCRIPTIVE and SURGICAL. By HENRY GRAY, F.R.S. With about 400 Woodcuts from Dissections. Sixth Edition, by T. Holmes, M.A. Cantab, with a new Introduction by the Editor. Royal 8 ro. $28 s$. 
A TREATISE on the CONTINUED FEVERS of GREAT BRITAIN. By Charles Murchison, M.D. LL.D. F.R.S. F.R.C.P. \&c. Second Edition, thoroughly revised and enlarged, with numerous Illustrations. $8 \mathrm{vo}$. price $24 s$.

CLINICAL LECTURES on DISEASES of the LIVER, JAUNDICE, and ABDOMINAL DROPSY. By Charles Murchison, M.D. Post 8vo. with 25 Woodcuts, $10 s .6 d$.

OUTLINES of PHYSIOLOGY, Human and Comparative. By JoHN MarshalL, F.R.C.S. Surgeon to the University College Hospital. 2 vols. crown 8vo. with 122 Woodeuts, $32 s$.

PHYSIOLOGICAL ANATOMY and PHYSIOLOGY of MAN. By tho late R. B. TODD, M.D. F.R.S. and W. Bowmar, F.R.S. of King's College. With numerous milustrations. Vol. II. 8vo. 25̃s.

Vol. I. New Edition by Dr. LIONEL. S. Beale, F.R.S. in course of publication, with many Illustrations. PARTS I. and II. price 7s. $6 d$. each.

COPLAND'S DICTIONARY of PRACTICAL MEDICINE, abridged from the larger work and throughout brought down to the present State of Medical Science. 8 vo. $36 s$.

On the MANUFACTURE of BEET-ROOT SUGAR in ENGLAND and IRELAND. By Willuax Crookes, F.R.S. Crown 8vo. with 11 Woodcuts, $8 s .6 d$.

DR. PEREIRA'S ELEIENTS of MATERIA MEDICA and THERAPEUTICS, abridged and adapted for the use of Medical and Pharmaceutical Practitioners and Students; and comprising all the Medicines of the British Pharmacopœia, with such others as are frequently ordered in Prescriptions or required by the Physician. Edited by Professor Bestuer, F.L.S. \&c. and by Dr. ReEWOOD, F.C.S. \&c. With 125 Woodcut Illustrations. 8vo. price $25 s$.

The ESSENTIALS of MATERIA MCEDICA and THERAPEUTICS. By Alfred Baring Garrod, M.D. F.R.S. \&c. Physician to King's College Hospital. Third Edition. Seventh Impression, brought up to 1870. Crown 8vo. price $12 s .6 d$.

\section{The Fine Arts, and Illustrated Editions.}

The THREE CATHEDRALS DEDICATED to ST. PAUL, in IONDON ; their History from the Foundation of the First Building in the Sixth Century to the Proposals for the Adornment of the Present Cathedral. By WILLIAM LONGMAN, F.A.S. with numerous Illustrations. Square crown 8vo. price $21 s$.

GROTESQUE ANIMAIS, inrented, described, and portrayed by E. W. Cooke, R.A. F.R.S. F.G.S. F.Z.S. \&c. in Twenty-four Plates, with Elucidatory Comment3. Royal 4 to. $21 s$.

IN FAIRYLAND; Pictures from the Elf-World. By Richand DOYLE. With a Poem by W. AlLINGHAM. With Sixteen Plates, containing Thirty-six Designs printed in Colours. Folio, $31 s .6 d$.

HALF-HOUR LECTURES on the HISTORY and PRACTICE of the Fine and Ornamental Arts. By William B. Scotr. New Edition, revised by the Author; with 50 Woodeuts. Crown $8 \mathrm{vo} .8 s .6 d$.

ALBERT DURER, HIS LIFE and WORKS; including Autobiographical Papers and Complete Catalogues. By WiLliam B. ScoTT. With Six Etchings by the Author, and other lllustrations. $8 \mathrm{vo} .16 s$. 
The CHORALE BOOK for ENGLAND: the Hymns translated by Miss C. WINkworth; the Tunes arranged by Prof. W. S. BENNETT and OTTO GoldschMIDT. Fcp. 4to. 12s. 6d.

The NEW TESTAMENT, illustrated with Wood Engravings after the Farly Masters, chiefly of the Italian School. Crown 4to. 63s. cloth, gilt top; or $£ 5$ 5s. elegantly bound in morocco.

IYRA GERMANICA ; the Christian Year. Translated by Catherine WrNKWORTH; with 125 Illustrations on Wood drawn by J. LEIGHTON, F.S.A. 4to. 21 s.

IYRA GERMANICA; the Christian Life. Translated by CATHERINE WINkWORTH ; with about 200 Woodeut Illustrations by J. LEIGHTON, F.S.A., and other Artists. 4 to. $21 s$.

The LIFE of MAN SYMBOLISED by the MONTHS of the YEAR. Text selected by R. PIGot; Illustrations on Wood from Original Designs by J. LEIGHTON, F.S.A. 4 to. $42 s$.

CATS' and FARLIE'S MORAI EMBLEMS; with Aphorisms, Adages, and Proverbs of all Nations. 121 Illustrations on Wood by J. LeighToN, F.S.A. Text selected by R. PIGot. Imperial $8 \mathrm{vo} .31 s .6 d$.

SACRED and LEGENDARY ART. By MRS. JAMESON.

Legends of the Saints and Martyrs. New Edition, with 19 Etchings and 187 Woodcuts. 2 vols. square crown $8 \mathrm{vo} .31 s .6 d$.

Legends of the Monastic Orders. New Edition, with 11 Etchings and 88 Woodcuts. 1 vol. square crown 8 vo. $21 s$.

Legends of the Madonna. New Edition, with 27 Etchings and 165 Woodcuts. 1 vol. square crown $8 \mathrm{vo} .21$ s.

The History of Our Lord, with that of his Types and Precursors. Completed by Lady EASTLAKE. Revised Edition, with 31 Etchings and 281 Woodcuts. 2 vols. square crown 8 vo. $42 s$.

\section{The Useful Arts, Manufactures, \&c.}

HISTORY of the GOTHIC REVIVAL; an Attempt to shew how far the taste for Mediæval Architecture was retained in England during the last two centuries, and has been re-developed in the present. By C. L. EASTIAKE, Architect. With 48 Illustrations (36 full size of page). Imperial 8vo. price $31 s, 6 d$.

GWILT'S ENCYCLOP EDIA of ARCHITECTURE, with abore 1,600 Engravings on Wood. Fifth Edition, revised and enlarged by WYATT PAPWORTH. $8 \mathrm{vo} .52 s_{*} 6 d$.

A MANUAL of ARCHITECTURE: being a Concise History and Explanation of the principal Styles of European Architecture. Ancient, Mediæval, and Renaissance; with a Glossary of Technical Terms. By Thomas Mrtcheld. Crown 8vo. with 150 Woodcuts, $10 \mathrm{~s} .6 \mathrm{~d}$.

HINTS On HOUSEHOLD TASTE in FURNITURE, UPHOLSTERY, and other Details. By CharLes L. EAsTLAKE, Architect. New Edition, with about 90 Illustrations. Square crown 8 vo. $14 s$. 
PRINCIPLES of MECHANISM, designed for the Use of Students in the Universities, and for Engineering Students generally. By $\mathbf{R}$. WILLIS, M.A. F.R.S. \&c. Jacksonian Professor in the University of Cambridge. Second Edition, enlarged; with 374 Woodcuts. 8vo. $18 s$.

GEOMETRIC TURNING : comprising a Description of Plant's New Geometric Chuck, with directions for its use, and a series of Patterns cut by it, with explanations of the mode of producing them, and an account of a New Process of Deep Cutting and of Graving on Copper. By H. S. SAvory. With numerous Woodcuts. 8vo. 21s.

LATHES and TURNING, Simple, Mechanical, and ORNAMENTAL. By W. HENRY NORTHCoTt. With about 240 Illustrations on Steel and Wood. 8vo. 18s.

PERSPECTIVE ; or, the Art of Drawing what One Sees. Explained and adapted to the use of those Sketching from Nature. By Lieut. W. H. CoLLINS, R.E. F.R.A.S. With 37 Woodcuts. Crown 8 vo. price $5 s$.

URE'S DICTIONARY of ARTS, MANUFACTURES, and MINES. Sixth Edition, chiefly rewritten and greatly enlarged by ROBERT AUNT, F.R.S. assisted by numerous Contributors eminent in Science and the Arts, and familiar with Manufactures. With above 2,000 Woodcuts. 3 vols. medium 8vo. price $£ 414 s$. $6 d$.

HANDBOOK OF PRACTICAI TELEGRAPHY. By R. S. CULLEY, Memb. Inst. C.E. Engineer-in-Chief of Telegraphs to the Post Office. Fifth Edition, with 118 Woodeuts and 9 Plates. 8vo. price $14 s$.

ENCYCLOP EDIA of CIVIL ENGINEERING, Historical, Theoretical, and Practical. By E. Cress, C.E. With above 3,000 Woodcuts. 8 ro. 42s.

The STRAINS IN TRUSSES Computed by means of Diagrams; with 20 Examples drawn to Scale. By F. A. RANKEN, M.A. C.E. Lecturer at the Hartley Institution, Southampton. With 35 Diagrams. Square crown 8 vo. price $6 s .6 d$.

TREATISE on MILLS and MILLWORK. By Sir W. FAIRBAIRN, Bart. F.R.S. New Edition, with 18 Plates and 322 Woodcuts, 2 vols. 870. $32 s$.

USEFUL INFORMATION for ENGINEERS. By the same Author. FIRST, SECOND, and THIRD SERIES, with many Plates and Woodcuts, 3 vols. crown 8vo. 10s. 6d. each.

The APPLICATION of CAST and WROUGHT IRON to Building Purposes. By Sir W. FAIrBaIRN, Bart. F.R.S. Fourth Edition, enlarged; with 6 Plates and 118 Woodcuts. 8vo. price $16 s$.

A TREATISE on the STEAII ENGINE, in its various Applications to Mines, Mills, Steam Navigation, Railways, and Agriculture. By J. Bourse, C.E. Eighth Edition; with Portrait, 37 Plates, and 546 Wood cuts. 4to. $42 s$.

CATECHISM of the STEAMI ENGINE, in its various Applications to Mines, Mills, Steam Navigation, Railways, and Agriculture. By the same Author. With 89 Woodcuts. Fep. 6 s.

HANDBOOK of the STEAII ENGINE. By the same Author, forming a KEY to the Catechism of the Steam Engine, with 67 Woodcuts. Fcp. $9 s$.

BOURNE'S RECENT IMPROVEMENTS in the STEAM ENGINE in its various applications to Mines, Mills, Steam Navigation, Railways, and Agriculture. Being a Supplement to the Author's 'Catechism of the Steam Engine.' By JOHN BOURNE, C.E. New Edition, including many New Examples; with 124 Woodents. Fep. 8vo. $6 s$. 
PRACTICAL TREATISE on METALIURGY, adapted from the last German Edition of Professor KenL's Metallurgy by W. CROoKes, F.R.S. \&c. and E. BöHRIG, Ph.D. M.E. With 625 Woodcuts. 3 vols. 8 vo. price 2419 s.

IIITCHELI'S MANUAI of PRACTICAL ASSAYING. Fourth Edition, for the most part rewritten, with all the recent Discoveries incorporated, by W. Crookes, F.R.S. With 199 Woodcuts. 8 vo. $31 s .6 d$.

IOUDON'S ENCYCLOPEDIA of AGRICULTURE: comprising the Laying-out, Improvement, and Management of Landed Property, and the Cultivation and Economy of the Productions of Agriculture. With 1,100 Woodcuts. 8ro. $21 s$.

Loudon's Encyclopædia of Gardening: comprising the Theory and Practice of Horticulture, Floriculture, Arboriculture, and Landscape Gardening. With 1,000 Woodcuts. 8vo. $21 s$.

BAYLDON'S ART of VALUING RENTS and TILLAGES, and Claims of Tenants upon Quitting Farms, both at Michaelmas and Lady Day. Eighth Edition, revised by J. C. MonTon. 8vo. 10s. $6 d$.

\section{Religious and Moral Works.}

INTRODUCTION to the SCIENCE of RELIGION. Four Lectures delivered at the Royal Institution; with Two Essays on False Analogies and the Philosophy of Mythology. By F. MAx Mtiller, M.A. Crown 8vo. price $10 s .6 d$.

DSSAYS on the HISTORY of the CERISTIAN RELIGION. By JoHN Earl Russei.t. Second Edition, revised, 8vo. price 10s. 6 d.

EIGHT ESSAYS on ECCIESTASTICAL REFORM, by Various Writers; together with a Preface and Analysis of the Essays. Edited by the Rev. OrBY SHIPLEY, M.A. Crown 8vo. $10 s .6 d$.

The SPEAKER'S BIBLE COMMENTARY, by Bishops and other Clergy of the Anglican Church, critically examined by the Right Rev. J. W. Colenso, D.D. Bishop of Natal. 8vo. PART I. Genesis, 3s. 6d. PART II. Exodus. 4s. 6d. PART III. Leviticus, 2s. 6d. PART IV. Numbers, 3s. $6 d$. PARE V. Deuteronomy, 5 s.

The OUTLINES of the CHRTSTIAN MINISTRY DELINEATED, and brought to the Test of Reason, Holy Scripture History, and Experience, with a view to the Reconciliation of Existing Differences concerning it, especially between Presbyterians and Episcopalians. By C. WordsworTH, D.C.L. Bishop of St. Andrews. Crown 8vo. price $7 s .6 d$.

CHRIST the CONSOLER; a Book of Comfort for the Sick. With a Preface by the Right Rev. the Lord Bishop of Carlisle. Small 8vo. price 6s.

REASONS of FAITH; or, the ORDER of the Christian Argument Developed and Explained. By the Rev. G. S. Drew, M.A. Second Edition, revised and enlarged. Fcp. 8 vo. price $6 s$.

The TRUE DOCTRINE of the EUCHARIST. By Thomas S. L. Vogan, D.D. Canon and Prebendary of Chichester and Rural Dean. 8vo. price 18s.

SYNONYMS of the OLD TESTAMENT, their BEARING on CHRISTIAN FAITH and PRACTIUE. By the Rev. ROBERT BAKER Girolistone, M.A. 8ro. price 15 s. 
An INTRODUCTION to the THEOLOGY of the CHURCH of ENGLAND, in an Exposition of the Thirty-nine Articles. By the Rev. T. P. Boultaee, LL.D. New Edition, Fep. 8vo. price $6 s$.

FUNDAMENTALS ; or, Bases of Belief concerning MAN and GOD : a Handbook of Mental, Moral, and Religious Philosophy. By the Rev. T. GRIFHTTH, M.A. 8 vo. price $10 s$. $6 d$.

PRAYERS for the FAMILY and for PRIVATE USE, selected from the COLLECTION of the late BARON BUNSEN, and Translated by Catherine WinkWorth. Fcp. 8vo. price $3 s .6 d$.

The STUDENT'S COMPENDIUM of the BOOK of COMMON PRAYER; being Notes Historical and Explanatory of the Liturgy of the Church of England. By the Rev. H. Aruden NASH. Fcp. 8vo. price 2s. $6 d$.

An EXPOSITION of the 39 ARTICLES, Historical and Doctrinal. By E. Harold Browne, D.D. Lord Bishop of Ely. Ninth Edit. 8vo. 16s.

The IIFE and EPISTLES of ST. PAUL. By the Rev. W. J. Conybeare, M.A., and the Very Rev. J. S. Howson, D.D. Dean of Chester :LrBRARY EDITION, with all the Origiral Illustrations, Maps, Landscapes on Steel, Woodcuts, \&c. 2 vols, 4 to. $48 s$.

INTERMEDIATE EDITION, with a Selection of Maps, Plates, and Woodcuts. 2 vols. square crown 8 vo. 21 s.

STUDENT's EDITION, revised and condensed, with 46 Illustrations and Maps. 1 vol. crown 8vo. price $9 s$.

The VOYAGE and SHIPWRECK of ST. PAUL; with Dissertations on the Life and Writings of St. Luke and the Ships and Navigation of the Ancients. By James Smirh, F.R.S. Third Edition. Crown 8vo. 10s. 6d.

COMMENTARY on the EPISTLE to the ROMANS. By the Rev. W. A. O'Conon, B.A. Rector of St. Simon and St. Jude, Manchester. Crown 8vo. price 3s. $6 d$.

The EPISTLE to the HEBREWS; with Analytical Introduction and Notes. By the Rev. W. A. O'Conor, B.A. Crown 8vo. price 4s. $6 d$.

A CRITICAI and GRAMMATICAL COMMENTARY on ST. PAUL'S Epistles. By C. J. EluICo'TT, D.D. Lord Bishop of Gloucester and Bristol. 8vo. Galatians, Fourth Edition, $8 s .6 d$.

Ephesians, Fourth Edition, 8s. $6 d$.

Pastoral Epistles, Fourth Edition, 10s. $6 d$.

Philippians, Colossians, and Philemon, Third Edition, 10s. 6d.

Thessalonians, Third Edition, 7s. 6d.

HISTORICAL LECTURES on the LIFE of OUR LORD JESUS CHRIST : being the Hulsean Lectures for 1859. By C. J. ELIICOTT, D.D. Lord Bishop of Gloucester and Bristol. Fifth Edition. 8vo. price $12 \mathrm{~s}$.

EVIDENCE of the TRUTH of the CHRISTIAN RELIGION derived from the Literal Fulfilment of Prophecy. By Alexander KEITH, D.D. 37th Edition, with numerous Plates, in square 8то. 12s. 6d.; also the 39 th Edition, in post 8vo. with 5 Plates, $6 s$.

History and Destiny of the World and Church, according to Scripture. By the same Author. Square 8vo. with 40 Illustrations, 10s.

The HISTORY and LITERATURE of the ISRAELITES, according to the Old Testament and the Apocrypha. By C. DE RothscHILD and A.DE Rothschild. Second Edition, revised. 2 vols. post 8 vo. with Two Maps, price $12 s .6 d$. Abridged Edition, in 1 vol. fcp. 8 vo. price $3 s .6 d$. 
An INTRODUCTION to the STUDY of the NEW TESTAMENT, Critical, Exegetical, and Theological. By the Rev. S. DAVIDSon, D.D. LI.D. 2 vols. 8 vo. 30 s.

EWALD'S HISTORY of ISRAEL to the DEATH of MOSES. Trans'lated from the German. Edited, with a Preface and an Appendix, by Russerc Martineau, M.A. Second Edition. 2 vols. 8vo, 24s. Vols. III. and IV. edited by J. E. CARPENTER, M.A. price 21s. Vor. V. translated by Mr. CARPENTER, is in the press.

The TREASURY of BIBLE KNOWLEDGE; being a Dictionary of the Books, Persons, Places, Events, and other matters of which mention is made in Holy Scriptnre. By Rev. J. AYRs, M.A. With Maps, 16 Plates, and numerous Woodcuts. Ficp. 8vo. price 6s. cloth, or 10s. neatly bound in calf.

EVERY-DAY SCRIPTURE DIFFICULTIES explained and illustrated. By J. E. PrescotT, M.A. Vol. I. Matthew aud Mark; VoL. II. Luke and John, 2 vols. 8 ro. 9 s. each.

IIECTURES on the PENTATEUCH and the MOABITE STONE; with Appendices, containing-I. The Elohistic Narrative; II. The Original Story of the Exodus ; III. The Pre-Christian Cross. By the Right Rev. JoHN WILLTAM Colenso, D.D. Bishop of Natal. 8vo. price 12s.

ThE PENTATEUCH and BOOK of JOSHUA CRITICALIX EXAMINED. By the Right Rev. J. W. Collenso, D.D. Lord Bishop of Natal. People's Edition, in 1 vol, crown 8 vo. $6 s$.

The FORMATION of ChRISTENDOM. By T. W. Allies. Pants I. and II. 87o. price 12s, each Part.

ENGLAND and ChRISTENDOM. By ARchishop Manning, D.D. Post 8vo. price 10s. $6 d$.

A VIEW of the SCRIPTURE REVELATIONS CONCERNING a FUTURE STATE. By RICHARD WHATELX, D.D. late Archbishop of Dublin. Ninth Edition. Fcp. 8vo. 5s.

THOUGHTS for the AGE. By Elizadetr M. Sewell, Author of 'Amy Herbert,' \&c. Kew Edition, revised. Fcp. 8vo, price $5 s$.

Passing Thoughts on Religion. By the same Author. Fep. 8 vo. $3 s 6 d$.

Self-Examination before Confirmation. By the same Author, $32 \mathrm{mo}$. price 1s. $6 d$.

Readings for a Month Preparatory to Confirmation, from Writers of the Early and English Church. By the same Author. Fep. 4s.

Readings for Every Day in Lent, compiled from the Writings of Bishop Jeremy TAyLor. By the same Author. Fep. 5s.

Preparation for the Holy Communion; the Devotions chiefly from the Works of JEREMY TAYLoR. By the same Author. 32mo. 3s.

THOUGHTS for the HOLY WEEK for Young Persons. By the Author of 'Amy Herbert.' New Edition. Fcp. 8vo. 2s.

PRINCIPLES of EDUCATION Drawn from Nature and Revelation, and applied to Female Education in the Upper Classes. By the Author of 'Amy Herbert.' 2 vols. fcp, 12s, $6 d$. 
LYRA GERMANICA, translated from the German by Miss C. WINKwORTH. FIrst SERIES, Hymns for the Sundays and Chief Festivals. SECOND SERIES, the Christian Life. Fcp. $3 s .6 d$. each SERIES.

SPIRITUAL SONGS for the SUNDAYS and HOLIDAYS throughout the Year. By J. S. B. Monsel, LL.D. Vicar of Egham and Rural Dean. Fourth Edition. Sixth Thousand. Fcp. 4s, 6d.

TRADITIONS and CUSTOMS of CATHEDRALS. By MACKENZIE E. C. WALCOTT, B.D. F.S.A. Præcentor and Prebendary of Chichester. Second Edition, revised and enlarged. Crown 8vo. price 6s.

ENDEAVOURS after the CHRISTIAN LIFE: Discourses. By JAMES MARTINEAU. Fourth Edition, carefully revised. Post 8vo. 7s.6d.

WHATELY'S INTRODUCTORY LESSONS on the CHRISTIAN Evidences. $18 \mathrm{mo} .6 d$.

BISHOP JEREMY TAYLOR'S ENTIRE WORKS. With Life by Bishop HeBer. Revised and corrected by the Rev. C. P. Eden. Complete in Ten Volumes, 8vo. cloth, price $£ 5.5 s$.

\section{Travels, Voyages, \&c.}

SLAVE-CATCHING in the INDIAN OCEAN. By Capt. CoLOMB, R.N. With a Map and Illustrations from Photographs and Original Drawings. 8vo. price $21 s$.

UNTRODDEN PEAKS and UNFREQUENTED VALLEYS; a Midsummer Ramble among the Dolomites. By AxErra B. EDWARDS. With a Map and 27 Illustrations, engraved on Wood from Sketches by the Author. Medium 8 vo. price $21 s$.

The DOLOMITE MOUNTAINS; Excursions through Tyrol, Carinthia, Carniola, and Friuli, 1861-1863. By J. GILBERT and G. C. ChƯrcHILL, F.R.G.S. With numerous Illustrations. Square crown 8vo. 21s.

CADORE; or, TITIAN'S COUNTRY. By JosIaH GILBERT, one of the Authors of the 'Dolomite Mountains.' With Map, Facsimile, and 40 Illustrations. Imperial $8 \mathrm{vo} .31 s .6 d$.

HOURS of EXERCISE in the ALPS. By JoHN TYNDALL, LL.D. D.C.L. F.R.S. Third Edition, with 7 Woodcuts by E. Whymper. Crown 8 vo. price $12 s .6 d$.

MAP of the CHAIN of MONT BLANC, from an Actual Surrey in 1863-1864. By AdAMrs-Reilly, F.R.G.S. M.A.C. Published under the Authority of the Alpine Club. In Chromolithography on extra stout drawingpaper $28 \mathrm{in} . \times 17$ in. price $10 s$. or mounted on canvas in a folding case, $12 s .6 d$.

TRAVELS in the CENTRAL CAUCASUS and BASHAN. Including Visits to Ararat and Tabreez and Ascents of Kazbek and Elbruz. By D. W. Freshrited. Square crown 8vo. with Maps, \&c. 18s.

PAU and the PYRENEes. By Count Henry Russeld, Member of the Alpine Club, \&c. With 2 Maps. Fcp. 8vo. price $5 s$.

HOW to SEE NORWAY. By Captain J. R. CAMpBell. With Map and 5 Woodcuts. Fep. 8 vo. price $5 s$. 
LIFE in INDIA; a Series of Sketches shewing something of the Anglo-Indian, the Land he lives in, and the People among whom he lives. By EDWARD BRADDON. Post 8vo, price 9s.

MY WIFE and I in QUEENSLAND; Eight Years' Experience in the Colony, with some account of Polynesian Labour. By CHARLES H. EDEN. With Map and Frontispiece. Crown 8vo. price $9 s$.

The Japanese in america. By Charlfs lanman, American Secretary, Japanese Legation, Washington, U.S.A. Post 8 vo. price 10s. $6 d$.

RAMBLES, by Patricius WaLKer. Reprinted from Fraser's Magazine, with a Vignette of the Queen's Bower in the New Forest. Crown 8vo. 10s. 6d.

HISTORY of DISCOVERY in our AUSTRAIASIAN COLONIES, Australia, Tasmania, and New Zealand, from the Eariiest Date to the Present Day. By WILLIAM HowITT. 2 vols. 8 vo. with 3 Maps. 203.

JOTTINGS DURING the CRUISE of HER MAJESTY'S SHIP, the CURACOA, AMONG the SOUTH SEA ISLANDS in 1865. By the late Julus BRenchley, Esq. M.A. F.R.G.S. With Chart, 43 Coloured Plates and Chromolithographs, and 9 Illustrations in Lithography, 8 full-page Wood Engravings and several other Plates, and 36 Woodcuts in the Text. Imperial 8 vo. price $42 s$.

GUIDE to the PYRENEES, for the use of Mountaineers. By Charles Packr, 2nd Edition, with Map and Illustrations. Cr. 8vo. 7s.6d.

The ALPINE GUIDE. By John BaLL, M.R.I.A. late President of the Alpine Club. 3 vols. post 8vo. Thoroughly Revised Editions, with Maps and Illustrations:-I. Western Alps, $6 s_{0} 6 d_{\text {. }}$ II. Central Alps, $7 s_{0} 6 d$. III. Eastern Alps, 10s. $6 d$.

Introduction on Alpine Travelling in General, and on the Geology of the Alps, price 1s. Each of the Three Volumes or Parts of the Alpine Guide may be had with this IxTroducrios prefixed, price $1 s$. extra.

VISITS to REMARKABLE PLACES : Old Halls, Battle-Fields, and Stones Illustrative of Striking Passages in English History and Poetry. By WILLIAM HowITT. 2 vols. square crown 8vo. with Woodcuts, $25 s$.

The RURAL LIFE of ENGLAND. By the same Author. With Woodcuts by Bewick and Williams. Medium 8vo. 12s. $6 d$.

\section{Works of Fiction.}

LADY WILLOUGHBY'S DIARY, 1635-1663; Charles the First, the Protectorate, and the Restoration. Reproduced in the Style of the Period to which the Diary relates. Crown 8vo. price $7 s, 6 d$.

POPULAR ROMANCES of the MIDDLE AGES. By GEORGE W. Cox, M.A., Author of the 'Mythology of the Aryan Nations,' \&c. and EustaCE HrNTON JONEs. Crown 8vo. price $10 s, 6 d$.

TALES of the TEUTONIC LANDS; a Sequel to 'Popular Romances of the Middle Ages.' By the same Authors. Crown 8vo.10s. 6d.

The BURGOMASTER'S FAMILY; or, Weal and Woe in a Little World. By Christrne MULLer, Translated from the Dutch by Sir JoHx SHAW LEFEVRE, F.R.S. Crown 8 ro. price $6 s$. 
NOVELs and TALES. By the Right Hon. B. Disraeli, M.P. Cabinet Edition, complete in Ten Volumes, crown 8vo. price $6 s$, each, as follows:-

LOTHAIR, $6 s$.

CoNingsBY, $6 s$.

SYBIL, $6 s$.

TANCRED, $6 s$.

VINETIA, $6 s$.
HENRIETTA TEMPLE, $6 s$.

Contarini Fleming, \&c. $6 s$.

ALROY, IxION, \&c. $6 s$.

The YOUNG DUKe, \&c. $6 s$.

VIVIAN GRRY, $6 s$.

The MODERN NOVELIST'S LIERARY. Each Work, in crown $8 \mathrm{ro}$.

complete in a Single Volume :-

Atherstone Priony. By L. N. Comyn, 2s. boards ; $2 s .6 d$. cloth.

MELVILLE'S GLADIATORS, $2 s$ boards; $2 s .6 d$. cloth.

- GOOD FOR NOTHING, $2 s$. hoards ; $2 s .6 d$. cloth.

HOLMBY HOUSE, $2 s$. boards; $2 s .6 d$. cloth.

INTERPRETER, $2 s$, boards ; $2 s .6 d$. cloth.

Kate Coventroy, $2 s$. boards; $2 s .6 d$. cloth.

QUEEN'S MARIES, $2 s$. boards ; $2 s .6 d$. cloth.

DigBY GRaND, $2 s$. boards; $2 s .6 d$. cloth.

Genkral BounCE, $2 s$. boards; $2 s .6 d$. cloth.

TroLLOPE'S WARDEN, $1 s$. $6 d$. boards ; $2 s$. cloth.

-BARChEster Towers, $2 s$. boards; $2 s .6 d$. cloth.

BRAMLEX-MOORE's SIX SISTERS of the VAlLEYS, $2 s$. boards; $2 s .6 d$. cloth.

CABINET EDITION of STORIES and TALES by Miss SEwELl:-

AMY HERBERT, $2 s, 6 a$.

Gertrude, $2 s, 6 d$.

The EARL'S Daughter, $2 s .6 d$.

EXPERIENCE of LiFE, $2 s .6 d$.

Cleve Hall, $2 s .6 d$.
Ivons, $2 s .6 d$.

KATHARINE ASHTON, $2 s .6 d$.

Margaret Percival, $3 s .6 d$.

LaNeTON Parsonage, $3 s .6 d$.

URSULA, $3 s, 6 d$.

CYLLENE; or, the Fall of Paganism. By Henry Sneyd, M.A. University College, Oxford, 2 vols. post $8 \mathrm{vo}$. price 14s.

BECKER'S GALIUS; or, Roman Scenes of the Time of Augustus : with Notes and Excursuses. New Edition. Post 8vo. $7 s .6 d$.

BECKER'S CHARICLES; a Tale illustrative of Private Life among the Ancient Greeks : with Notes and Excursuses. New Edition. Post 8vo. 7s.6d.

TALES of ANCIENT GREECE. By George W. Cox, M.A. late Scholar of Trin. Coll. Oxon. Crown 8ro. price $6 s .6 d$.

\section{Poetry and The Drama.}

FAUsT: a Dramatic Poem. By Goethe. Translated into English Prose, with Notes, by A. HAYWARD. Eighth Edition. Fcp. 8vo. price $3 s$.

BALLADS and LYRICS of OLD FRANCE; with other Poems. By A. LANG, Fellow of Merton College, Oxford. Square fcp. 8vo. price 5s.

IMOORE'S IRISH MELODIES, Maclise's Edition, with 161 Steel Plates from Original Drawings. Super-royal 8vo. 31s. $6 d$.

Miniature Edition of Moore's Irish Melodies, with Maclise's Designs (as above) reduced in Lithography. Imp. 16mo. 10s. $6 d$.

MOORE'S LALLA ROOKH. Tenniel's Edition, with 68 Wood Engravings from Original Drawings and other Illustrations. Fcp. 4to. 21s.

SOUTHEY'S POETICAL WORKS, with the Author's last Corrections and copyright Additions. Library Edition, in 1 vol. medium 8vo. with Portrait and Vignette, $14 s$. 
IAXS of ANCIENT ROME; with IVRY and the ARMADA. By the Right Hon. Liord M.ACaULAy. : 16mo. $3 s .6 d$.

Iord Macaulay's Lays of Ancient Rome. With 90 Illustrations on Wood, from the Antique, from Drawings by G. ScHARP. Fcp. 4to. $21 s$.

Miniature Edition of Lord Macaulay's Lays of Ancient Rome, with the Illustrations (as above) reduced in Lithography. Imp. $16 \mathrm{mo} .10 \mathrm{~s}, 6 d$.

GOLDSMITH'S POETICAI WORKS, with Wood Engravings from Designs by Members of the Etching-Club. Imp. $16 \mathrm{mo} .7 s, 6 d$.

The ENEID of VIRGIL. Translated into English Verse. By-JoHs CoNington, M.A. New Edition. Crown 8vo. $9 s$.

The ODES and EPODES of HORACE; a Metrical Translation into English, with Introduction and Commentaries. By Lord LYTTON. With Latin Text. New Edition. Post 8vo. price 10s. 6d.

HORATII OPERA. Library Edition, with Marginal References and English Notes. Edited by the Rer. J. E. YoNGE. Sro. 21s.

BOWDLER'S FAMILY SHAKSPEARE, cheaper Genuine Editions. Medium 8vo. large type, with 36 WooDcurs, price 14s. Cabinet Edition, with the same Iritustratrons, 6 vols. fep. $3 s .6 d$. each.

POEMS. By J JAAN INGELow. 2 vols. fep. 8 vo. price $10 s$. FIrst Sertes, containing 'DIVIDRD,' 'The STAR's MONUMENT,' \&c. Sixteenth Thousand. Fcp. 8vo. price 5s. SECOND SERIES, 'A STORY of DOOM,' 'Gladys and her IslaNd,' \&c. Fifth Thousand. Fcp. 8vo. price 5s.

POEMS by Jean Ingelow. Frrst SERTES, with nearly 100 Illustrations, engraved on Wood by Dalziel Brothers. Fep. 4to. 21s.

\section{- Rural Sports, \&c.}

The DEAD SHOT; or, Sportsman's Complete Guide: a Treatise on the Use of the Gun, Dog-breaking, Pigeon-shooting, \&c. By MarksMan. Revised Edition. Fep. 8vo. with Plates, 5s.

ENCYCLOPIEDIA of RURAL SPORTS; a complete Account, Historical, Practical, and Descriptive, of Hunting, Shooting, Fishing, Racing, and all other Rural and Athletic Sports and Pastimes. By D. P. BLAINE. With above 600 Woodeuts (20 from Designs by JOHN LEECH), 87o. 21 s.

The FLY-FISHER'S ENTOMOLOGY. By ALFRed RoNards. With coloured Representations of the Natural and Artificial Insect. Sixth Edition, with 20 coloured Plates. 8vo. $14 s$.

A BOOK on ANGLING; a complete Treatise on the Art of Angling in every branch. By Fraxcis Francrs. New. Edition, with Portrait and 15 other Plates, plain and coloured. Post 8ro. 15 s.

WILCOCKS'S SEA-FISHERMAN ; comprising the Chief Methods of Hook and Line Wishing in the British ard other Seas, a Glance at 'Nets, and Remarks on Eoats and Boating. Second Edition, enlarged; with 80 Woodeuts.

Post 8 ro. $12 s, 6 d$. 
GYMNASTS and GYMNASTICS. By JoHN H. HowARD, Author of 'Athletic and Gymnastic Exercises.' New and Cheaper Edition, with 135 Woodcuts. Crown 8vo. price 6s.

HORSES and STABLES. By Colonel F. Fitzwygram, XV. the King's Hussars. With Twenty-four Plates of Illustrations, containing very numerous Figures engraved on Wood. 8vo. 15s.

The HORSE'S FOOT, and HOW to KEEP it SOUND. By 'W. Mrues, Esq. Ninth Edition; with Illustrations. Imperial 8vo. 12s. 6d.

A PLAIN TREATISE on HORSE-SHOEING. By the same Author. Sixth Edition. Post 8vo. with Illustrations, 2s. 6d.

STABLES and STABLE-FITTINGS. By the same. Imp. 8ro. with 13 Plates, $15 s$.

REMARKS on HORSES' TEETH, addressed to Purchasers. By the same. Post 8vo. 1s. $6 d$.

A TREATISE On HORSE-SHOEING and IAMENESS. By JOSEPH GAMGEE, Veterinary Surgeon, formerly Lecturer on the Principles and Practice of Farriery in the New Veterinary College, Edinburgh. 8vo. with 55 Woodcuts, price $15 s$.

The HORSE: with a Treatise on Draught. By Wfutiam Yodatr. New Edition, revised and enlarged. $8 \mathrm{vo}$. with numerous Woodcuts, $12 s .6 d$.

The DOG. By the same Author. 8vo. with numerous Woodcuts, 6s.

The DOG in HEALTH and DISEASE. By STONEHENGE. With 70 Wood Engravings. Square crown 8vo. 7s. $6 d$.

The GREYHOUND. By Stonehenge. Revised Edition, with 24 Portraits of Greyhounds. Square crown 8vo. 10s. $6 d$.

The SETTER: with Notices of the most Eminent Breeds now. Extant. Instructions how to Breed, Rear, and Break, Dog Shows, Field Trials; and General Management, \&c. By EDWARD Laverack. Crown 4 to. with 2 plates, price $7 s .6 d$.

The 0X; his Diseases and their Treatment: with an Essay on Parturition in the Cow. By J. R. Dobson. Crown 8vo. with Illustrations, 7s. 6d.

\section{Works of Utility and General Information.}

The THEORY and PRACTICE of BANKING. By H. D. MACLEOD, M.A. Barrister-at-Law. Second Edition, entirely remodelled. 2 vols. $8 \mathrm{vo} .30 \mathrm{~s}$.

A DICTIONARY, Practical, Theoretical, and Historical, of Commerce and Commercial Navigation. By J.R. M'CulLoch. New and thoroughly revised Edition. 87o. price 63s. cloth, or 70s. half-bd. in russia.

The CABINET LAWYER; a Popular Digest of the Laws of England, Civil, Criminal, and Constitutional : intended for Practical Use and General Information. Twenty-third Edition. Fcp. 8vo. price 7s. $6 d$.

A PROFITABILE BOOK UPON DOMESTIC LAW ; Essays for English Women and Law Students. 'BY Perkrss, Junior, M.A. Barrister-at-Law. Post $8 \mathrm{vo} .10 s .6 d$. 
BLACKSTONE ECONOMISED, a Compendium of the Laws of England to the Present time, in Four Books, each embracing the Legal Principles and Practical Information contained in their respective volumes of Blackstone, supplemented by Subsequent Statutory Enactments, Important Legal Decisions, \&c. By D. M. AIRD, of the Middle Temple, Barrister-at-Law. Second Edition, with Emendations. Post 8vo. 7s. 6d.

A HISTORY and EXPLANATION of the STAMP DUTIES. By StEPHEN DOWELL, M.A., Assistant-Solicitor of Inland Revenue. 87o. 12s. 6d.

PEWTNER'S COMPREFIENSIVE SPECIFIER; a Guide to the Practical Specification of every kind of Building-Artificers' Work; with Forms of Building Conditions and Agreements, an Appendix, Foot-Notes, and a copious Index. Edited by W. Young, Architect. Crown 8vo. price $6 s$.

COAL at HOME and ABROAD in RELATION to COST, CONSUMPTION, and QUANTITY, and other IMPORTANT QUESTIONS. By J. R. Leirchild, M.A. Post 8vo. price 4s. 6d.

COLLIERIES and COLLIERS; a Handbook of the Law and Leading Cases relating theretn. By J. C. FowLElr, of the Inner Temple, Barrister. Third Edition. Fep. 8vo. $7 s .6 d$.

The MATERNAL MAITAGEMENT of CHILDREN in HEALTH and Disease. By Thomas Buld, M.D. Fcp. $5 s$.

HINTS to MOTHERS on the MANAGEMENT of their HEALTH during the Period of Pregnancy and in the Lying-in Room. By the late Thomas Bull, M.D. Fep. 5s.

HOW to NURSE SICK CHILDREN; containing Directions which may be found of service to all who have charge of the Young. By CHaRLES WEST, M.D. Second Edition. Fcp. 8ro. 1s. $6 d$.

NOTES on LYING-IN INSTITUTIONS ; with a Proposal for Organising an Institution for Training Midwives and Midwifery Nurses. By FloReNCE Nightivgale. With 5 Plans. Square crown 8vo. $7 s .6 d$.

The THEORY of the MODERN SCIENTIFIC GAME of WHIST. By Wirlíam Pole, F.R.S. Mus. Doc. Oxon. Fourth Edition, enlarged. Fcp. 8 vo. price $2 s .6 d$.

CHEST OPENINGS. By F. W. Longman, Balliol College, Oxford. Fcp. 8vo. 2s. $6 d$.

A PRACTICAL TREATISE on BREWING; with Formulæ for Public Brewers, and Instructions for Private Families. By W. BlAck. 8vo. 10s.6d.

MODERN COOKERY for PRIVATE FAMILIES, reduced to a System of Easy Practice in a Series of carefully-tested Receipts. By Eurza ActoN. Newly revised and enlarged Edition; with 8 Plates of Figures and 150 Woodcuts. Ficp. $6 s$.

WILLICH'S POPOLAR TABLES, for ascertaining, according to the Carlisle Table of Mortality, the value of Lifehold, Leasehold, and Church Property, Renewal Fines, Reversions, \&c. Seventh Edition, edited by MoxtagUE Marriott, Barrister-at-Law. Post 8vo. price 10 s.

MAUNDER'S TREASURY of KNOWLEDGE and LIBRARY of Reference: comprising an English Dictionary and Grammar, Universal Gazetteer, Classical Dictionary, Chronology, Law Dictionary, a synopsis of the Peerage, useful Tables, \&c. Revised Edition. Fcp. 8ro. price 6s. 


\section{N D E X.}

Acton's Modern Cookery

AIRD's Blackstone Economised.

28 28 AlLIES on Formation of Christendom ...... 22 Alpine Guide (The) ............................... 24 AMos's Jurisprudence ARNOLD's Manual of English Literature... Atherstone Priory Autumn Holidays of a Country Parson ...... AYRE's Treasury of Bible Knowledge ......

BacoN's Essays, by WhatelY .................. 6 Life and Letters, by SPEDDING ...... 5 Works, edited by SPFDDING ......... 6

BAIN's Logic, Deductive and Inductive...... 10 Mental and Moral Science ............ 10 on the Senses and Intellect ............... 10

BALL's Alpine Guide BAYLDON's Rents and Tillages BECKER's Charicles and Gallus .................... 25 BewFEY's Sanskrit Dictionary ................. 8 BLACK's Treatise on Brewing .................... 28 BLACKLEY's German-English Dictionary... 8 BLAINE's Rural Sports................................ 20. BLOXAM's Metals ..................................... 12 Bou ut Bef on 39 Articles ......................... 21 BOURNE's Catechism of the Steam Engine. 19 Handbook of Steam Engine ...... 19 Improvements in the Steam Engine Treatise on the Steam Engine ...

Bowpre Tramily BRADDON's Iife in India ......................... 24 BRAMLEY-MOORE's Six Sisters of the Valleys.

BRANDE's Dictionary of Science, Literature, and Art.

BRAY's Manual of Anthropology ............... Philosophy of Necessity .................. on Force

BRENCHLEY's Cruise of H.M.S. Curacoa :.. BROWNE's Exposition of the 39 Articles...... BURNEL's Life of BRUNEL ....................... BUCKLE'S History of Civilization Miscellaneous Writings ................

BULL's Hints to Mothers Maternal Management of Children BUNsEx's God in History Prayers

\section{Burgomaster's Family (The)}

Borke's Rise of Great Families.

Vicissitudes of Families

Burtox's Christian Church

Cabinet Lawyer

CAMPBRLL's Norway

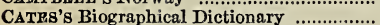
and WOODWARD's Encyclopædia CATs' and FARLIE's Moral Emblems......... Changed Aspects of Unchanged Truths...... CHESXEY's Indian Polity
Chesney's Waterloo Campaign

Chorale Book for England ......................... 18

Christ the Consoler.................................... 20

CLovgH's Lives from Plutarch .................. \&

Codringmon's (Admiral) Memoirs ............ 4

Colenso (Bishop) on Pentateuch .............. 22 on Moabjte Stone, \&c.................. 22 on Speaker's Bible Commentary 20

CoLmins's Perspective.............................. 19

CoLOMB's Slave Catching ........................... 23

Commonplace Philosopher, by A.K.H.B.... 8

ConNINGTON's Translation of the Aneid... 26

Miscellaneous Writings

CoNTANSEAJ's French-English Dictionaries

ConyBFarR and Howson's St. Paul ......... 2l

CotTON's (Bishop) Life ............................ 4

CoOKE's Grotesque Animals......................... 17

COOPER's Surgical Dictionary................... 16

COPLAND's Dictionary of Practical Medicine 17

Cotrox's (Bishop) Memoir ...................... 4

Counsel and Comfort from a City Pulpit......

Cox's Aryan Mythology............................. 3

- History of Greece .............................. \&

Tale of the Great Persian War ..........

Tales of Ancient Greece..................... 25

and Jorres's Popular Romances ...... 24 Tales of Teutonic Lands 21

Creasy on British Constitutions ............... 3

CresY's Encyclopedia of Civil Engineer-

ing .

Critical Easays of a Country Parson .......... 19

Crookes on Beet-Root Sugar.................... 17 's Chemical Analysis .................. 15

CULLEX's Handbook of Telegraphy............ 19

CUSACK's History of Ireland .....................

DAvidson's Introduction to NewTestament 22

Dead Shot (The), by MARksMaN ............. 20

DrCAISN E and LE MAOUT's Botany ......... 14

DE MORGAN's Budget of Paradoxes............ 10

DISRAELI's Lord George Bentinck ........... 4

Novels and Tales .................... 25

DoBson on the Ox................................. 27

DONkIN on Diabetes .................................. 16

Dove on Storms ...................................... 11

DowELI, on Stamp Duties......................... 28

DoYLE's Fairyland ............................... J7

DREW's Reasons of Faith ........................ 20

DUNSANY's (Lord) Gaul or Teuton ? ......... z

EAstLake's Hints on Household Taste...... 18 Gothic Revival ..................... Is

EDEN's Queensland ............................... 24

EDEN's Queensland ...............................

Elements of Botany ............................... 15

ELLICOTT's Commentary on Ephesians ...... 21 Galatians ....... 21 Pastoral Epist. 21 Philippians, \&c 21 
ELLICOTT's Commentary on Thessalonians 21 Lectures on the Life of Christ...

ERICHSEN's Surgery

Eraxs's Ancient Stone Implements............. 13

EWALD's History of Israel

22

FAIRBAIRx's Applicationg of Iron ............ 19 Information for Engineers ... 19 Mills and Millwork .............. 19

FARADAX's Life and Letters...........................

FITZWYGRAM on Horses and Stables ......... 26

FowLIen's Collieries and Colliers ................ 28

Fraxcis's Fishing Book ........................... 26

FreshwiELD's Travels in the Caucasus....... 23

FRoUDE's English in Ireland ....................... History of England ..................... 1 Short Studies on Great Subjects

GAMGEE on Horse-Shoeing Ganot's Elementary Physics

Natural Philosophy

GarRoD's Materia Medica

GILBERT's Cadore, or Titian's Country .......

GILBERT and CHURCHILL's Dolomites......

GIRDLRSTONR's Bible Synonymes................

GÆTHE's Faust, translated by Hayward ...

GoLDSirit H's Poems, Illustrated ................

GooDErE's Mechanism

GRANT's Ethics of Aristotle

Graver Thoughts of a Country Parson

GRAY's Anatomy

GRRENHOW on Bronchitis .........

GRIFFIN's Algebra and Trigonometry .......

GRIF'FTH's Fundamentals .........................

Grove on Correlation of Physical Forces ... 13

GURKRY's Chapters of French History ...... 1

GwrLT's Encyclopædia of Architecture...... 18

HARE on Election of Representatives ..........

HARTWIG's Harmonies of Nature................. 14

Sea and its Living Wonders ... 14

Subterranean World ................. 14

Tropical World ........................ 14

HATHERTON's Memoir and Correspondence 2

HAUGHTON's Animal Mechanics ................ 13

HAYWARD'S Biographical and Critical

Essays ; Second Series ...............................

HELMHOTZ's Popular Lectures ..................... 12

HransLeY's Handbook of Trees and Plants 14

HERSCHEL's Outlines of Astronomy .......... 10

HEWITT on Diseases of Women ................... 15

HodGsox's Theory of Practice ................... 10

Hime and Space ......................... 10

HoLLAND's Recollections ............................. 5

HoLMes's System of Surgery ...................... 16

- Surgical Diseases of Infancy....... 16

HoWARD's Gymnasts and Gymnastics ....... 26

HowITT's Australian Discovery ................. 24

Rural Life of England ............... 24

Visits to Remarkable Places...... 24

IUUBNER's Memoir of Sixtus V...............

HUGHes's (W.) Manual of Geography ...... 12
HгMвоLDT's Centenary Biography ............

HUME's Essays .......................................... 10

….... 10

IHNE'S Roman History ............................... 2

INGELOW's Poems ......................................... 26

JAMESON's Saints and Martyrs ................. 18

Iegends of the Madonna ........... 13

Monastic Orders ....................... 13

JAMESON and EASTLAKE'S Saviour ............ 18

JoHxsTox's Geographical Dictionary .......... II

KalISCH's Commentary on the Bible ......... 7

KEITH on Fulfilment of Prophecy................ 21

Destiny of the World .................... 21

KENYON, Life of the First Lord ......................

KERL's Metallurgy ..................................... 20

KIRBX and SPENCE's Entomology................. is

LAxG's Ballads and Lyrics ........................ 25

LANMAN's Japanese in America .................... 24

LATHAM's English Dictionary …................ 7

LAUGHTON's Nautical Surveying ................ 11

LAVERACK's Setter ....................................... 27

LECKY's History of European Morals.......... 3

_ Rationalism ................. 3

Leaders of Public Opinion ............. 5

LEIFCHILD on Coal ................................. 28

Leisure Hours in Town, by A.K.H.B......... 8

Lessons of Middle Age, by A.K.H.B. ......... $\cdot 9$

LEWEs' History of Philosophy .................... 3

LIDDELL and SCOTT's Two Lexicons .......... 8

Life of Man Symbolised ............................... 18

LINDLEY and MOORE's Treasury of Botany 15

LLOYD's Wave-Theory of Light ............... 13

LoxGMaN's Edward the Third ................... 2

Lectures on History of England 2

Old and New St. Paul's ............ 17

Chess Openings ......................... 28

LoU Don's Agriculture.................................. 20

Gardening ................................ 20

Plants ........................................ 15

LUBBOCK on Origin of Civilisation .............. 13

Iyra Germanica........................................ 18, 23

LYTTON's Odes of Horace ............................ 26

MACAULAX's (Iord) Essays ......................... 3 History of England ... I - Lays of Ancient Rome 26 -MiscellaneousWritings 9 Speeches ...................... ? Complete Works.......... 1

MACLEOD's Economical Philosophy .......... 6 Theory and Practice of Banking 27

MCCULLOCH's Dictionary of Commerce ... 27 Mankind, their Origin and Destiny ............ 14

MANrING's England and Christendom ....... 22

MARCET's Natural Philosophy . ................. 12

MARSFALL'S Physiology............................... 17

MARSHMAN's Iife of Havelock .................... 5

History of India ..................... 3

MantineaU's Christian Life ....................... 23

MIASSINGBERD's History of the Reformation 4 
MAUNDER's Biographical Treasury

Geographical Treasury

torical Treasury ................

and Literary Trea-

sury

Treasury of Knowledge.............

Treasury of Natural History ...

MAXWELL's Theory of Heat.

MAY's Constitutional History of England...

MELVILLE's Novels and Tales

MENDELSSOHx's Letters

MERIVALE's Fall of the Roman Republic...

Romans under the Empire ....

MERRIFLELD's Arithmetic \& Mensuration. Magnetism

MrLes on Horse's Feet and Horseshoeing ...

Horses' Tceth and Stables............ 27

MILL (J.) on the Mind...

MILL (J. S.) on Liberty ............................... on Representative Government on Utilitarianism

MILL's (J.S.) Dissertations and Discussions Political Economy

System of Logic ...

Hamilton's Philosophy..........

Subjection of Women

MrLLER's Elements of Chemistry

Inorganic Chemistry Manual of Assaying ........

MoNSELL's Spiritual Songs ........................ 23

MoorE's Irish Melodies ................................ 25

Lalla Rookh

MORELL's Elements of Psychology Mental Philosophy

Mossmax's Christian Church ........................

MÜLLER's (MAX) Chips from a German Workshop

Lectures on Language Science of Religion ......

MURChison on Continued Fevers...

on Liver Complaints

NASH's Compendium of the Prayer Book ... 21

New Testament, Illustrated Edition ... 18

NIGHTINGALE on Lying-In Institutions .... 28

NILSSON's Scandinavia .............................. 13

NoRTHCOTT's Lathes and Turning .............. 19

O'CoroR's Commentary on Hebrews ......... 21

O

ODLING's Course of Practical Chemistry .... 15

Owex's Lectures on the Invertebrata ......... 13

Comparative Anatomy and Physio-logy of Vertebrate Animals ... 13

PACKE's Guide to the Pyrenees

PAGET's Lectures on Surgical Pathol........ 24 Peririra's Elements of Materia Medica ... Perkixs's Legal Essays............................... 27 PEWTIER's Comprehensive Specifier ……... 28 POLE on Whist ......................................... 28 PIENDERGaST's Mastery of Language ...... 8 PRESCOTT'S Scripture Difficulties ................. 22
Present-Day Thoughts, by A. K. H. B. ...... 9 Proctor's Astronomical Essays ............... 10 Moon ........................................ 11

New Star Atlas ........................... 11

Orbs Around Us............................ 11

Plurality of Worlds ..................... il

Saturn and its System ................. 11

Star Depths ................................ 11

Scientific Essays (Two Series)... 12

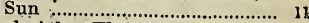

Public Schools Atlas (The) ........................ I1

QUAIN's Anatomy ...................................... 16

RANKEN on Strains in Trusses '................. 19

RAWLINSON's Parthia.......................................

Recreations of a Country Parson, by

A.K.H.B. ...................................... \&

REEVE's Royal and Republican France......

REILLY's Map of Mont Blanc ....................... 23

RIoH's Dictionary of Antiquities .................

RIVERS' Rose Amateur's Guide .................... 15

ROGERs's Eclipse of Faith...............................

Defence of ditto ...................................

RoGET's English Words and Pbrases .......... 7

RoNALD's Fly-Fisher's Entomology '.......... 26

RosE's Ignatius Loyola ................................

RoTHSCHILD's Israelites........................................ 21

RUSsEll's (Count) Pau and the Pyrenees... 23 - (Lord) Essays on the Christian Religion ................... 20

SANDARS's Justinian Institutes ................... 6

SANFORD's English Kings.............................. 1

SAVORY's Geometric Turning ....................... 19

SCHELLEN's Spectrum Analysis................... 11

ScoTT's Lectures on the Fine Arts ............. 17 Albert Durer ................................... 17

Seaside Musings by A. K. H. B. ................... \&

SEевонм's Oxford Reformers of 1498 .......... 2

SEWELL'S Examination for Confirmation... 22

History of the Early Church ......

- Passing Thoughts on Religion.... 22

- Preparations for Communion...... 22

- Principles of Education ............. 22

_- Readings for Confirmation ........... 22

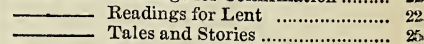

_ Thoughts for the Age................... 22

__ Thoughts for the Holy Week....... 22

SHELLEY's W'orkshop Appliances ................ 12

SHIPLEY on Ecclesiastical Reform ............. 20

SHoRT's Church History............................... 3

SMITH's (J.) Paul's Voyage and Shipwreck 21

- (SYDNEY) Miscellaneous Works ... 9 Wit and Wisdom .......... 8 Life and Letters .............. 5

(Dr. R. A.) Air and Rain............... 11

(Dr. Fly) Handbook for Midwives 15

SNEYD's Cyllene ............................................. 25

SOUTHEY's Doctor........................................ 7

Poetical Works .......................... 25

STANLEY's History of British Birds ............ 14

STEPHEN's Ecclesiastical Biography ........... 5

STIRLING'S HAMILTON ............................... 9 
STIRLING'S HEGEL. Philosophy of Low .................. Protoplasm

Stockyar's (Baron) Memoirs

STOX on the Greyhound.

STRICKLAND's Queens of England

STUART-GLENNIE's Morningland

Sunday Afternoons at the Parish Church of a Scottish University City, by A.K. H. B.

TAYLoR's History of India (Jeremy) Works, edited by EDTi

Text-Books of Science

ThIRLWALL' 8 History of Greece .............. 2

THomsox's Laws of Thought ................... 6

THudrchus's Chemical Physiology ........ 15

TODD (A.) on Parliamentary Government... 1

TODD and BowMAx's Anatomy and Phy-

siology of Man

17

TrencH's Realities of Irish Life.................. 3

TrouLOPE's Barchester Towers ................ 25

Warden

TYNDALL on Diamagnetism ...................... 12

Electricity ............................ 13

Heat ........................... 12

Sound ................................ 12

's Americen Lectures on Light . 13

Faraday as a Discoverer......... 5

Fragments of Science ............ 13

Hours of Exercise in the Alps 23

Lectures on Tight ................ 13

Molecular Physics ................. 12

UHBERWEG'S System of L Logic................... 10

URE's Arts, Manufactures, and Mines........ 19

Vogax's Doctrine of the Eucharist ........... 20

W ALCOTT's Traditions of Cathedrals
WALKER's Rambles

WATsON's Geometry

Principles \& Practice of Physic..... 12

WATT's Dictionary of Chemistry .............. 15

WeBB's Objects for Common Tele scopes ... 11

WhLLINGTON's Life, by GLEIG ................. 5

WrST on Children's Diseases .................... 16

Nursing Sick Children .................. 2

-'s Lumleian Lectures ....................... 16

WHA'TELY's English Synonymes .............. 6 Logic.

Rhetoric

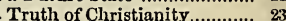

WHITE' \& Latin-English Dictionaries ......... 7

WILCocks's Sea Fisherman ....................... 26

WILLIAMs's Aristotle's Ethics ................. 6

WILLIAMS on Climate of South of France . 16

- Consumption ...................... 16

WILIICH's Popular Tables ........................ 28

WILLIS's Principles of Mechanism ............ 19

WILlOUGHBY's (Lady) Diary.................... 24

Woon's Bible Animals ............................ 13

. Homes without Hands ................... 13

Insects at Home ......................... 14

-1 Abroad............................... 14

_ Strange Dwellings ....................... 14

(T.) Chemical Notes ................... 15

Wordswor'tH's Christian Ministry ........ 20

YONGE's English-Greek Lexicons............... 7

Horace...................................... 26

History of England ..................... 1

— English Literature....................... 7

- Modern History ............................. 2

YoUATT on the Dog ............................... 27

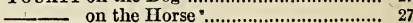

ZELLER's Socrates ...................................... 6

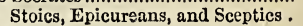

Wpottiswoode \& Co., Printers, New-street Square, London. 








SMITHSONIAN INSTITUTION LIBRARIES 